\title{
The Role of Serotonin
}

in MDMA

Self-administration

\section{in Rats}

by

Sarah Bradbury

A thesis submitted in fulfilment of the requirements for the degree of Doctor of Philosophy

Victoria University of Wellington

2014 


\section{Acknowledgements}

I would like to express my sincere gratitude to my family- Mama, Dad and Richie for their continued love and immense support. To my lab family, in particular to the morning coffee group and to "the girls", thank you for making me look forward to coming in to the lab each day (6+ days a week!). In terms of my research: (old man) Richard- thank you for making it possible; Joyce- thank you for teaching me all of my lab skills.

To Sue, thank you for imparting a wealth of knowledge to me, and thank you for showing me how to think critically. 
Contents

$\begin{array}{lr}\text { Acknowledgements } & 2\end{array}$

$\begin{array}{lr}\text { List of Abbreviations } & 6\end{array}$

$\begin{array}{lc}\text { General Introduction } & \mathbf{1 0}\end{array}$

$\begin{array}{ll}\text { History of MDMA } & 10\end{array}$

$\begin{array}{ll}\text { Prevalence of use } & 10\end{array}$

Pharmacology of MDMA 11

Effects of Ecstasy 13

$\begin{array}{ll}\text { Interpretation of Clinical Data } & 14\end{array}$

The Effects of MDMA on Tissue Levels of 5HT and DA 14

The Effects of Repeated MDMA on Tissue 5HT \& DA 15

Effects of Repeated MDMA on Extracellular 5HT and DA 17

$\begin{array}{ll}\text { Self-administration } & 17\end{array}$

Self-Administration History 18

The Role of DA in Self-administration $\quad 18$

The Role of 5HT in Self-administration 20

$\begin{array}{ll}\text { Acquisition of Self-administration } & 21\end{array}$

MDMA Self-administration $\quad 23$

$\begin{array}{ll}\text { Current Thesis } & 25\end{array}$

General Methods $\quad 26$

$\begin{array}{ll}\text { Animals } & 26\end{array}$

$\begin{array}{ll}\text { Surgery } & 26\end{array}$

$\begin{array}{ll}\text { Apparatus } & 26\end{array}$

$\begin{array}{ll}\text { Procedure } & 27\end{array}$

Chapter 1: Rats that fail to acquire MDMA self-administration have greater MDMA-induced increases of extracellular 5HT 28

$\begin{array}{ll}\text { Introduction } & 28\end{array}$

$\begin{array}{ll}\text { Methods } & 28\end{array}$

$\begin{array}{ll}\text { Results } & 31\end{array}$

$\begin{array}{ll}\text { Discussion } & 36\end{array}$

Chapter 2: Depleted 5HT levels facilitates the acquisition of MDMA selfadministration 39

Introduction $\quad 39$

$\begin{array}{ll}\text { Methods } & 40\end{array}$ 
Results $\quad 42$

$\begin{array}{ll}\text { Discussion } & 45\end{array}$

Chapter 3: MDMA self-administration produces transient 5HT deficits and $\begin{array}{ll}\text { persistent DA sensitisation } & 48\end{array}$

Introduction $\quad 48$

Methods $\quad 50$

Results $\quad 52$

$\begin{array}{ll}\text { Discussion } & 59\end{array}$

Chapter 4: The 5HT response to MDMA is not critical to the maintenance of $\begin{array}{lr}\text { MDMA self-administration } & 68\end{array}$

$\begin{array}{ll}\text { Introduction } & 68\end{array}$

$\begin{array}{ll}\text { Methods } & 69\end{array}$

$\begin{array}{ll}\text { Results } & 71\end{array}$

$\begin{array}{ll}\text { Discussion } & 73\end{array}$

$\begin{array}{lr}\text { General Discussion } & 78\end{array}$

$\begin{array}{lr}\text { References } & 81\end{array}$ 
List of Abbreviations

5,7-DHT: 5, 7- dihydroxytryptamine

5D: 5 days of abstinence

5HIAA: 5-hydroxyindoleacetic acid

5HT: serotonin

5-HTP: 5-hydroxytryptophan

6-OHDA: 6-hydroxydopamine

ACQ: acquired

AMPH: amphetamine

ANOVA: analysis of variance

COC: cocaine

CPP: conditioned place preference

d-fen: d-fenfluramine

DA: dopamine

DAT: dopamine transporter

DOPAC: 3,4-Dihydroxyphenylacetic acid

EDTA: ethylenediaminetetraacetic acid

EtOH: ethanol

FC: frontal cortex

GABA: gamma- aminobutyric acid

HPLC: high performance liquid chromatography

HVA: homovanillic acid

icv: intracerebroventricular

iv: intravenous

MAO: monoamine oxidase

MDMA: 3, 4-methylenedioxymethamphetamine

METH: methamphetamine

MFB: medial forebrain bundle

NAc: nucleus accumbens

NE: norepinephrine

NET: norepinephrine transporter

NO-ACQ: not acquired

PCA: perchloric acid 
PET: positron emission topography

SERT: serotonin transporter

SPECT: single photon emission computed tomography

TPH: tryptophan hydroxylase

VMAT2: vesicular monoamine transporter

VTA: ventral tegmental area 


\begin{abstract}
Rationale: The profile of acquisition for MDMA self-administration differs from that of amphetamine and cocaine self-administration in that fewer rats meet an acquisition criterion and the latency to acquisition is longer. These characteristics of MDMA selfadministration may be because it preferentially stimulates serotonin (5HT) release whereas self-administration has generally been attributed to enhanced dopamine (DA) neurotransmission. Because 5HTergic agonists are not self-administered and increased synaptic 5HT decreased self-administration of other drugs, MDMA selfadministration may be initially inhibited by the pronounced 5HT response. Accordingly, the acquisition of MDMA self-administration might proceed as a result of deficits in 5HT neurotransmission and a corresponding disinhibition of DA neurotransmission.
\end{abstract}

Objective: The primary objective was to determine the role of 5HT in the acquisition and maintenance of MDMA self-administration.

Methods: MDMA-induced increases of extracellular 5HT and DA and their primary metabolites were measured in the DA terminal regions of the nucleus accumbens (NAc) using in vivo microdialysis, prior to the commencement of MDMA selfadministration. The relationship between MDMA-induced increases of neurotransmitter levels and the acquisition of MDMA self-administration was assessed. A subsequent study depleted brain 5HT by administering the neurotoxin, 5,7 - DHT, or vehicle into the lateral ventricle of the left hemisphere, prior to the commencement of MDMA self-administration. The proportion of subjects that acquired MDMA self-administration and the latency to acquire MDMA selfadministration was compared for the two groups. In order to determine effects of MDMA self-administration on 5HT and DA responses, behaviours that reflect 5HT and/or DA neurotransmission were measured 5 or 14 days after self-administration of $165 \mathrm{mg} / \mathrm{kg}$ MDMA, or 14 days after vehicle self-administration. These time periods were chosen because they reflect a period of 5HT deficits (5 days) and recovery (14 days). Finally, the effect of abstinence on MDMA self-administration was measured. Results: The MDMA-induced increase of extracellular 5HT was significantly lower for the group that subsequently acquired MDMA self-administration but the MDMAinduced increase in DA was not different from the group that failed to acquire selfadministration. 5, 7-DHT administration significantly decreased tissue levels of 5HT, 
but not DA. MDMA self-administration was facilitated by the lesion; $100 \%$ of the lesion group acquired MDMA self-administration, whereas only $50 \%$ of the control group acquired self-administration. Five days following the last MDMA selfadministration session, DAergic behaviours were enhanced and 5HTergic behaviours were reduced relative to the control group. These differences in 5HTergic mediated behaviours were not apparent 14 days after self-administration but the DAergic behaviours remained elevated. The pattern of self-administration did not differ as a function of the length of the abstinence period.

Conclusions: The variability in acquisition of MDMA self-administration was related to the magnitude of the 5HT response evoked by initial exposure to MDMA. These findings suggested that predisposing differences in the 5HT response might explain differences in the variability in acquisition of MDMA self-administration. The negative impact of 5HT on the acquisition of MDMA self-administration was clearly demonstrated following a 5, 7-DHT lesion. Thus, 5HT limits the development of MDMA self-administration. With repeated exposure to self-administered MDMA, behavioural responses indicative of 5HT activation were reduced whereas behavioural indices of DA activation were increased. The maintenance of MDMA selfadministration was comparable regardless of whether there was a forced abstinence period or not. These data are consistent with the hypotheses that 5HT is inhibitory to the acquisition, but not the maintenance, of MDMA self-administration. Rather, the maintenance of self-administration might reflect sensitised DA responses that became apparent following repeated exposure. 


\section{General Introduction}

\section{History of MDMA}

The pharmaceutical company, Merck, first synthesised 3, 4methylenedioxymethamphetamine (MDMA) while attempting to create a medication to stop bleeding. Merck applied for the patent of MDMA as an intermediate chemical in the synthesis of the styptic, hydrastinine, in December 1912. Until 1953, MDMA was mentioned only twice in scientific literature and only as a by-product of chemical reactions (Swarts, 2006). After that the U.S. Army Chemical Center funded the testing of MDMA on 5 animal species: mice, rats, guinea pigs, dogs and monkeys (Hardman, Haavik, \& Seevers, 1973). In 1975, MDMA was classified as a Class A drug under the Misuse of Drugs Regulation (1975) in the United Kingdom because it was considered to have no medicinal use (Advisory on the Misuse of Drugs, 2009).

The first report of the effects of MDMA was published by Shulgin and Nichols (1978). Shulgin synthesised MDMA in 1976 and recorded his experiences following consumption of the drug. MDMA induced an "easily controlled altered state of consciousness, with emotional and sensual overtones "(Shulgin, 1986; p 299), and he therefore recommended the drug for use as an adjunct to psychotherapy. The use of MDMA in this capacity was not highly publicised (as LSD had recently been scheduled and thus removed from therapeutic practice (E. Greer, 1985). Recreational use of MDMA in the U.S.A. increased in the early 1980s and became controlled as a Schedule I substance in 1985. Drugs classified as Schedule I are described as having high abuse potential, and as having no accepted use for clinical application (The United States Department of Justice, 2008).

\section{Prevalence of use}

MDMA is the primary psychoactive component of the street drug, Ecstasy. According to the (World Drug Report, 2013) ecstasy use has declined, with an estimated $0.2-0.6 \%$ of the population having taken ecstasy annually since 2011 . Other surveys have reported increases in ecstasy use. The latest Monitoring the Future survey reported that ecstasy use in U.S. college students aged between 15 and 18 has increased from, between 2.6-3\% in 2005, to between 3.6- 4\% in 2013 (Johnston, O'Malley, Miech, Bachman, \& Schulenberg, 2014). Ecstasy use in Oceania continues to be highest with $2.9 \%$ of the population having consumed it in 2011 . In New 
Zealand, ecstasy is the second most widely used illegal drug, and the number of seizures rose markedly in 2011 (Wilkins \& Sweetsur, 2008). Further, frequent users of ecstasy in NZ perceive the drug to be "easy" to obtain, and the mean price of pills has decreased since 2006 (Wilkins, Sweetsur, Smart, Warne, \& Jawalkar, 2012).

The pattern of ecstasy use differs from that of other drugs of abuse in that many users consume ecstasy sporadically and fail to exhibit the compulsive use that characterises abuse (Solowij, Hall, \& Lee, 1992). Some surveys, however, indicate that the frequency of use increases over time for some users (Degenhardt, Barker, \& Topp, 2004; Fox, Parrott, \& Turner, 2001; George, Kinner, Bruno, Degenhardt, \& Dunn, 2010; Scholey et al., 2004; Soar, Turner, \& Parrott, 2006) and that some users meet the criteria for dependence and/or abuse (Cottler, Womack, Compton, \& Ben-Abdallah, 2001; Degenhardt et al., 2009; Leung, Ben Abdallah, Copeland, \& Cottler, 2010; von Sydow, Lieb, Pfister, Höfler, \& Wittchen, 2002), including craving and drug-seeking (Hopper et al., 2006).

\section{Pharmacology of MDMA}

The primary neurochemical effect of MDMA is to increase the release of the neurotransmitter, serotonin (5HT). MDMA was first reported to induce the release of 5HT after the observation that both stereoisomers of the drug released ${ }^{3} \mathrm{H}-5 \mathrm{HT}$ from hippocampal slices (Johnson, Hoffman, \& Nichols, 1986). Subsequent experiments determined that MDMA induced the release of 5HT via a carrier-mediated mechanism (Berger, Gu, \& Azmitia, 1992; Gu \& Azmitia, 1993; Gudelsky \& Nash, 1996; Hekmatpanah \& Peroutka, 1990).

MDMA causes the release of 5HT via two processes. First, MDMA binds to the 5HT transporter (SERT), and reverses the transport of 5HT across the neuronal membrane so that 5HT moves out of the neuron as MDMA moves into the neuron (Rudnick \& Wall, 1992). Second, MDMA enters the neuron and reverses the action of the vesicular monoamine transporter (VMAT2). In 5HTergic nerve terminals, VMAT2 transports unbound cytosolic 5HT into vesicles (Rudnick \& Wall, 1992). MDMA interferes with this system by binding to VMAT2 and consequently increases cytosolic 5HT via two means. First, the binding of MDMA to VMAT2 blocks 5HT from doing so and thus prevents cytosolic 5HT from being transported into vesicles. Second, the binding of MDMA to VMAT2 results in the influx of MDMA into vesicles and concurrently, the efflux of vesicular 5HT to the cytosol. Additionally, 
MDMA increases cytosolic 5HT by inhibiting its metabolism. MDMA inhibits the metabolising enzyme, monoamine oxidase (MAO; Leonardi \& Azmitia, 1994). The interactions of MDMA with VMAT2 and MAO increase cytosolic 5HT and lead to a greater amount of 5HT being released through the reversed SERT into the synapse.

Like all other drugs of abuse, MDMA increases extracellular levels of dopamine (DA). MDMA induces the dose- and region- dependent release of DA as shown in vivo, as measured by microdialysis, and in vitro, as measured in tissue slices (Gough, Ali, Slikker Jr, \& Holson, 1991; Johnson et al., 1986; Schmidt, 1987; B. K. Yamamoto \& Spanos, 1988).

The increase in DA is due to decreased uptake due to inhibition of the DA transporter (DAT): DAT inhibitors prevented MDMA-induced increases in DA following local administration in vivo (Nash \& Brodkin, 1991), or in brain slices (Koch \& Galloway, 1997), or synaptosomes (Crespi, Mennini, \& Gobbi, 1997). The affinity for DAT is at least 10-fold less than affinity for the SERT (Battaglia, Brooks, Kulsakdinun, \& De Souza, 1988), which might explain why MDMA-produced increases in 5HT are so much greater than increases of DA. A summary of the microdialysis studies that measured MDMA-induced increases of synaptic 5HT and DA can be found in Schenk (2011), where table 1 shows conclusively that MDMA increases extracellular 5HT to a much greater extent than it does extracellular DA. For example, MDMA $(1.5 \mathrm{mg} / \mathrm{kg})$ administered into the peritoneum increased accumbal $5 \mathrm{HT}$ by $500 \%$, but had no effect on DA. At the higher dose of $7.5 \mathrm{mg} / \mathrm{kg}$, MDMA increased 5HT by $3000 \%$ and DA by 500\% (Baumann, Clark, \& Rothman, 2008).

Because MDMA preferentially increases 5HT, the possibility that 5HT release impacts induced DA release has been investigated. The data indicate that the relationship between 5HT and DA neurotransmission is complicated, and the effects depend on the 5HT receptor systems stimulated. Many 5HT receptors are localised on DA terminals (Bubar, Stutz, \& Cunningham, 2011; Miner, Backstrom, Sanders-Bush, \& Sesack, 2003; Nayak, Rondé, Spier, Lummis, \& Nichols, 2000) and antagonists of the $5 \mathrm{HT}_{1 \mathrm{~A}}, 5 \mathrm{HT}_{1 \mathrm{~B}}$ and $5 \mathrm{HT}_{2}$ receptors have all been shown to increase endogenous levels of DA (Navailles \& De Deurwaerdère, 2011). A handful of studies has investigated the role of the $5 \mathrm{HT}_{2 \mathrm{~A}}$ receptor in MDMA-produced DA release. The selective $5 \mathrm{HT}_{2 \mathrm{~A}}$ receptor antagonist, MDL 100907, and the $5 \mathrm{HT}_{2 \mathrm{~A} / 2 \mathrm{C}}$ antagonists, ritanserin and ketanserin, blocked MDMA-induced increases of synaptic DA (Nash, 1990; Schmidt, Fadayel, Sullivan, \& Taylor, 1992; Schmidt, Sullivan, \& Fedayal, 
1994; B. K. Yamamoto, Nash, \& Gudelsky, 1995). In contrast, the 5HT2A agonists, DOI and 5-MeODMT enhanced MDMA-induced DA release (Gudelsky, Yamamoto, \& Nash, 1994). MDMA-induced increases of DA, therefore, are mediated by MDMA-induced 5HT release via specific receptor activation. These receptormediated effects might also explain why administration of the 5HT precursor, 5hydroxytryptophan, potentiated MDMA-induced DA release (Gudelsky \& Nash, 1996); and why the inhibition of MDMA-induced 5HT release via administration of the SERT uptake inhibitor, fluoxetine (Gudelsky \& Nash, 1996), or the global depletion of 5HT induced by the 5HT synthesis inhibitor, pCPA (Brodkin, Malyala, \& Frank Nash, 1993), decreased MDMA-produced striatal DA release. Irrespective of the specific mechanism, these data support the idea that at least part of the effect of MDMA on DA is indirect and requires 5HT.

\section{Effects of Ecstasy}

Recreational users report that the euphoria produced by ecstasy entices them to take it (Cohen, 1995; Solowij et al., 1992). Other commonly reported positive psychological effects include increased energy, sexual arousal, well-being and selfconfidence, and an enhanced feeling of closeness to others (Cohen, 1995; Downing, 1986; G. Greer \& Tolbert, 1986; Peroutka, Newman, \& Harris, 1988; Solowij et al., 1992). MDMA also produces negative effects, including depression, anxiety and paranoia (Cohen, 1995).

There are long-term psychological and physiological effects even following a single ingestion of ecstasy. These include depersonalisation, insomnia, depression, frequent headaches, back and stomach pain and joint stiffness (Cohen, 1995). Memory deficits (Fisk, Montgomery, \& Hadjiefthyvoulou, 2011), and compromised executive functioning and reasoning abilities (Fisk, Montgomery, Wareing, \& Murphy, 2005; von Geusau, Stalenhoef, Huizinga, Snel, \& Ridderinkhof, 2004) have also been reported. These impairments are persistent and have been reported even after years of abstinence (M. Morgan, McFie, Fleetwood, \& Robinson, 2002; Taurah, Chandler, \& Sanders, 2013)

The long-term psychological and cognitive effects of ecstasy use may be due to the persistence of neuroadaptations and deficits in 5HT neurotransmission that are characteristic of ecstasy users (Cowan, Roberts, \& Joers, 2008). There were increased levels of the 5HT precursor, tryptophan, following a tryptophan drink in ecstasy users 
that had been abstinent for at least one year (Curran \& Verheyden, 2003). SERT availability, as measured by positron emission topography (PET), was decreased in current ecstasy users (Buchert et al., 2004) and SERT density, as measured by PET, was decreased in users that had been abstinent for 2 or 3 weeks (McCann, Szabo, Scheffel, Dannals, \& Ricaurte, 1998; McCann et al., 2008). Ecstasy-produced changes in SERT appear to depend on life-time use of ecstasy and the frequency with which it was consumed. Recreational users, who averaged using ecstasy 3 times every 2 months, did not exhibit alterations of SERT as measured by endocrine responses to the SERT uptake inhibitor, citalopram (Allott et al., 2009). SERT binding was, however, negatively related to life-time use of ecstasy and the maximum dose used (Kish et al., 2010; McCann et al., 1998; McCann et al., 2008). These decreases in SERT might not be persistent since SERT binding increased with abstinence from ecstasy (Buchert et al., 2004).

Ecstasy use also appears to alter the binding characteristics of post-synaptic 5HT receptors. Both PET and single photon emission computed tomography (SPECT) showed increased $5 \mathrm{HT}_{2 \mathrm{~A}}$ receptor binding in abstinent ecstasy users (Reneman, Booij, Schmand, van den Brink, \& Gunning, 2000; Urban et al., 2012) that was positively related to life-time ecstasy use (Di Iorio et al., 2011). Ecstasy users also were less responsive to the neuroendocrine response, and showed fewer physical effects to the 5HT $2 \mathrm{C}$ agonist, mCPP (McCann, Eligulashvili, Mertl, Murphy, \& Ricaurte, 1999).

\section{Interpretation of Clinical Data}

Reports of the effects of ecstasy provide invaluable information; however, interpretation of the clinical data is problematic for a number of reasons. Due to ethical considerations clinical data rely on retrospective studies using current or abstinent ecstasy users. It is therefore unclear whether reported effects were preexisting or due to drug use. Because there is no accurate information about the dose of MDMA taken, the number of times ecstasy was consumed, and the purity of the ecstasy used, it is difficult to attribute doses of MDMA to long-term effects of drug use (Green, Mechan, Elliott, O'Shea, \& Colado, 2003). Further, polydrug use is common in ecstasy users and prevents the attribution of long-term effects of drug use to MDMA (Green et al., 2003). Animal models provide a means to control for these factors. 


\section{The Effects of MDMA on Tissue Levels of 5HT and DA}

MDMA produces deficits in 5HT and markers of 5HT but not other monoamines. In a seminal experiment, an acute, subcutaneous administration of 10.0 $\mathrm{mg} / \mathrm{kg}$ MDMA significantly decreased tissue levels of 5HT, tryptophan hydroxylase (TPH; the rate-limiting enzyme of 5HT synthesis), and 5-Hydroxyindoleacetic acid (5HIAA; the main metabolite of 5HT) in the neostriatum, hippocampus and frontal cortex (FC) 3 hours post drug administration (Stone, Stahl, Hanson, \& Gibb, 1986). Subsequent experiments demonstrated that the MDMA-induced 5HTergic depletions were dose-dependent (Schmidt, Wu, \& Lovenberg, 1986).

There was recovery of 5HT depletions that was both dose- and timedependent (Schmidt et al., 1986; Stone, Hanson, \& Gibb, 1987). MDMA decreased 5HT levels 3 hours after administration. This depletion was still present up to 6 hours post-administration, but had recovered within 24 hours of MDMA administration. A second decline in tissue levels of 5HT was observed 1 day after drug administration and was still present 7 days (Schmidt et al., 1986), and 14 days (Stone, Merchant, Hanson, \& Gibb, 1987), later .

MDMA administration produced an increase in tissue DA. In rats, tissue levels of DA were dose-dependently increased 1 (B. K. Yamamoto \& Spanos, 1988), 2 (B. K. Yamamoto \& Spanos, 1988), and 3 (Logan, Laverty, Sanderson, \& Yee, 1988; Schmidt et al., 1986; Stone et al., 1986) hours after an acute administration of MDMA. That increased DA levels are found concurrently with 5HT deficits is in contrast to the effect of 5HT neurotransmission on extracellular levels of DA. The increase may be a reflection of MDMA inhibiting the action of MAO, as the concentration of the DA metabolite, 3,4-Dihydroxyphenylacetic acid (DOPAC), was concurrently decreased (B. K. Yamamoto \& Spanos, 1988).

\section{The Effects of Repeated MDMA on Tissue 5HT \& DA}

Arguably the most consistent finding of effects of repeated exposure to MDMA is reduced tissue levels of 5HT. Repeated exposure to MDMA produces species-dependent reductions in 5HT and markers of 5HT; dose-dependent 5HTergic deficits were observed in non-human primates and rats (Battaglia, Yeh, \& De Souza, 1988; Insel, Battaglia, Johannessen, Marra, \& De Souza, 1989), but not mice (Battaglia, Yeh, et al., 1988; Stone, Hanson, et al., 1987). The frequency of MDMA administration also influences the magnitude of 5HT deficits. O'Shea, Granados, 
Esteban, Colado, and Green (1998) measured 5HT deficits following administration of $4.0 \mathrm{mg} / \mathrm{kg}$ MDMA daily for 4 days, twice-weekly for 8 weeks, or twice daily for 4 days. Only the latter dosing regimen decreased 5HT, suggesting that the cumulative effects of repeated administrations of MDMA caused deficits, and that dosing with lower frequency allows for recovery.

A decrease in density of SERT binding sites was found only after repeated exposure to high doses of MDMA (Insel et al., 1989). In rats, a dosing regimen of $20.0 \mathrm{mg} / \mathrm{kg}$ MDMA (sc) twice daily for 4 days, led to a decrease in the density of cortical and striatal 5HT uptake sites 18 hours after the final drug administration. SERT density was still decreased one month later, but had recovered 12 months after MDMA (Battaglia, Yeh, et al., 1988).

The marked effects of MDMA on tissue levels of 5HT and SERT density have led to a debate as to whether the decreases are due to neuroadaptation, or to neurotoxicity that results in degeneration of 5HT terminals or neurons (Biezonski \& Meyer, 2011). Decreased SERT density was initially considered an indication of neurotoxicity (for example, Battaglia, Brooks, et al., 1988). The decreases may, however, reflect a reduction in functional SERT. X. Wang, Baumann, Xu, Morales, and Rothman (2005) hypothesised that reported decreases of SERT binding were due to the internalisation of SERT, which reduced the number of functional SERT. MDMA did not, however, alter the distribution of SERT in subcellular fractions. It must be noted though, that the specificity of the SERT antibody has since been questioned (Kivell, Day, Bosch, Schenk, \& Miller, 2010). Other data suggest MDMA causes the internalisation of SERT; prolonged exposure to MDMA induced SERT internalisation in cultured 5HT neurons (Kittler, Lau, \& Schloss, 2010), and dosedependent internalisation of SERT was found in cell lines following MDMA treatment (Kivell et al., 2010). These studies suggest that, at least following some exposure regimens, the decrease in SERT binding is due to neuroadaptive changesspecifically, internalisation of SERT- rather than to neurotoxicity.

Further evidence for a neuroadaptive rather than neurodegenerative response to MDMA has been found in studies that measured VMAT2. Located in the terminals, the protein can be measured as a marker of terminal degeneration. MDMA (4 x 10.0 $\mathrm{mg} / \mathrm{kg}$ with 1 hour between each administration) decreased SERT, but not VMAT2, expression in rats, as measured by immunoblotting (Biezonski \& Meyer, 2011). 
Doses of MDMA that cause the long-term reduction of 5HT and markers of the 5HT system do not cause long-term decreases in DA neurotransmission. Markers of DA (Colado \& Green, 1994), the function of DAT (for example; Battaglia et al., 1987; Lew et al., 1996; Schmidt \& Kehne, 1990; Stone et al., 1986) and the fibre density of DAergic neurons (O'Hearn, Battaglia, De Souza, Kuhar, \& Molliver, 1988) were not altered by repeated MDMA. Stringent dosing regimens that used extremely high doses of MDMA, however, seem to produce a transient decrease in tissue levels of DA and metabolites that is region-dependent (Biezonski et al., 2013; Commins et al., 1987; Slikker et al., 1988).

\section{Effects of Repeated MDMA on Extracellular 5HT and DA}

Repeated exposure to MDMA does not affect basal levels of extracellular 5HT (Gartside, McQuade, \& Sharp, 1996; Reveron, Maier, \& Duvauchelle, 2010; Shankaran \& Gudelsky, 1999), but decreased both MDMA- (Shankaran \& Gudelsky, 1999) and electrical- (Gartside et al., 1996) stimulated release of 5HT.

Repeated exposure to MDMA, whether self-administered or experimenteradministered, did not alter basal levels of extracellular DA (Colussi-Mas, Wise, Howard, \& Schenk, 2010; Kalivas, Duffy, \& White, 1998; A. E. Morgan, Horan, Dewey, \& Ashby Jr, 1997; Reveron et al., 2010). Few studies have measured the effects of repeated MDMA on the stimulated release of extracellular DA. Repeated exposure to MDMA augmented cocaine- (COC; A. E. Morgan et al., 1997) and MDMA- (Kalivas et al., 1998) induced increases in DA in the nucleus accumbens (NAc). A different dosing regimen, however, had no effect on MDMA-induced extracellular DA in the striatum (Shankaran \& Gudelsky, 1999).

\section{Self-administration}

Data from animal research reports similar neurochemical effects to clinical reports. The laboratory studies, however, vary markedly in the doses of MDMA used and questions have been asked of whether these doses are relevant to human consumption. The translation of doses of drugs used by humans to drug doses used for animal research is complicated. A number of factors influence the scaling, including metabolism of drug, pharmacokinetics, animal size, and drug distribution, and as a result a number of calculations for translating doses have been offered (for example, Reagan-Shaw, Nihal, \& Ahmad, 2008; United States Department of Health and 
Human Services, 2005). In addition, it has been well established that the neurochemical effects of drugs differ depending on whether the drug is selfadministered or is non-contingently administered (Dworkin, Mirkis, \& Smith, 1995; Hemby, Koves, Smith, \& Dworkin, 1997). Thus the neurochemical effects produced following human consumption can be expected to differ from those found in animals after experimenter-administered drug. A typical ecstasy tablet contains about $100 \mathrm{mg}$ of MDMA, which equates to a dose of $1.4 \mathrm{mg} / \mathrm{kg}$ in a $70 \mathrm{~kg}$ person. The animal research described previously used much higher doses of MDMA, and therefore the translational value of these experiments is questionable. These dosing problems are minimised in the self-administration model, in which the animal regulates its intake.

\section{Self-Administration History}

In 1962 the development of the chronic indwelling intravenous catheter permitted studies of long-term drug self-administration in laboratory animals (Weeks, 1962). Self-administration experiments have since been conducted in a number of species, namely: non-human primates (T. Thompson \& Schuster, 1964; Yanagita, Deneau, \& Seevers, 1963); rats (Weeks \& Collins, 1964); mice (Hillman \& Schneider, 1975); cats (Balster, Kilbey, \& Ellinwood Jr, 1976); and dogs (Risner \& Jones, 1975).

The self-administration paradigm is considered the "gold-standard" animal model of human drug-taking behaviour. Most drugs that are abused by humans are self-administered by animals, and drugs that are not abused by humans are not selfadministered by animals (Griffiths, 1980; Johanson \& Balster, 1978; Schuster \& Thompson, 1969). As a result, self-administration procedures are considered valid tests of the abuse liability of novel compounds (Schuster \& Johanson, 1974).

\section{The Role of DA in Self-administration}

A large number of studies has documented the critical role of DA in the positively reinforcing properties of drugs using self-administration measures. Early studies showed that DA ligands, but not norepinephrine (NE) ligands, considerably altered responding for amphetamine (AMPH; Yokel \& Wise, 1976), and responding was maintained when DA receptor agonists were made available following the selfadministration of AMPH (Yokel \& Wise, 1978). 
All drugs of abuse share the characteristic of increasing DA (Di Chiara, Acquas, Tanda, \& Cadoni, 1992) and drugs of abuse, but not non-abused drugs, increased extracellular levels of DA (Di Chiara \& Imperato, 1988). Further, drugnaïve animals self-administered DAergic agonists (Self, Belluzzi, Kossuth, \& Stein, 1996; Self \& Stein, 1992; Weed \& Woolverton, 1995) and COC-trained animals continued to respond when $\mathrm{D}_{1}$ and $\mathrm{D}_{2}$ receptor agonists were made available (Ranaldi, Wang, \& Woolverton, 2001; Weed \& Woolverton, 1995; Woolverton, Goldberg, \& Ginos, 1984). Furthermore, co-administration of DA agonists shifted the dose-effect curve of responding for COC leftward (Barrett, Miller, Dohrmann, \& Caine, 2004), comparable to what is found when the dose of COC is increased.

The attenuation of DA neurotransmission retards self-administration of drugs of abuse. Neurotoxic 6-OHDA lesions that decreased DA levels attenuated responding maintained by AMPH (Lyness, Friedle, \& Moore, 1979), COC (Caine \& Koob, 1994a; D Roberts, Corcoran, \& Fibiger, 1977; D Roberts \& Koob, 1982), morphine (J. E. Smith, Guerin, Co, Barr, \& Lane, 1985) and nicotine (Singer, Wallace, \& Hall, 1982), whereas lesions that decreased NE had no effect (D Roberts et al., 1977). The lesions also inhibited the acquisition of AMPH self-administration (Lyness et al., 1979).

A multitude of data now show that $\mathrm{D}_{1}$ and $\mathrm{D}_{2}$ antagonists decreased responding for, or caused a rightward shift in the dose-effect curve of responding for, drugs of abuse- comparable to what is found when the dose of drug is lowered. $\mathrm{D}_{1}$ receptor antagonists decreased responding for methamphetamine (METH; Brennan, Carati, Lea, Fitzmaurice, \& Schenk, 2009), and caused a rightward shift in the doseeffect curve of responding for MDMA (Daniela, Brennan, Gittings, Hely, \& Schenk, 2004) and COC (Barrett et al., 2004; Britton et al., 1991; Caine \& Koob, 1994a; Corrigall \& Coen, 1991; Hubner \& Moreton, 1991; Koob, Le, \& Creese, 1987). D2 receptor antagonists decreased responding for AMPH (Amit \& Smith, 1992; Fletcher, 1998) and caused a rightward shift of the dose-effect curve for MDMA (Brennan et al., 2009) and COC (Barrett et al., 2004; Britton et al., 1991; Caine \& Koob, 1994a; Corrigall \& Coen, 1991; Hubner \& Moreton, 1991).

Local infusion of drugs of abuse and DA ligands has identified the DA projections of the mesolimbic DA system to be critical to self-administration of drugs of abuse. 6-OHDA lesions of the ventral tegmental area (VTA), which contains the cell bodies of DA neurons that comprise the mesolimbic system decreased responding 
maintained by COC (D Roberts \& Koob, 1982). 6-OHDA lesions of the DA terminals in the NAc decreased responding maintained by $\mathrm{COC}$, AMPH, morphine, nicotine and morphine (Caine \& Koob, 1994b; Lyness et al., 1979; Pettit, Ettenberg, Bloom, \& Koob, 1984; D Roberts et al., 1977; D Roberts, Koob, Klonoff, \& Fibiger, 1980; Singer et al., 1982; J. E. Smith et al., 1985). Similarly, the localised infusion of $\mathrm{D}_{1}$ and $\mathrm{D}_{2}$ antagonists into the NAc attenuated responding for MDMA (Shin, Qin, Liu, \& Ikemoto, 2008) or COC (Bari \& Pierce, 2005; Veeneman, Broekhoven, Damsteegt, \& Vanderschuren, 2012), and caused a rightward shift in the dose-effect curve of responding for COC (Caine, Heinrichs, Coffin, \& Koob, 1995) or AMPH (Phillips, Robbins, \& Everitt, 1994). Further evidence for the role of the NAc in drug-produced reinforcement is found with the acquisition of MDMA (Shin et al., 2008), COC (Rodd-Henricks, McKinzie, Li, Murphy, \& McBride, 2002) and AMPH (Ikemoto, Qin, \& Liu, 2005) self-administration when drug was infused directly into the NAc.

The pattern of responding also appears to be DA-dependent. An elegant microdialysis study showed that the time-course of COC self-administration was tightly linked to NAc DA levels. Responding was rapid at the beginning of a COC self-administration session and NAc extracellular DA was increased. When DA levels dropped below a certain, threshold, level a response was produced (Pettit \& Justice Jr, 1989; Wise et al., 1995).

\section{The Role of 5HT in Self-administration}

There is conclusive evidence to show that $5 \mathrm{HT}$ is inhibitory to selfadministration of drugs of abuse. It has been suggested that this inhibition is due to manipulation of DA (Czoty, Ginsburg, \& Howell, 2002), but the data is inconclusive due to the complicated relationship between the two neurotransmitter systems. Serotonergic agonists are not self-administered (Götestam \& Andersson, 1975; Howell \& Byrd, 1995; D Roberts et al., 1999; Tessel \& Woods, 1975; Vanover, Nader, \& Woolverton, 1992). The DAT is the primary mechanism for limiting DA transmission (Caron, 1996), and has been implicated in the propensity to selfadminister drugs of abuse (D. Yamamoto et al., 2013). Binding affinity at SERT, however, was negatively correlated with potency as a reinforcer (Ritz \& Kuhar, 1989). Further, the potency of re-uptake blockers for DAT relative to SERT was positively correlated with reinforcing potency (D Roberts et al., 1999). Similarly, the reinforcing potency of a group of compounds with similar DA-releasing abilities was 
dependent on their ability to release 5HT. Reinforcing potency was positively correlated with the relative release of DA: 5HT (Wee et al., 2005).

Pharmacological manipulations of 5HT altered the reinforcing potency of a range of abused drugs. Reuptake inhibitors, the releasing stimulant d-fenfluramine (dfen), and the 5-HT precursor, L-tryptophan, decreased AMPH (Porrino et al., 1989; F. L. Smith, Yu, Smith, Leccese, \& Lyness, 1986), METH (Munzar, Baumann, Shoaib, \& Goldberg, 1999), COC (Carroll, Lac, Asencio, \& Kragh, 1990a, 1990b; Czoty et al., 2002; Howell \& Byrd, 1995; A. McGregor, Lacosta, \& Roberts, 1993; Negus, Mello, Blough, Baumann, \& Rothman, 2007; Porrino et al., 1989), heroin (Higgins, Wang, Corrigall, \& Sellers, 1994; Y. Wang, Joharchi, Fletcher, Sellers, \& Higgins, 1995) and morphine (Raz \& Berger, 2010) self-administration.

Other studies have shown that decreased 5HTergic transmission facilitated self-administration. pCPA pre-treatment, which induced about an $80 \%$ reduction in whole-brain 5HT levels, increased ethanol $(\mathrm{EtOH})$ self-administration (Lyness \& Smith, 1992). Dorsal and median raphe, medial forebrain bundle (MFB) or intracerebroventricular (icv) lesions produced by the selective 5HT neurotoxin, 5, 7dihydroxytryptamine (5,7- DHT), resulted in significantly higher levels of AMPH self-administration (Fletcher, Korth, \& Chambers, 1999; Leccese \& Lyness, 1984; Lyness, Friedle, \& Moore, 1980). Bilateral NAc 5, 7 -DHT lesions increased morphine self-administration (J. E. Smith, Shultz, Co, Goeders, \& Dworkin, 1987), but similar lesions did not alter AMPH self-administration (Lyness et al., 1980). icv, intra-amygdala, and MFB 5, 7-DHT lesions increased the break-points on a progressive ratio schedule (Loh \& Roberts, 1990; DCS Roberts, Loh, Baker, \& Vickers, 1994)

\section{Acquisition of Self-administration}

Most self-administration studies have examined effects of manipulations following acquisition of self-administration. Some, however, have documented acquisition profiles in order to determine factors that might impact susceptibility to drug dependence. Variability in basal extracellular DA was related to susceptibility to self-administer drugs; basal levels of striatal DA were inversely related to the number of responses produced during acquisition of COC (Glick, Raucci, Wang, Keller Jr, \& Carlson, 1994). 
One means of measuring factors that might influence susceptibility to the positive reinforcing effects of drugs is to examine acquisition profiles. The latency to acquire COC and AMPH self-administration was inversely related to the dose of drug; higher doses led to more rapid acquisition (Carroll \& Lac, 1997; Schenk et al., 1993; Van Ree, Slangen, \& de Wied, 1978). Therefore, changes in susceptibility can be examined by measuring shifts in the acquisition curves. More rapid acquisition would suggest a more sensitive response whereas delayed acquisition would suggest a less sensitive response.

One factor that has been shown to alter the latency to acquisition of selfadministration is prior drug exposure. The acquisition of AMPH self-administration was facilitated following pre-treatment with AMPH (Piazza, Deminière, Le Moal, \& Simon, 1989), and pre-treatment with COC produced a leftward shift in the acquisition curve for COC self-administration (Horger, Shelton, \& Schenk, 1990). The acquisition of self-administration was also altered by pre-treatment with some drugs that were different from the self-administration drug. For example, the repeated administration of MDMA, nicotine, or AMPH enhanced the acquisition of selfadministration of low-doses of COC self-administration (Fletcher, Robinson, \& Slippoy, 2001; Horger, Giles, \& Schenk, 1992). The pharmacological basis for these data is thought to be due to the drug pre-treatment inducing sensitisation of the mesolimbic DAergic system (Kalivas, Sorg, \& Hooks, 1993; Kalivas \& Stewart, 1991; Sorg \& Kalivas, 1991) which facilitates the reinforcing effects of drug.

There are other predisposing factors in drug self-administration that have also been attributed to enhanced DA responses. Rats that display a heightened behavioural response to a novel (but not familiar) environment (HR rats) were more likely to selfadminister COC and AMPH (Dellu, Piazza, Mayo, Le Moal, \& Simon, 1996; Hooks, Jones, Smith, Neill, \& Justice, 1991; Mandt, Schenk, Zahniser, \& Allen, 2008; Piazza et al., 1990; Piazza et al., 1989; Rougé-Pont, Deroche, Moal, \& Piazza, 1998). HRs showed an upward shift of the COC dose-effect curve and COC self-administration was maintained by lower doses than Low Responders (LR). This might reflect the increased DAergic response to drugs by HR rats. Extracellular DA was higher in HRs after COC administered either peripherally (Hooks et al., 1991) or directly into the NAc (Hooks et al., 1994).

Food restriction also facilitated the acquisition of self-administration of different classes of drug, using different routes of administration and in a range of 
species (Carroll, 1985; Carroll, France, \& Meisch, 1979; Carroll \& Lac, 1993; Oei, 1983; Papasava, Singer, \& Papasava, 1986). The extent of the food restriction, as measured by percentage of body weight lost, was correlated with the rate of acquisition of COC self-administration (De Vry, Donselaar, \& Van Ree, 1989). Food deprivation also enhances the DAergic response to drugs of abuse. Sensitisation of the increase in extracellular DA induced by repeated treatment with a range of drugs was augmented following food-deprivation (Cadoni, Solinas, Valentini, \& Di Chiara, 2003).

\section{MDMA Self-administration}

The data show that DA neurotransmission underlies the reinforcing effects of drugs of abuse; manipulations that increase DA increase self-administration. But the preferential neurochemical effect of MDMA is to increase 5HT neurotransmission, which is inhibitory to self-administration. Based on its neurochemical effects, therefore, MDMA would not be expected to be self-administered. MDMA, however, is abused by humans, and is self-administered by monkeys (Beardsley, Balster, \& Harris, 1986; Fantegrossi, Ullrich, Rice, Woods, \& Winger, 2002), baboons (Lamb \& Griffiths, 1987), rats (Ratzenboeck, Saria, Kriechbaum, \& Zernig, 2001), and mice (Trigo, Panayi, Soria, Maldonado, \& Robledo, 2006).

Like all other drugs of abuse, racemic, (+)- and (-)- MDMA produce dosedependent responding in the shape of an inverted $\mathrm{U}$; high and low doses are selfadministered at low levels, and intermediate doses are self-administered at higher levels (Beardsley et al., 1986; Fantegrossi et al., 2002; Fantegrossi et al., 2004; Lamb \& Griffiths, 1987; Schenk, Gittings, Johnstone, \& Daniela, 2003).

Early MDMA self-administration experiments employed a substitution method, whereby ( \pm )-MDMA was introduced to COC-trained animals (Beardsley et al., 1986; Lamb \& Griffiths, 1987; Schenk et al., 2003). In the first experiment, 3 of the 4 monkeys tested self-administered MDMA, indicating that MDMA produced reinforcing effects. Further, at one dose, 100ug/kg/ infusion, 2 of the monkeys responded more than when COC was self-administered (Beardsley et al., 1986). Subsequent studies, however, reported low levels of responding maintained by MDMA and high levels of variability between subjects. COC-trained baboons responded for about 5-6 infusions of MDMA (1.0 mg/kg/infusion) in a $24 \mathrm{hr}$ session (Lamb \& Griffiths, 1987). Initial studies in rodents revealed extremely low numbers 
of responses, and responding was not dose-dependent. Rats that were initially trained to perform an operant to receive food pellets self-administered about 3-4 infusions per session, regardless of dose (De La Garza II, Fabrizio, \& Gupta, 2007; Ratzenboeck et al., 2001). In one study, only 1 of 5 rats tested responded reliably (De La Garza II et al., 2007). Because responding maintained by MDMA was low, researchers suggested that MDMA had relatively weak reinforcing effects (Beardsley et al., 1986; Lamb \& Griffiths, 1987). More recent MDMA self-administration studies, however, have reported higher levels of responding (Bradbury et al., 2013; Do \& Schenk, 2011; Reveron et al., 2010; Schenk, Colussi-Mas, Do, \& Bird, 2012; Schenk et al., 2003; Schenk et al., 2007). The failure of earlier studies to find reliable MDMA selfadministration might be due to methodological disparities; in particular MDMA dose, and drug infusion length (De La Garza II et al., 2007), or the number of test sessions. High rates of MDMA self-administration was produced only after an average of 15 daily test sessions (Schenk et al., 2012).

There are many aspects of MDMA self-administration that differentiate it from the self-administration of other drugs. First, the acquisition of MDMA selfadministration is not dose-dependent. The proportion of rats that acquired MDMA self-administration and the latency to acquisition was comparable when 1.0 and 0.25 mg/kg MDMA were tested (Schenk et al., 2007). The latency to acquire AMPH and COC self-administration, however, was inversely related to the dose of drug (Carroll \& Lac, 1997; Schenk et al., 1993; Van Ree et al., 1978).

Second, the latency to acquisition of MDMA self-administration is much longer than the latency to acquisition for COC and AMPH. Whereas selfadministration of moderate to high doses of COC and AMPH is acquired within a small number of limited-access daily sessions (e.g. Carroll \& Lac, 1997), 15 test sessions are typically required for MDMA self-administration (Schenk et al., 2012). This is reflected in the low level of responding for MDMA found during initial sessions (Reveron et al., 2010; Schenk et al., 2003; Schenk et al., 2007).

Third, the most striking difference between the acquisition of MDMA selfadministration and that of other drugs is the number of subjects that acquire selfadministration. Our laboratory consistently finds that only about $50 \%$ of test subjects acquire MDMA self-administration (Schenk et al., 2012). The self-administration of moderate and high doses of drugs such as $\mathrm{COC}$ and $\mathrm{AMPH}$, however, is acquired by the vast majority of subjects (e.g. Carroll \& Lac, 1997). 
Once MDMA self-administration has been acquired, it becomes comparable to that of AMPH or COC in that responding became dose-dependent (Schenk et al., 2003; Schenk et al., 2007). Coincident with the change in the behavioural profile is a change in the neurochemical effects of MDMA. The DAergic response to MDMA became augmented (Colussi-Mas et al., 2010) and the 5HT response decreased (Reveron et al., 2010), and tissue levels of 5HT, but not DA, were decreased (Do \& Schenk, 2011; Schenk, Gittings, \& Colussi-Mas, 2011) following MDMA selfadministration. Further, similar to what is found with other psychostimulants, DAergic mechanisms were associated with MDMA-seeking following extensive selfadministration. Drug seeking following the self-administration of MDMA was reinstated by the $\mathrm{D}_{2}$ agonist, quinpirole, the DA releaser, $\mathrm{AMPH}$, and the DA reuptake inhibitor, GBR 12909 (Schenk et al., 2011); and MDMA-produced drugseeking was attenuated by the $\mathrm{D}_{1}$ antagonist, $\mathrm{SCH} 23390$, and the $\mathrm{D}_{2}$ antagonist, eticlopride (Schenk et al., 2011).

It appears then, that MDMA self-administration progresses with changes of the neurochemical response. Initially, the 5HT response is marked and responding for MDMA is low. Following repeated testing, the 5HT response is decreased and the DA response is increased, and responding is comparable to that maintained by AMPH or COC.

\section{Current Thesis}

The current thesis aims to test the ideas that (1) susceptibility to acquire MDMA self-administration is related to the MDMA-produced 5HT response, (2) MDMA self-administration progresses as the MDMA-produced 5HT response decreases and the MDMA-produced DA response increases, and (3) that responding maintained by MDMA is not dependent on 5HT neurotransmission. Based on previous literature, it was hypothesised that the acquisition of MDMA selfadministration is initially limited by the MDMA-produced 5HT response, but that this response decreases with repeated exposure to MDMA. The MDMA-produced DA response was hypothesised to concurrently increase, and to underlie the maintenance of MDMA self-administration. 


\section{General Methods}

The methodology contained in this section was used for each and every experiment undertaken for this thesis. The methods sections contained in chapters describe any further methodology required for individual experiments.

\section{Animals}

Male Sprague-Dawley rats weighing between 290 and 330g at the start of the experiment were used. The rats were bred in the vivarium at Victoria University of Wellington and housed in groups of 4 until they weighed $280 \mathrm{~g}$. Thereafter, they were housed individually in hanging polycarbonate cages for 4 days prior to surgery. The animal colony was humidity- $(55 \%)$ and temperature- $\left(21^{\circ} \mathrm{C}\right)$ controlled, and was on a 12/12 hour light cycle, with lights on at $0700 \mathrm{hr}$. Food and water were available ad libitum except during testing. All procedures were approved by the Animal Ethics Committee at Victoria University of Wellington.

\section{MDMA Self-Administration Testing}

Surgery

All rats were surgically implanted with an intrajugular catheter. Deep anaesthesia was produced by an injection of ketamine $(90.0 \mathrm{mg} / \mathrm{kg}$, ip, PhoenixPharm) and xylazine $(9.0 \mathrm{mg} / \mathrm{kg}$, ip, Provet), and this was followed by an injection of the anti-inflammatory anaesthetic, Carprofen® $(5.0 \mathrm{mg} / \mathrm{kg}, \mathrm{sc}$, Pfizer Animal Health). Briefly, the external jugular vein was isolated from surrounding tissue and tied off. An incision was made in the vein and a silastic catheter (Dow Corning, Midland, MI, USA) was inserted and fixed. The distal end of the catheter was then threaded subcutaneously to the exposed skull.

A compound sodium lactate solution (Hartmann's solution, $2 \times 6 \mathrm{ml}, \mathrm{sc}$ ) was administered to restore electrolyte balance. Carprofen ${ }^{\circledR}(5.0 \mathrm{mg} / \mathrm{kg}, \mathrm{sc})$ was administered on each of the two days following surgery. Catheters were infused with $0.2 \mathrm{~mL}$ of a sterile $0.9 \%$ heparinised saline solution, containing penicillin $\mathrm{G}$ potassium $(250,000 \mathrm{IU} / \mathrm{mL})$ each day for 3 days post-surgery.

\section{Apparatus}


Self-administration was conducted in operant chambers (Med Associates, ENV-001, St Albans, VT, USA) equipped with 2 levers. Depression of the right, 'active' lever resulted in a 12 second intravenous infusion of $0.1 \mathrm{~mL} \pm \mathrm{MDMA}(1.0$ $\mathrm{mg} / \mathrm{kg} /$ infusion, Environmental Science and Research Ltd, Porirua, New Zealand; Experiments 1 and 2) and the illumination of a stimulus light located directly above the active lever. Depression of the left, 'inactive' lever was recorded but had no programmed response. The $1.0 \mathrm{mg} / \mathrm{kg}$ dose of MDMA was chosen because it has been demonstrated to produce reliable acquisition of self-administration (Schenk et al., 2003; 2007; 2012).

\section{Procedure}

Each day, prior to self-administration testing, catheters were flushed with 0.2 $\mathrm{mL}$ of the heparinised penicillin solution. Daily test sessions were 2 hours in duration, 6 days a week. Each session commenced with an experimenter-administered infusion of $0.1 \mathrm{~mL}$ drug to clear the catheter of the penicillin solution. Thereafter, drug infusions of MDMA (1.0 mg/kg/ infusion) were delivered according to a fixed ratio 1 schedule of reinforcement. Testing continued for 25 daily sessions, or until the session during which the total cumulative amount of self-administered MDMA reached $90 \pm 5$ infusions, whichever came first. Rats that met this criterion within the 25 day cut-off were considered to have acquired (ACQ) and those that failed to meet the criterion within this test period were considered to have not acquired (NO-ACQ) selfadministration. The latency to acquisition was defined as the number of test sessions required to meet this acquisition criterion. 


\section{Chapter 1}

This chapter has been adapted from Bradbury et al. (2013)

\section{Introduction}

The experiments of Chapter 1 sought to elucidate whether the variability in acquisition of MDMA self-administration could be explained by the MDMA-induced increase of synaptic 5HT or DA. Variability in COC and AMPH self-administration has previously been attributed to differences in drug-induced increases of synaptic DA (Nelson, Larson, \& Zahniser, 2009; Piazza et al., 1991). MDMA differs from COC and AMPH, however, in that it preferentially increases synaptic 5HT. This would be expected to limit the acquisition of self-administration because of inhibitory effects on DA. If so, it was expected that the latency to acquisition of MDMA selfadministration would be negatively related to the MDMA- produced 5HT response and positively related to the DA response. In order to investigate these possibilities extracellular levels of 5HT and DA in response to an acute injection of MDMA were measured prior to the commencement of MDMA self-administration.

Microdialysis probes were aimed at the shell of the NAc. Previous research has documented that drugs of abuse, including MDMA, induce a preferential increase in shell DA relative to the core (Cadoni et al., 2005), that has been related to the drugs' reinforcing properties (Di Chiara, 1999).

\section{Method}

Experimental Overview

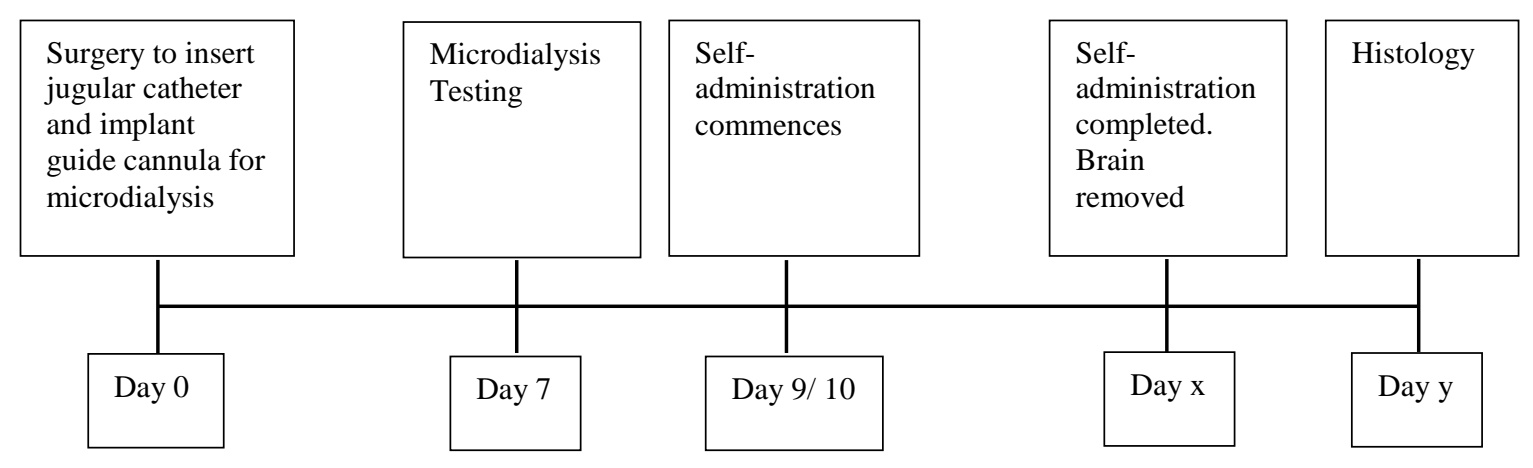

Surgery

Concurrent with the implantation of the jugular catheter (as described in the General Methods), a guide cannula (MAB 4.15.IC, microbiotech, Sweden) was 
stereotaxically implanted $1 \mathrm{~mm}$ above the right NAc (antero-posterior $+1.0 \mathrm{~mm}$ from bregma, lateral -0.85mm from midline, ventral $-5.5 \mathrm{~mm}$ from dura; Paxinos \& Watson, 2006). The cannula was fixed to the skull alongside the distal end of the catheter using dental screws and dental acrylic.

\section{Microdialysis}

\section{Procedure}

Six days following surgery, the rats were transported to the testing room and held in a transparent plastic cage. A microdialysis probe (MAB 4.15.2.Cu, Microbiotech, Sweden) was inserted into the guide cannula and protruded $3 \mathrm{~mm}$ past the guide (membrane length: $2 \mathrm{~mm})$. Artificial cerebrospinal fluid $(149 \mathrm{mmol} / \mathrm{L} \mathrm{NACl}$; $2.8 \mathrm{mmol} / \mathrm{L} \mathrm{KCl} ; 1.2 \mathrm{mmol} / \mathrm{LMgCl}_{2} ; 1.2 \mathrm{mmol} / \mathrm{LCaCl}_{2} ; 0.45 \mathrm{mmol} / \mathrm{LNaH}_{2} \mathrm{PO}_{4} ; 2.33$ $\mathrm{mmol} / \mathrm{LNa}_{2} \mathrm{HPO}_{4}, \mathrm{pH}$ 7.4) was perfused through the probe overnight at a flow rate of $1.0 \mu \mathrm{L} / \mathrm{min}$. Probe recovery rates were calculated individually for each rat following perfusion with known concentrations of DA and 5HT and averaged $12.3 \pm 1.9 \%$ for DA and $18.4 \pm 2.2 \%$ for $5 \mathrm{HT}$.

The following day, the rat was moved into a clear, plexiglass chamber of dimensions $42 \times 42 \times 30 \mathrm{~cm}$, which served as the testing chamber and 3 baseline samples were collected at 30 min intervals in a tube containing $3.75 \mu \mathrm{L} 0.01 \mathrm{~N}$ PCA. Each rat then received an injection of $1.0 \mathrm{mg} / \mathrm{kg}$ MDMA (iv) followed, 2 hours later, by an injection of $3.0 \mathrm{mg} / \mathrm{kg}$ MDMA (iv). Dialysis samples were collected at 30 minute intervals for 2 hours after each injection. The microdialysis probe was then removed from the guide, the dummy cannula was re-inserted, and the rats were returned to their home cage. Self-administration testing began 2 to 3 days later.

\section{Dialysate Analysis}

The concentration of DA and 5HT in dialysates was determined using high performance liquid chromatography (HPLC; 1100 series, Agilent, Santa Clara, CA, USA) equipped with a coulometric detector (Coulochem III, ESA Inc., Chelmsford, MA, USA). Samples were split for the purpose of analysis. For DA, $10 \mu \mathrm{L}$ of dialysate was injected onto a column (C18 reversed phase; Agilent Eclipse XDB-C18, $4.6 \times 150 \mathrm{~mm}, 5 \mu \mathrm{m}$ particle size) and the mobile phase consisted of $75 \mathrm{mmol} / \mathrm{L}$ $\mathrm{NaH}_{2} \mathrm{PO}_{4}, 1.7 \mathrm{mmol} / \mathrm{L}$ octanesulfonic acid, $0.25 \mathrm{mmol} / \mathrm{L}$ EDTA, $100 \mu \mathrm{L} / \mathrm{l}$ 
triethylamine, $10 \%(\mathrm{v} / \mathrm{v})$ acetonitrile, $\mathrm{pH} 3$, delivered at a constant flow rate of $1.0 \mathrm{ml} / \mathrm{min}$. For $5 \mathrm{HT}, 20 \mu \mathrm{L}$ of dialysate was injected into a $\mathrm{C} 18$ reversed phase column (Luna C18(2), $2.0 \times 100 \mathrm{~mm}, 3 \mu \mathrm{m}$ particle size, Phenomenex). The mobile phase consisted of $90 \mathrm{mmol} / \mathrm{L} \mathrm{NaH}_{2} \mathrm{PO}_{4}, 1.7 \mathrm{mmol} / \mathrm{L}$ octanesulfonic acid, $50 \mu \mathrm{mol} / \mathrm{L}$ EDTA, $50 \mathrm{mmol} / \mathrm{L}$ citric acid, 10\% (v/v) acetonitrile, $\mathrm{pH} \mathrm{3}$, delivered at a constant flow rate of $0.2 \mathrm{~mL} / \mathrm{min}$. Chromatograms were acquired with ChemStation software and peak heights of samples were compared to peak heights of standards with known concentrations of DA or 5HT. Concentrations are expressed as nmol/L, corrected for probe recovery. The lower limit of detection for DA was $3 \mathrm{fmol}$, and for 5HT 0.88 fmol.

\section{Histology}

Following the completion of self-administration testing, rats were sacrificed by $\mathrm{CO}_{2}$ asphyxiation and the brains were removed and stored at $-80^{\circ} \mathrm{C}$. Brains were sliced on a cryostat in 60 or $80 \mu \mathrm{m}$ sections and sections were stained with Neutral Red. Sections were examined by an experimenter blind to the results and data from rats with incorrect placements were not included in any analyses. A complete set of samples for 5HT was collected from 14 rats ( $n=7$ acquired; $n=7$ non-acquired) and for DA from 12 rats ( $\mathrm{n}=7$ acquired; $\mathrm{n}=5$ non-acquired. $\mathrm{Nb}$, samples from 2 non-acquired rats were lost due to hplc problems).

\section{Data Analysis}

Active and inactive lever responding for the ACQ and NO-ACQ groups were compared for the first 3 and last 3 days of responding maintained by MDMA using a three-way analysis of variance (ANOVA; Group X Lever X Training). Post-hoc tests were conducted using the Bonferroni correction. MDMA-induced changes in DA and 5HT were expressed as a percentage of the baseline value, calculated as the average of the initial three baseline samples collected in the testing chamber. Changes in MDMA-induced DA and 5HT overflow for the ACQ or NO-ACQ group were evaluated using a three-way ANOVA (Group X Time X Dose) followed by post hoc tests using the Bonferroni correction . Correlations were conducted between the MDMA-induced increases of 5HT and DA, expressed as either the average concentration across the 4 samples or as the peak concentration, and the acquisition 
data, expressed as either the number of sessions required to reach the acquisition criterion or the average MDMA intake over the last 3 days of self-administration testing. 


\section{Results}

\section{MDMA self-administration}

Figure 1.1 depicts the location of the microdialysis probes. The acquisition criterion was met by 7 of the 14 rats. The 90 infusions of $1.0 \mathrm{mg} / \mathrm{kg} / \mathrm{infusion}$ MDMA were self-administered in an average of 15 test sessions (range $=7-22$ days), consistent with previous findings from our laboratory (Schenk et al., 2012).

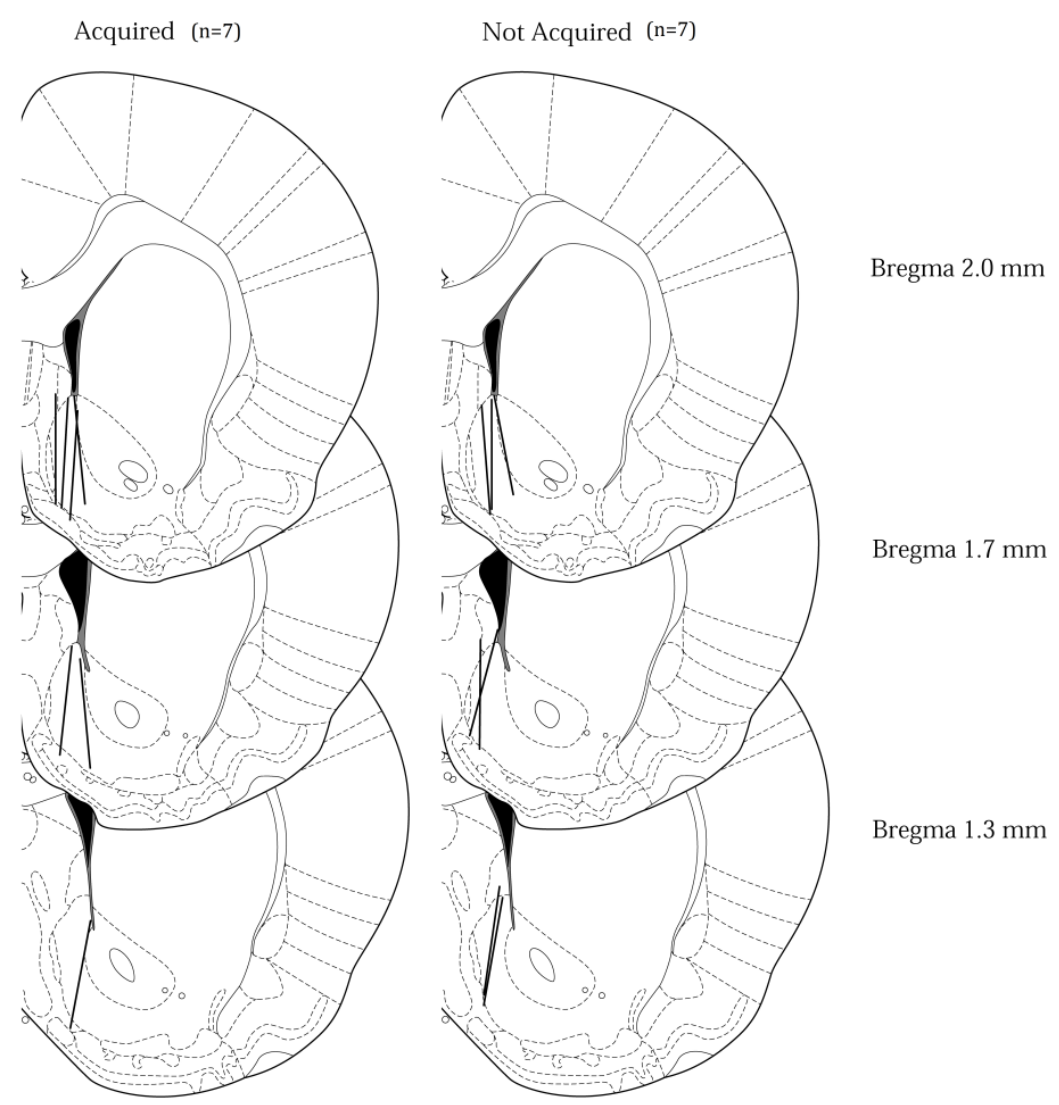

Figure 1.1 Location of microdialysis probes for the Acquired (left panel; $\mathrm{n}=7$ ) and Not Acquired (right panel; $n=7$ ) groups, adapted from Paxinos\& Watson (2005)

Figure 1.2 shows the average number of lever responses during the first 3 and the last 3 days of MDMA self-administration for the ACQ and the NO-ACQ groups. The ACQ group reached the acquisition criterion in an average of $14.8( \pm 1.8)$ test sessions. A significant Group X Lever X Training interaction was found $\left(\mathrm{F}_{(1,12)}=6.05\right.$, $p<0.05)$. Significant Lever $X$ Training $\left(\mathrm{F}_{(1,12)}=10.69, p<0.05\right)$, and Group X Lever $\left(\mathrm{F}_{(1,12)}=10.79, p<0.05\right)$ interactions were found. During initial test sessions responding on the active lever was low for both groups, but with repeated daily 
training, responding on the active lever increased significantly in the ACQ group ( $\mathrm{p}<$ 0.05). On the last 3 days of self-administration, the number of active lever responses produced by the ACQ rats was significantly higher than both the number of inactive lever responses $(\mathrm{p}<0.05)$ and the number of active lever responses in the NO-ACQ group $(\mathrm{p}<0.05)$.

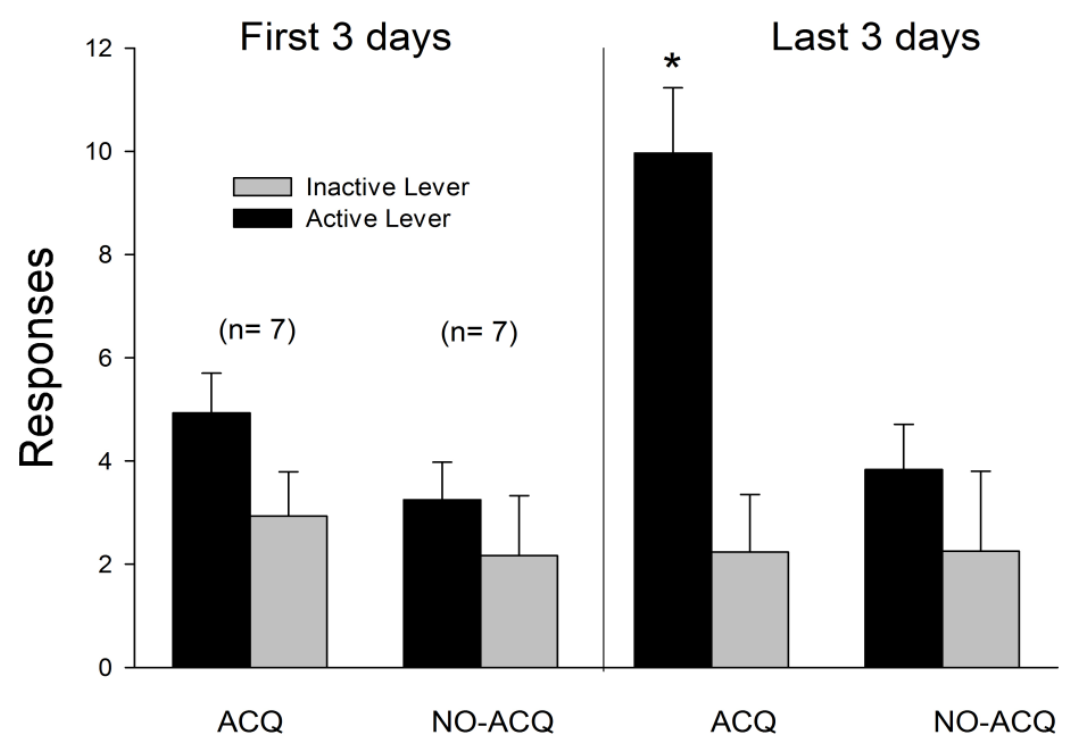

Figure 1.2 The average number of responses on the active and inactive levers for the first 3 , and last 3, days of self-administration testing for both the ACQ $(n=10)$ and NO-ACQ $(n=8)$ groups. $* \mathrm{p}<0.05$ compared to inactive lever responses for the last 3 days, active lever responses for the first 3 days by the ACQ group, and active lever pressing for the last 3 days by the NO-ACQ group.

Relationship between the neurochemical response to the initial exposure to MDMA and acquisition of MDMA self-administration

The basal concentrations of 5HT or DA were not significantly different between rats from the ACQ $(5 \mathrm{HT} ; 1.1 \pm 0.3 \mathrm{nmol} / \mathrm{L}$; DA; $11.7 \pm 4.5 \mathrm{nmol} / \mathrm{L})$ and NOACQ (5HT; $0.9 \pm 0.2 \mathrm{nmol} ; \mathrm{DA} ; 9.1 \pm 2.3 \mathrm{nmol} / \mathrm{L})$ groups $\left(5 \mathrm{HT} ; \mathrm{F}_{(1,10)}=0.020\right.$, n.s; DA; $F_{(1,12)}=0.388$, n.s.). Figure 1.3 graphs the MDMA-induced increases of 5HT (upper panel) and DA (lower panel) relative to baseline. For 5HT, a 3-way ANOVA (Dose X Sample X Group) revealed a significant main effect of Dose $\left(\mathrm{F}_{(1,12)}=14.88\right.$, $p<0.05)$ but not of Group $\left(\mathrm{F}_{(1,12)}=4.32\right.$, n.s. $)$. There was a significant Group X Dose interaction $\left(\mathrm{F}_{(1,12)}=5.13, p<0.05\right)$ and post-hoc tests confirmed that the increase following $3.0 \mathrm{mg} / \mathrm{kg}$ MDMA was higher for the NO-ACQ group $(\mathrm{p}<0.05)$. For DA, a 
3-way ANOVA (Dose X Sample X Group) revealed only a significant main effect of Dose $\left(\mathrm{F}_{(1,10)}=5.17, p<0.05\right)$.

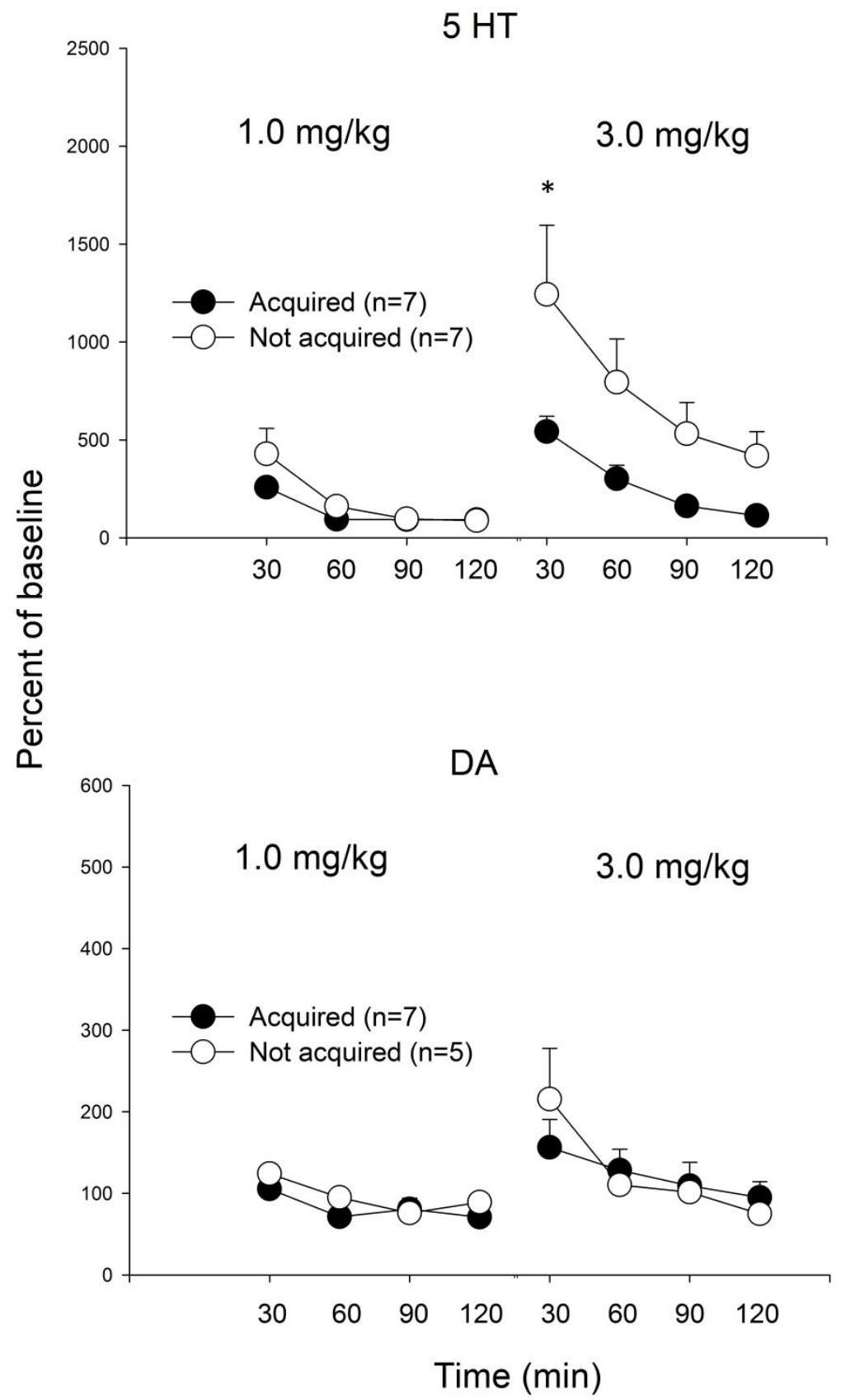

Figure 1.3 shows the MDMA-produced percent increase in 5HT and DA as a function of baseline neurotransmitter levels. Percent increases are shown for the ACQ group and NO-ACQ group for 4 samples collected following 1.0 or $3.0 \mathrm{mg} / \mathrm{kg}$ MDMA. * $\mathrm{p}<$ 0.05 compared to the MDMA-induced increase in 5HT of the ACQ group 
The variability in latency to reach the acquisition criterion, however, was not related to $3.0 \mathrm{mg} / \mathrm{kg}$ MDMA-induced increases of $5 \mathrm{HT}$ or DA. The $5 \mathrm{HT}$ response, measured as the average concentration of the 4 samples $(M=13.23, \mathrm{SD}=12.68)$, or the peak concentration of $5 \mathrm{HT}(\mathrm{M}=6.26, \mathrm{SD}=5.66)$ was not correlated with days to acquisition $(\mathrm{M}=14.75, \mathrm{SD}=5.12), \mathrm{r}=0.336, \mathrm{p}=\mathrm{n} . \mathrm{s}$ and $\mathrm{r}=0.355, \mathrm{p}=\mathrm{n} . \mathrm{s}$, respectively. Similarly, no correlation was found between average extracellular levels of DA averaged out over the 4 samples $(M=40.81, S D=29.67)$ or the peak increase of $\mathrm{DA}$ $(\mathrm{M}=14.40, \mathrm{SD}=11.02)$ and days to acquire self-administration, $\mathrm{r}=0.472, \mathrm{p}=\mathrm{n} . \mathrm{s}$ and $\mathrm{r}=0.290, \mathrm{p}=\mathrm{n} . \mathrm{s}$, respectively.

In addition, there was no significant relationship between the extracellular levels of 5HT- whether the average of the 4 samples or the peak concentration was used- and the average number of infusions over the last 3 self-administration sessions $(\mathrm{M}=10.5, \mathrm{SD}=4.07), \mathrm{r}=-0.398, \mathrm{p}=\mathrm{n} . \mathrm{s}$ and $\mathrm{r}=-0.432, \mathrm{p}=\mathrm{n} . \mathrm{s}$, respectively. Likewise, neither average extracellular DA nor peak DA significantly correlated with the average number of infusions over the last 3 self-administration sessions, $r=0.01$, n.s and $\mathrm{r}=-0.16, \mathrm{p}=\mathrm{n} . \mathrm{s}$, respectively.

Figure 1.4 plots the number of infusions of MDMA obtained over the last 3 self-administration test sessions as a function of the MDMA-produced increases in 5HT (top) and DA (bottom) for individual rats. Although all analyses revealed nonsignificant results, a trend exists in that greater MDMA-induced increase in 5HT corresponded with fewer infusions of self-administered MDMA. 

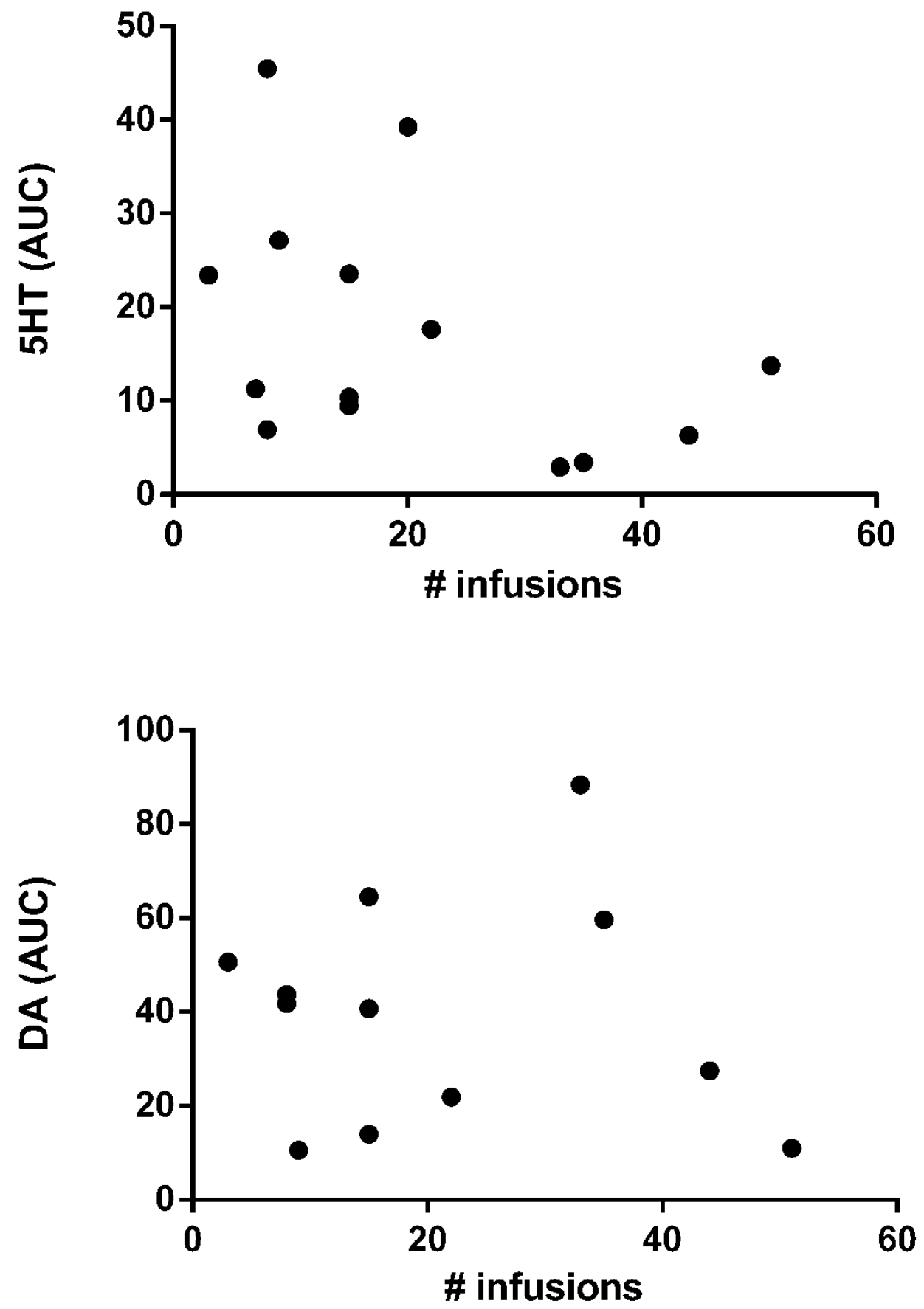

Figure 1.4 plots the number of infusions of MDMA obtained over the last 3 self-administration test sessions as a function of the MDMA-produced increases in 5HT (top) and DA (bottom) for individual rats. 5HT and DA levels are represented by the area under the curve produced by plotting the concentration of neurotransmitter across time. 


\section{Discussion}

Acute exposure to MDMA increased both DA and 5HT overflow and as has been previously documented (Baumann, Clark, Franken, Rutter, \& Rothman, 2008; Baumann, Clark, \& Rothman, 2008; Kurling, Kankaanpää, \& Seppälä, 2008; O'Shea et al., 2005; Reveron et al., 2010), the 5HT response was more pronounced. The DAergic response to MDMA was dose-dependent and the magnitude of the increase was similar to that previously reported following administration of the same doses, administered in the same manner (Baumann, Clark, \& Rothman, 2008). There was, however, no difference in the magnitude of the DA response for the rats that acquired or failed to acquire MDMA self-administration. MDMA also increased 5HT overflow in a dose-dependent manner, and the magnitude of the increase was also comparable to what has previously been reported following the same injection protocol (700\% and $1445 \%$ for $1.0 \mathrm{mg} / \mathrm{kg}$ and $3.0 \mathrm{mg} / \mathrm{kg}$, respectively; Baumann, Clark, \& Rothman, 2008). The MDMA-induced increase in $5 \mathrm{HT}$ following the $3.0 \mathrm{mg} / \mathrm{kg}$ injection was, however, significantly higher for the group that subsequently failed to meet the criterion for MDMA self-administration suggesting that 5HT impacts MDMA selfadministration.

Although $1.0 \mathrm{mg} / \mathrm{kg}$ was the self-administered dose, the effect of a single infusion of this dose of MDMA on 5HT was not different for the acquired and not acquired groups. Only the effect of the higher dose of $3.0 \mathrm{mg} / \mathrm{kg}$ produced an effect that was different for the two groups. This might suggest that the effects are not relevant to the MDMA self-administration data. During self-administration testing, however, rats are exposed to multiple infusions of the $1.0 \mathrm{mg} / \mathrm{kg}$ dose of MDMA. Further, as self-administration progresses, the average intake increases and exceeds $3.0 \mathrm{mg} / \mathrm{kg}$ per session. One cannot, therefore, directly compare the effect of a single experimenter-administered infusion to effects produced by multiple self-administered infusions.

The data suggest that MDMA self-administration is, at least initially, inhibited by MDMA-induced increases of 5HT. There was no relationship however, between latency to acquisition and MDMA-induced increases of 5HT. Thus individual differences in the 5HTergic response to MDMA may predict whether or not the subject will acquire MDMA self-administration, but not the latency to acquire selfadministration. 
A wealth of data has implicated the mesolimbic DAergic system in the reinforcing effects of psychostimulants (for a review, see Wise, 1998), including MDMA (Brennan et al., 2009; Daniela et al., 2004), and propensity to acquire psychostimulant self-administration was correlated with greater DA turnover and increased drug-induced extracellular DA in the NAc (Hooks, Colvin, Juncos, \& Justice Jr, 1992; Marinelli \& White, 2000; Piazza et al., 1991). In addition, the latency to acquire self-administration was negatively correlated with drug-induced DA (Carroll \& Lac, 1997; Schenk et al., 1993; Van Ree et al., 1978). Accordingly, the MDMA-produced DA response of the ACQ rats may have been expected to be higher because of either a greater direct effect of MDMA on DA or because of the indirect, and reduced inhibitory, effect of 5HT on DA. This response was, however, comparable regardless of whether the rats acquired or failed to acquire MDMA selfadministration. Further, the magnitude of the MDMA-induced DA release was not indicative of the latency to acquire MDMA self-administration.

The MDMA-produced increase in DA was modest compared to effects produced by other self-administered drugs (Ranaldi, Pocock, Zereik, \& Wise, 1999; Suto, Ecke, You, \& Wise, 2010; Weiss et al., 1992). It is therefore possible that the initial MDMA-produced increase in DA was insufficient to reinforce operant responding. Indeed, this might explain why none of the rats reliably self-administered MDMA during the first several sessions. It has been suggested that repeated exposure to small amounts of MDMA during the first few sessions is sufficient to produce deficits in 5HT neurotransmission for some of the rats, leading to a disinhibition of mesolimbic DA and the development of reliable self-administration; increased selfadministration would then produce additional 5HT deficits and a more substantial disinhibition of DA (Schenk, 2011). Following experimenter-administered MDMA that induced a decrease in 5HT levels equivocal results on DA overflow have been reported with increased (Kalivas et al., 1998), or no change in DA levels (Baumann, Clark, Franken, et al., 2008; Shankaran \& Gudelsky, 1999). In the limited number of studies that have investigated the effects of self-administered MDMA, low levels of self-administration failed to alter MDMA-induced DA overflow (Reveron et al., 2010) but more extensive self-administration increased MDMA-induced DA overflow to a greater extent for the ACQ group (Colussi-Mas et al., 2010).

The results of Chapter 1 demonstrate that the variability to acquire MDMA self-administration is not likely related to small, initial increases in DA levels, but 
might be due to differences in the ability of MDMA exposure to enhance 5HT neurotransmission. In particular, the data suggest that greater MDMA-induced increases of 5HT were inhibitory to acquisition of self-administration. If so, then a reduction of the MDMA-produced 5HT response should facilitate the acquisition of MDMA self-administration. This idea can be tested experimentally by manipulating MDMA-induced increases of 5HT. One way to decrease 5HT is via neurotoxic 5, 7 DHT lesions. Previous research has shown that these lesions increased responding during acquisition of AMPH self-administration (Leccese \& Lyness, 1984; Lyness et al., 1980). If 5HT also inhibits acquisition of MDMA self-administration, then it was expected that the lesion would facilitate acquisition, as measured by a decrease in latency. 


\section{Chapter 2}

This chapter has been adapted from Bradbury et al. (2013).

\section{Introduction}

The results of Chapter 1 showed that synaptic 5HT overflow following initial MDMA was increased to a lesser extent for the rats that subsequently acquired MDMA self-administration. If the variability in susceptibility to self-administer MDMA is negatively impacted by MDMA-induced increases of 5HT, then the widespread depletion of brain 5HT should enhance susceptibility to selfadministration. This idea was tested in the experiment of Chapter 2.

The neurotoxin, 5, 7-DHT, produces the widespread depletion of 5HT and NE. The meta-substituted dihydroxytryptamine is taken up into 5HTergic and NEergic neurons via the uptake transporter. Once transported into the cytosol, 5,7- DHT is metabolised by MAO and aldehyde dehydrogenase to form a dihydroxyindoleactic acid. This acid, along with deaminated 5, 7- DHT interacts with cytochrome-C oxidase of the mitochondria and together they are subjected to enhanced oxidation. This oxidation appears to be the greatest factor in the production of the neurotoxic effects, as the resulting intermediates attack nucleophiles in peptides and proteins to inactivate the $-\mathrm{SH}$ and $-\mathrm{NH}_{2}$ - functional groups.

Because 5, 7-DHT is transported into neurons via the uptake transporters it can be used as a selective 5HT neurotoxin by co-administering a NE transporter (NET) inhibitor to prevent uptake into NE neurons. The selective depletion of 5HT via icv or intra-medial forebrain bundle administration of 5,7 - DHT increased initial responding for AMPH (Leccese \& Lyness, 1984; Lyness et al., 1980). The experiment of chapter 2 used 5,7- DHT to produce widespread depletion of brain 5HT prior to the commencement of self-administration testing. It was hypothesised that depletion of brain 5HT would increase the proportion of subjects that self-administer MDMA, and decrease the latency to acquisition. 


\section{Method}

\section{Experimental Overview}

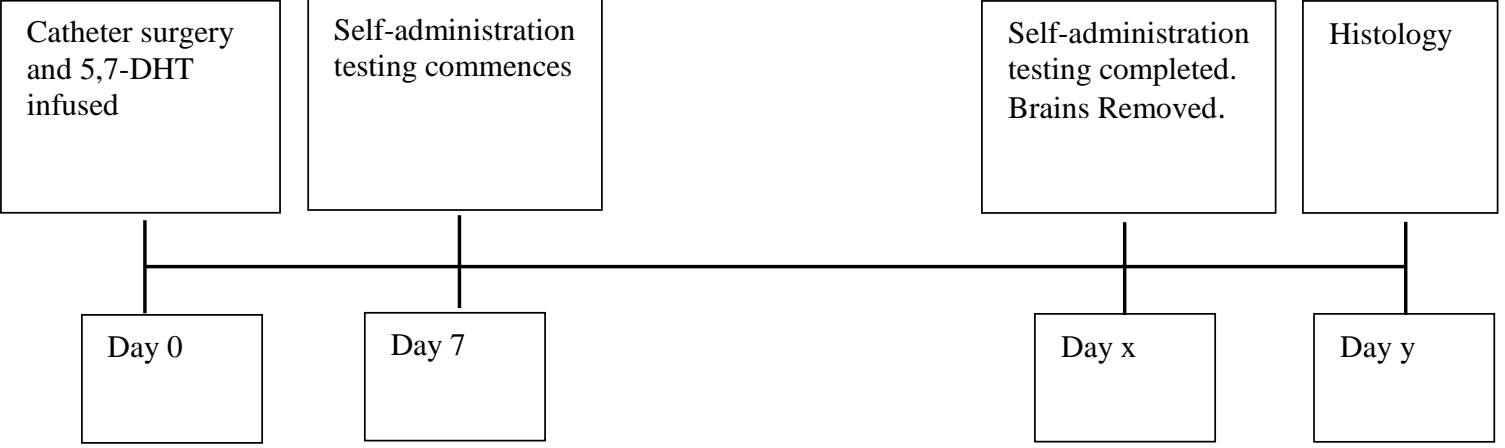

\section{Self-administration}

5, 7 - DHT was infused following implantation of the i.v catheter. In order to prevent uptake into NEergic neurons, the uptake inhibitor, desipramine $(25 \mathrm{mg} / \mathrm{kg}$, ip, Sigma Aldrich, Australia), was administered at least 30 minutes prior to administration of 5,7-DHT. In preliminary tests, xylazine produced adverse effects in rats subjected to the lesion, and so, instead, sodium pentobarbital $(20.0 \mathrm{mg} / \mathrm{kg}$, ip, Provet) was used as the aneasthetic. Following the insertion of a jugular catheter (see General Methods), a 28 gauge cannula (Plastics One, C313I-SPC; USA) was stereotaxically inserted into the left ventricle (antero-posterior $-1.5 \mathrm{~mm}$ from bregma, lateral $-1.7 \mathrm{~mm}$ from midline, ventral $-3.5 \mathrm{~mm}$ from dura; Paxinos \& Watson, 2006) and $10 \mu \mathrm{L}$ 5,7-DHT (150 $\mu \mathrm{g}$ freebase; Tran-Nguyen, Bellew, Grote, \& Neisewander, 2001 ) or the $1 \%$ ascorbic acid vehicle was infused over a $10 \min$ period ( $1 \mu \mathrm{L} / \mathrm{min}$ ). The cannula remained in situ for 2 minutes post-injection to allow diffusion of the neurotoxin. Self-administration testing began 10 days later.

\section{Neurochemical Consequences of the Lesion}

Separate groups of rats ( $n=5$ per group) were treated with 5, 7- DHT or vehicle, as above, and sacrificed 10 days later to measure tissue levels of 5HT and DA and their metabolites. Following $\mathrm{CO}_{2}$ asphyxiation, rats were sacrificed by decapitation, the FC and striatum were extracted and samples were stored at $-80^{\circ} \mathrm{C}$ until assay. The FC was chosen because it is richly innervated with 5HTergic neurons, and the striatum because it is richly innervated with DAergic neurons. The samples were combined with $10 \mu \mathrm{L} 0.1$ N PCA per mg of tissue. Samples were homogenised 
and then centrifuged at $13,000 \mathrm{rpm}$ for 30 minutes at $4^{\circ} \mathrm{C}$. The supernatant was then filtered into vials and injected onto the column. The column and mobile phase used was identical to that used for DA analysis in the microdialysis experiment. Chromatograms were acquired with ChemStation software and peak heights of samples were compared to peak heights of standards with known concentrations of 5HT, 5HIAA, DA and the DA metabolite, homovanillic acid (HVA). Regression analysis of the calibration curves was then used to calculate the concentration of the neurochemicals.

\section{Self-administration}

MDMA self-administration was carried out as reported in the General Methods: testing continued for 25 daily sessions, or until the session during which the total cumulative amount of self-administered MDMA reached $90 \pm 5$ infusions, whichever came first. Additionally, the effect of the 5, 7-DHT lesion on the acquisition curve for low-dose COC self-administration $(0.25 \mathrm{mg} / \mathrm{kg} / \mathrm{infusion})$ was measured for comparison. The acquisition criterion used was the same, with $90 \pm 5$ infusions required within 25 test sessions. The protocol used for COC selfadministration testing was identical to that of MDMA.

\section{Histology}

Following the completion of self-administration testing, rats were sacrificed by $\mathrm{CO}_{2}$ asphyxiation and the brains were removed and stored at $-80^{\circ} \mathrm{C}$. Brains were sliced on a cryostat in 60 or $80 \mu \mathrm{m}$ sections and sections were stained with Neutral Red. Sections were examined by an experimenter blind to the results and data from rats with incorrect placements were not included in any analyses. The selfadministration data from 19 rats of the MDMA groups (lesion=8; control=11) and 12 rats of the COC groups (lesion=5; control=7) were used.

\section{Data Analysis}

The number of test sessions required to self-administer 90 infusions of MDMA and COC was compared for vehicle and lesion groups using the KaplanMeier estimator for survival analysis that compared the mean time to event (latency to acquisition) between groups. The log-rank test was used to compare the survival curves of the lesion and control groups. The level of significance was set at $p<0.05$. 


\section{Results}

Table 2.1 shows tissue levels of 5HT, 5HIAA, DA and HVA in the FC and striatum following 5, 7-DHT or vehicle. One-way ANOVAs revealed that 5,7-DHT substantially reduced 5HT and 5HIAA in the $\mathrm{FC}(\mathrm{F}(1,9)=18.92, \mathrm{p}<0.05 ; \mathrm{F}(1,9)=$ 17.57, $\mathrm{p}<0.05)$ and striatum $(\mathrm{F}(1,9)=5.82, \mathrm{p}<0.05 ; \mathrm{F}(1,9)=14.03, \mathrm{p}<0.05)$. There were no differences in DA or HVA in the FC $(F(1,9)=0.10$, p=n.s; $F(1,9)=$ $.44, p=n . s)$ or striatum $(F(1,9)=0.86, p=n . s ; F(1,9)=0.02, p=n . s$.$) .$

\begin{tabular}{llll}
\hline & & Frontal Cortex & Striatum \\
\hline 5HT & Vehicle & $0.45(0.02)$ & $0.54(0.06)$ \\
& $5,7-$ DHT & $0.15(0.02)^{*}$ & $0.35(0.05)^{*}$ \\
\hline 5HIAA & Vehicle & $0.51(0.04)$ & $0.82(0.08)$ \\
& $5,7-$ DHT & $0.23(0.05)^{*}$ & $0.43(0.07)^{*}$ \\
\hline DA & Vehicle & $0.04(0.00)$ & $14.37(1.33)$ \\
& $5,7-$ DHT & $0.04(0.00)$ & $19.76(5.67)$ \\
\hline HVA & Vehicle & $0.03(0.00)$ & $1.77(0.58)$ \\
& $5,7-$ DHT & $0.03(0.00)$ & $1.67(0.27)$ \\
\hline
\end{tabular}

Table 2.1 5HT and 5HIAA levels (ng/mg tissue) in the FC and striatum following administration of 5, 7- DHT or the vehicle. Values are mean $(\mathrm{SEM}) . *$ denotes $\mathrm{p}<0.05$ compared to vehicle.

Figure 2.1 shows the cumulative percentage of rats that met the criterion for acquisition of MDMA (left) and COC (right) self-administration as a function of test session. Of the 11 rats in the control MDMA group, 5 (45.45\%) met the acquisition criterion. Following the lesion, all of the rats met the acquisition criterion for MDMA self-administration and the curve was shifted upwards compared to the control group $\left(\chi^{2}(1)=7.13, p<0.05\right)$. All control and lesioned rats met the criterion for acquisition of COC self-administration. The curve for the lesion group was shifted leftwards compared to the control group $\left(\chi^{2}(1)=8.49, \mathrm{p}<0.05\right)$. 

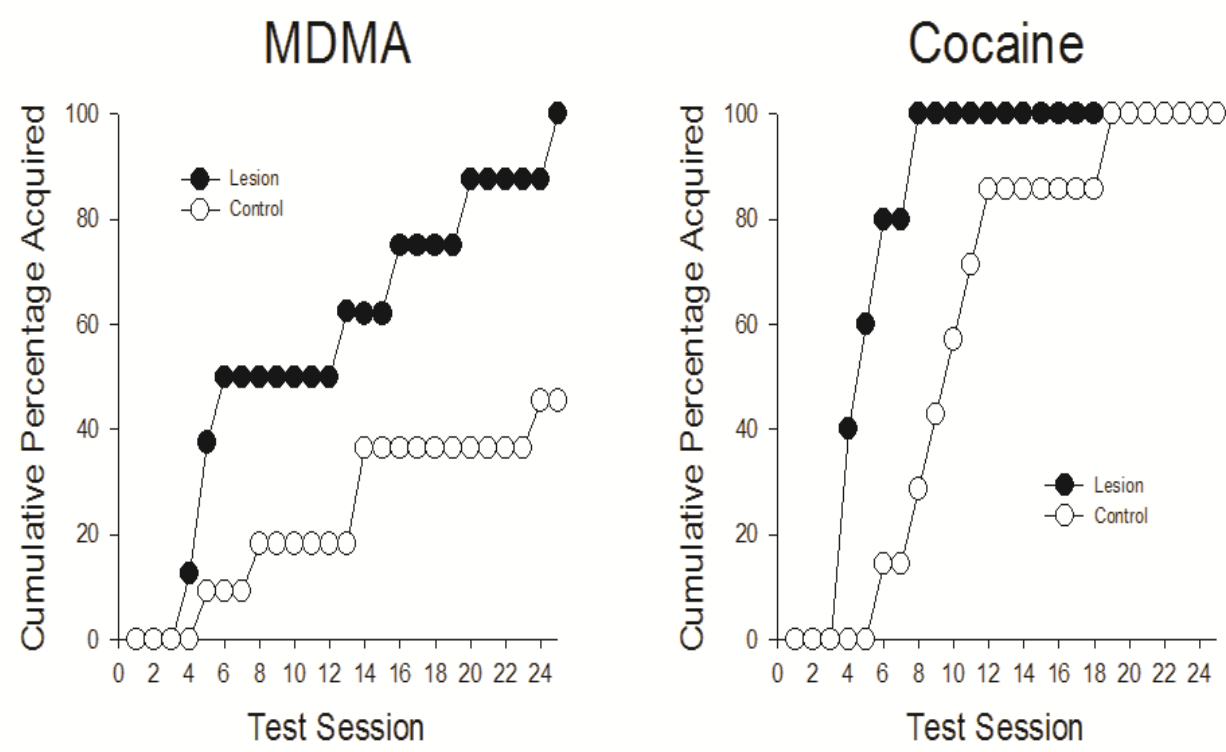

Figure 2.1 shows the cumulative acquisition curves for the lesion and control groups self-administering MDMA (top) or COC (bottom).

Figure 2.2 shows active lever responses for a representative control (top panel) and lesion (bottom panel) rat during 2-hour self-administration test sessions on days during acquisition testing. The lesion rat met criterion on Day 4 and the control rat on Day 8. Total responses during each daily session are noted on the right axis. During initial test sessions, both rats responded on the active lever throughout the 2 hours. During subsequent sessions, however, the lesioned rat responded during the first third of the test session only, whereas the control rat continued to respond throughout the 2 hours. 
Control
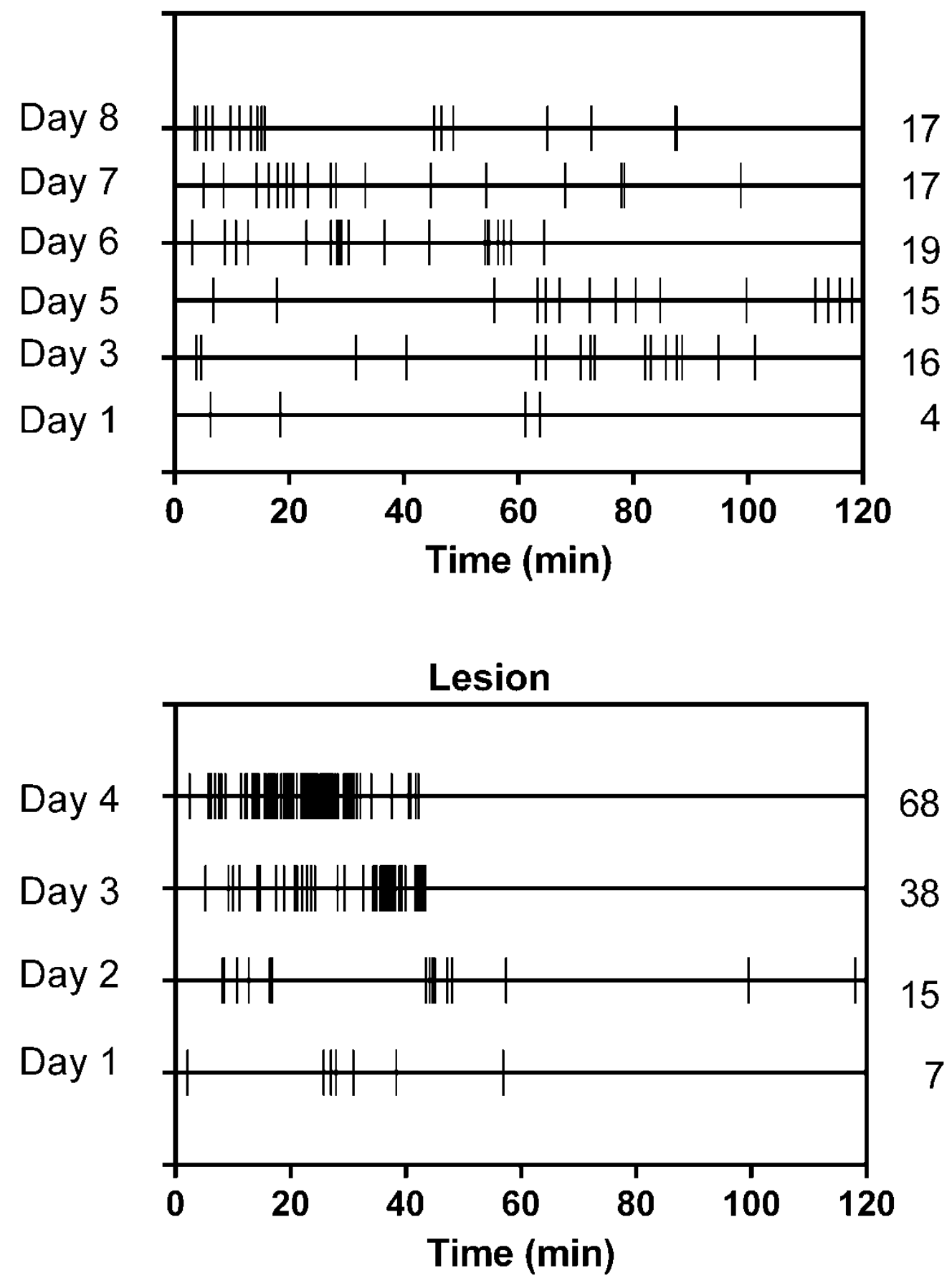

Figure 2.2 shows the temporal pattern of active lever responding for a representative control (top panel and lesion (bottom panel) rat during the 2-hour self-administration sessions. Data from the lesioned rat are shown during the 4 days required to reach criterion and for the control rat during the 8 days required to reach criterion. Each vertical symbol represents a lever response. Total number of responses for each session is noted on the right side

\section{Discussion}

In order to directly test the idea that 5HT negatively impacts the acquisition of MDMA self-administration, the latency to acquisition of self-administration was 
measured following brain 5HT depletion produced by neurotoxic 5,7-DHT lesions. The lesion markedly increased the percentage of rats that acquired MDMA selfadministration and appeared to decrease the latency to acquisition defined as the number of test sessions required to reach the criterion for acquisition of selfadministration. When COC self-administration was measured, all rats in both the lesion and control groups met the criterion for acquisition of self-administration but the latency to acquisition of COC self-administration was reduced by the lesion. These findings are similar to the effect of the lesion that has been observed when the acquisition or maintenance of self-administration of other drugs was measured (Leccese \& Lyness, 1984; Lyness et al., 1980; Pelloux, Dilleen, Economidou, Theobald, \& Everitt, 2012).

A leftward shift in the COC self-administration acquisition curve has been attributed to an increased potency since it is comparable to the effect of increasing drug dose; in both cases, the latency to acquisition of self-administration is shorter (Schenk, Horger, Peltier, \& Shelton, 1991; Schenk et al., 1993). Unlike COC selfadministration, however, the latency to acquisition of MDMA self-administration is not altered by dose. In particular, the acquisition curve for self-administration of dose of $0.25 \mathrm{mg} / \mathrm{kg} /$ infusions MDMA was not significantly different from the acquisition curve produced when $1.0 \mathrm{mg} / \mathrm{kg} /$ infusion was self-administered (Schenk et al., 2007); both the percentage of subjects that met criterion and the number of days to acquire self-administration were comparable regardless of dose. This suggests that, for a substantial proportion of subjects, MDMA self-administration is limited by specific effects of the drug. This specific effect was overcome following the 5,7 DHT lesion so that the percentage of rats that met the criterion with the 25 day test period increased to $100 \%$. These findings are consistent with the idea that susceptibility to self-administer MDMA is limited by the 5HTergic response to MDMA during initial exposures, as was suggested by the data obtained in Chapter 1.

Analysis of the pattern of responding within test sessions highlighted differences in responding between the lesion and control groups. During initial test sessions, rats in both groups responded sporadically throughout the session. With repeated testing, responding increased for rats in both treatment groups. Responding by the control rat was distributed throughout the test session but responding by the lesioned rat became restricted to the initial portion of the session. MDMA-produced 5HT may, therefore, limit rapid responding for the drug. Perhaps the most pronounced 
feature of the lesion group's time-course of responding was that no responses were made in the second half of the test session, which probably reflects the long half-life of MDMA (Schenk et al., 2003).

The data of Chapter 2 show that the global reduction of 5HT facilitates the acquisition of MDMA self-administration. The results therefore provide further support for the idea that the acquisition of MDMA self-administration is inhibited by MDMA-induced increases of 5HT. For some rats, this inhibiting action of 5HT must be overcome and MDMA self-administration is acquired. It has been suggested that this occurs as repeated exposures to small amounts of MDMA produce deficits in 5HT neurotransmission, leading to a disinhibition of DA (Schenk, 2011). If this is the case, MDMA-induced increases of 5HT should be reduced and MDMA-induced increases of DA augmented, following the acquisition of MDMA self-administration. 


\section{Chapter 3}

\section{Introduction}

The results from Chapters 1 and 2 support the idea that MDMA-induced increases of 5HT delay the acquisition of MDMA self-administration. If this is the case, the inhibitory effect must be overcome for MDMA self-administration to progress. It has been hypothesised that repeated exposure to MDMA during initial self-administration sessions produces deficits in 5HT neurotransmission, thereby disinhibiting DA neurotransmission, and increasing the reinforcing efficacy of MDMA (Schenk, 2011). Some data support this idea. Following self-administration of about $100 \mathrm{mg} / \mathrm{kg}$ MDMA across 20 sessions, the MDMA-produced 5HT response was decreased, but DA was unchanged (Reveron et al., 2010). Following more extensive exposure to self-administered MDMA, however, the DA response became sensitised (Colussi-Mas et al., 2010). Accordingly, behavioural responses to MDMA following MDMA self-administration should reflect these changes: 5HT-mediated behaviours should be reduced and DA-mediated behaviours should be increased.

A distinctive behavioural response to increased synaptic 5HT is the so-called '5HT syndrome'. This repertoire of behaviours includes head weaving, fore-limb treading, and low body posture. Administration of the 5HT precursor, 5hydroxytryptamine (5-HTP), produced these behavioural effects that were then enhanced by co-administering an MAO inhibitor that decreased 5HT metabolism (Bogdanski, Weissbach, \& Udenfriend, 1958; Page, 1958; Shore \& Brodie, 1958). Subsequent research showed that a number of non-selective 5HT agonists produced the 5HT syndrome. The majority of the behaviours that comprise the 5HT syndrome have been attributed to $5 \mathrm{HT}_{1 \mathrm{~A}}, 5 \mathrm{HT}_{2 \mathrm{~A}}$ and $5 \mathrm{HT}_{2} \mathrm{C}$ receptor mechanisms (for a review, see Haberzettl, Bert, Fink, \& Fox, 2013).

One behavioural correlate of increased synaptic DA is stimulated horizontal activity (hyperlocomotion). Local infusions of DA, but not 5HT or NE, into terminals of the mesolimbic DA system increased forward locomotion (Pijnenburg, Honig, Van der Heyden, \& Van Rossum, 1976). A wealth of data has subsequently shown similar effects following administration of DA agonists, and these effects are blocked by neurotoxic 6-OHDA lesions in the mesolimbic DA system (for example, Kelly \& Iversen, 1976) and by DA antagonists (Pijnenburg et al., 1976; Pijnenburg, Honig, \& Van Rossum, 1975). Repeated exposure to MDMA (Ball, Budreau, \& Rebec, 2006; 
Ball, Klein, Plocinski, \& Slack, 2011; Ball, Wellman, Fortenberry, \& Rebec, 2009; Ball, Wellman, Miller, \& Rebec, 2010; Bradbury, Gittings, \& Schenk, 2012;

Colussi-Mas \& Schenk, 2008; Kalivas et al., 1998; Lettfuss, Seeger-Armbruster, \& von Ameln-Mayerhofer, 2013; Ludwig, Mihov, \& Schwarting, 2008; McCreary, Bankson, \& Cunningham, 1999; Modi, Yang, Swann, \& Dafny, 2006), produced an augmented horizontal activity response following some dosing regimens, corresponding with an enhanced DA response (Kalivas et al., 1993; Kalivas \& Stewart, 1991; Sorg \& Kalivas, 1991). Enhanced synaptic DA also underlies increased vertical activity (rearing), although relatively fewer investigations of the neurochemical underpinnings of this behaviour have been conducted. The responses were produced by DA agonists (Cornish \& Kalivas, 2001; Costall, Eniojukan, \& Naylor, 1982; Nordquist et al., 2008), and were blocked when extracellular DA was decreased by administration of administration of the endogenous neuropeptide, Nociceptin/Orphanin FQ (Vazquez-DeRose et al., 2013).

In the current experiment, head-weaving, hyperlocomotion and rearing were measured either 5 or 14 days after MDMA self-administration. These time periods were chosen based on findings that MDMA self-administration produced 5HT deficits after 5, but not14, days of abstinence (Do \& Schenk, 2011). A potential complication is that behavioural measurements can sometimes be difficult to interpret because of competing behaviours produced by some doses of drugs. For example, the dose-effect curve for horizontal activity produced by psychostimulants is in the shape of an inverted " $U$ ". The ascending limb of the curve reflects dose-dependent increases of horizontal activity with low doses of drug. Following administration of higher doses, however, horizontal activity declines as psychostimulant-produced behaviour becomes dominated by repetitive stereotyped behaviour (Flagel \& Robinson, 2007; Randrup \& Munkvad, 1967). An increase in the dose of psychostimulant could therefore result in either an increase or decrease in horizontal behaviour. In addition, previous research has described difficulty in measuring 5HT syndrome during the simultaneous expression of other behaviours (Curzon, Fernando, \& Lees, 1979). In an effort to negate these potential confounds, three different measures of hyperlocomotion will be recorded, and the time course of all behaviours will be analysed. 


\section{Method}

\section{Experimental Overview}

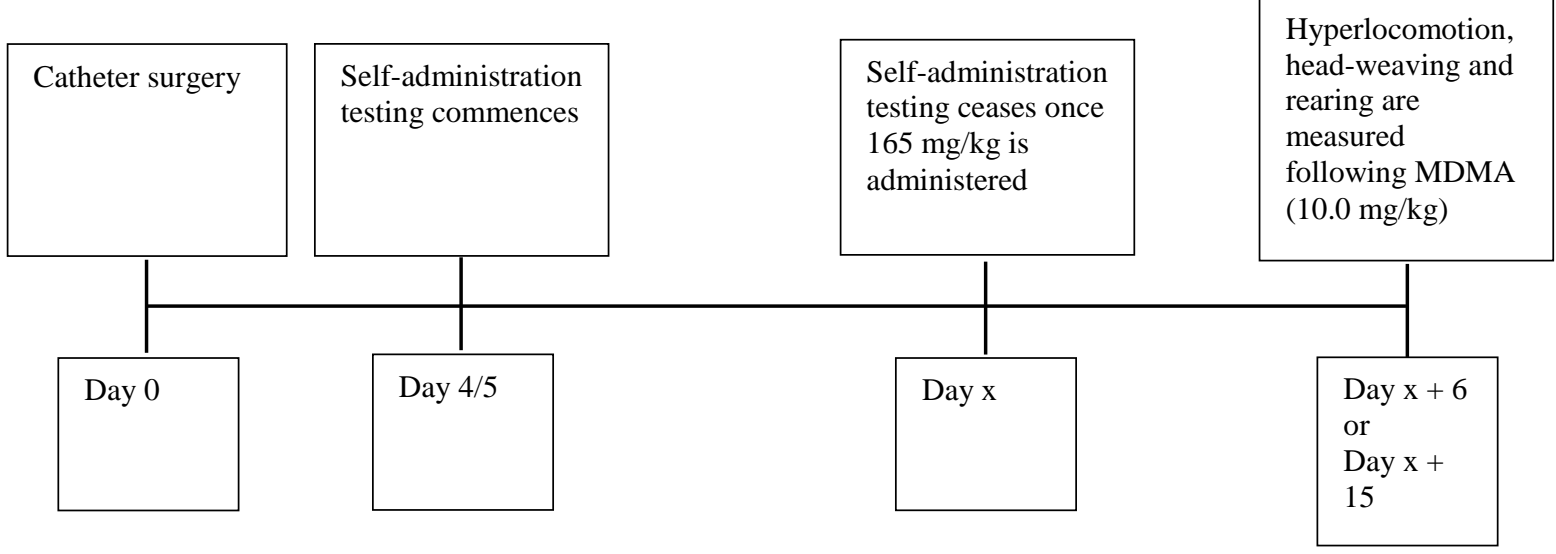

\section{Pilot Studies}

To find the dose of MDMA needed to induce 5HT syndrome, and to deduce a method to measure 5HT syndrome behaviours, a series of pilot studies were undertaken. Rats with varying drug histories were injected with $5.0 \mathrm{mg} / \mathrm{kg}(\mathrm{n}=3)$ or $10.0 \mathrm{mg} / \mathrm{kg}(\mathrm{n}=4)$ MDMA and videoed for 60 minutes. The videos were watched by multiple people and the head-weaving, fore-paw treading and low body posture were identified. It became obvious that the $10.0 \mathrm{mg} / \mathrm{kg}$ MDMA dose was required to induce 5HT syndrome.

\section{Self-administration Testing}

For these groups, the dose of MDMA was decreased to $0.5 \mathrm{mg} / \mathrm{kg} /$ infusion following the initial acquisition period. Testing continued until a total intake of 165 $\mathrm{mg} / \mathrm{kg}$ was reached (an additional 150 infusions), because previous research showed this dose of self-administered MDMA produced tissue deficits in 5HT. Each rat in the vehicle self-administration group ( $\mathrm{n}=9$ ) was matched to an MDMA self-administering rat. Behavioural testing was conducted after 5 days $(5 \mathrm{D} ; \mathrm{n}=8)$ or 14 days $(14 \mathrm{D} ; \mathrm{n}=8)$ of abstinence following the last self-administration session for the MDMA group, and 14 days of abstinence following the last self-administration session for the vehicle (Control) group. 


\section{Behavioural Testing}

Apparatus

A single clear Plexiglas chamber (Med Associates Inc, USA; model ENV515 ) measuring $42 \times 42 \times 30 \mathrm{~cm}$, set in a sound-attenuating box, was used to measure the behaviours. Four sets of 16 infra-red sensors spaced evenly $2.5 \mathrm{~cm}$ above the floor on each side of the box produced a lattice of beams that created squares of dimension $25 \times 25 \mathrm{~mm}$. One forward locomotor count was recorded following the sequential interruption of 3 beams, which equates to the approximate size of the body of the rat. The number of locomotor counts produced, and the time (sec) spent in forward locomotion, were determined. The average velocity of forward locomotion $(\mathrm{cm}$ travelled per second) was also measured. A second set of identical infra-red sensors located $14 \mathrm{~cm}$ above the floor of the chamber measured rearing counts.

A camera was mounted on the ceiling of the sound-attenuating box to record head-weaving, fore-limb treading and low body posture. It became apparent after watching the videos, however, that the orientation of the camera only allowed the measurement of head-weaving- MDMA self-administration markedly altered the behaviours produced by $10.0 \mathrm{~g} / \mathrm{kg}$ MDMA. The videos were then studied to derive a sound measurement system for head-weaving. Following extensive examination, it was decided that head-weaving was best measured by dividing the session into 5minute blocks and head weaving was measured for the first 60 seconds of each block. an ordinal scale of severity was decided on, as has been consistently used in previous research (Haberzettl et al., 2013; Jacobs, 1974a, 1974b). The head-weaving of every rat was quantified by one experimenter blind to the conditions. Measurement quality was checked by randomly assigning 3 videos each to 9 other experimenters. Previous studies have scored head-weaving using ordinal scales of severity. Head weaving was measured according to the following: 0 - absent; 0.5 - some signs of head weaving; 1 occasional head weaving; 1.5- frequent head weaving; 2- constant head weaving.

A white noise generator masked extraneous noise. Prior to each test, chambers were wiped with Virkon 'S' disinfectant (Southern Veterinary Supplies, NZ). All experiments were conducted between 1300 and $1900 \mathrm{~h}$ in a temperature-controlled room $\left(19^{\circ} \mathrm{C}\right)$ illuminated by red light. 
Procedure

Rats were habituated to the activity box for 30 minutes before the injection of MDMA (10.0 mg/kg; ip). The high dose of MDMA was chosen because a pilot study revealed that this dose evoked head-weaving most reliably. Forward locomotion, rearing and head-weaving were measured during the habituation period and for a further 45 minutes after MDMA administration.

\section{Statistical Analysis}

To measure the effect of MDMA administration on the behaviour of drugnaïve animals, individual one-way ANOVAs were conducted for the all of the behaviours of the Control group produced during the eleven 5-minute time intervals between Time $=-5$, and Time $=45$. Tukey post-hoc tests were used to identify the time-point(s) at which MDMA-produced behaviour significantly differed from that measured 5 minutes prior to MDMA administration (Time $=-5$ ). To determine the effects of abstinence, MDMA-produced behaviours were compared using separate repeated measures ANOVAs (Time X Group) for each of the behavioural measures. Main effects of Group or an interaction between Time and Group were further assessed using Tukey post-hoc tests.

\section{Results}

Control Group

MDMA (10.0 mg/kg; i.p) administration caused an immediate head-weaving response, followed by hyperlocomotion. Figure 3.1 shows the time-course of headweaving for the control group during the habituation phase and after the administration of MDMA. The time-course exhibited an unusual pattern; pronounced head-weaving was produced during the initial and final portions of the session but not during the intervening time period. The decrease in the middle of the test session might reflect the emergence of competing behaviours. Indeed, forward hyperlocomotion gradually increased after MDMA administration (see Fig 3.2A; F $(10,88)=10.27, \mathrm{p}<0.05)$ and was significantly increased from 15 minutes onward $(\mathrm{p}$ $<0.05)$. Hyperlocomotion peaked about 25 minutes after MDMA administration and during this time head-weaving became more difficult to distinguish from generalised hyperactivity. Because head-weaving could only be confidently scored during the first 20 minutes after MDMA, only these data were analysed. Head-weaving increased 
with time $(\mathrm{F}(5,48)=5.23, \mathrm{p}<0.05)$ and was significantly increased 10 minutes after MDMA administration $(\mathrm{p}<0.05)$.

Figure 3.2 shows the number of ambulatory counts (A), velocity of forward locomotion (B), time spent in forward locomotion (C), and the number of rears (D) for the control group after administration of MDMA $(10.0 \mathrm{mg} / \mathrm{kg}$; i.p). The velocity of forward locomotion increased rapidly following MDMA administration $(\mathrm{F}(10,88)=$ 1.96, $\mathrm{p}<0.05$; Fig 3.2B) and was significantly increased during the first 5-minute interval $(\mathrm{p}<0.05)$. The time spent in forward locomotion increased with time (F (10, $88)=13.73, \mathrm{p}<0.05 ;$ Fig $3.2 \mathrm{C}$ ) and was significantly elevated from 10 minutes after MDMA ( $<$ 0.05). Rearing (Fig 3.2D) was higher prior to MDMA administration and was not increased subsequent to $\operatorname{MDMA}(\mathrm{F}(10,88)=4.93, \mathrm{p}<0.05)$.

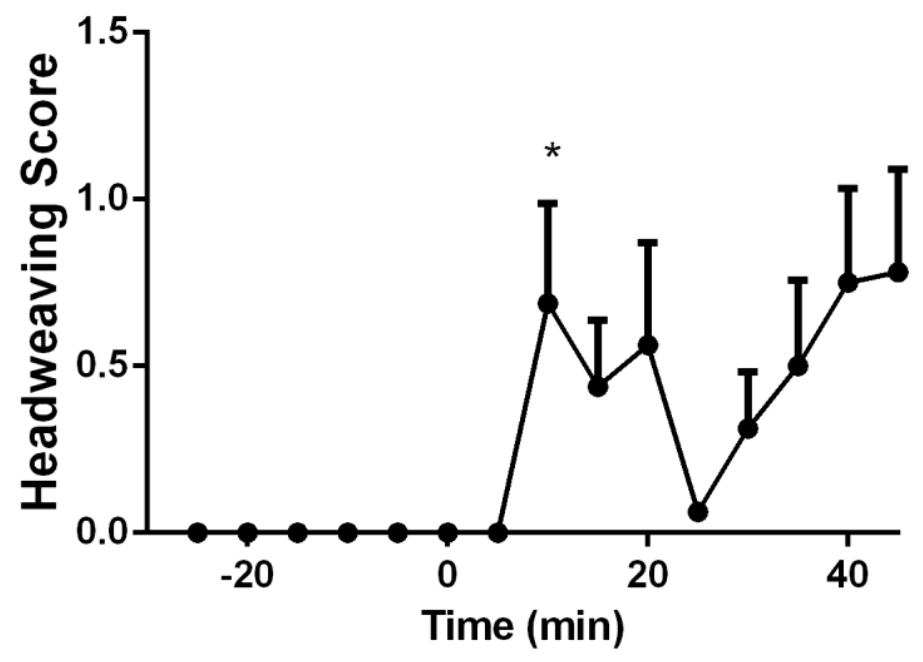

Figure 3.1 displays Head-weaving for the Control group following vehicle self-administration. Rats were subjected to 14 days of abstinence prior to behavioural testing. MDMA $(10.0 \mathrm{mg} / \mathrm{kg}$; ip $)$ was administered at Time $=0 . *$ denotes $\mathrm{p}<0.05$ vs behaviour at Time $=-5$ minutes. 

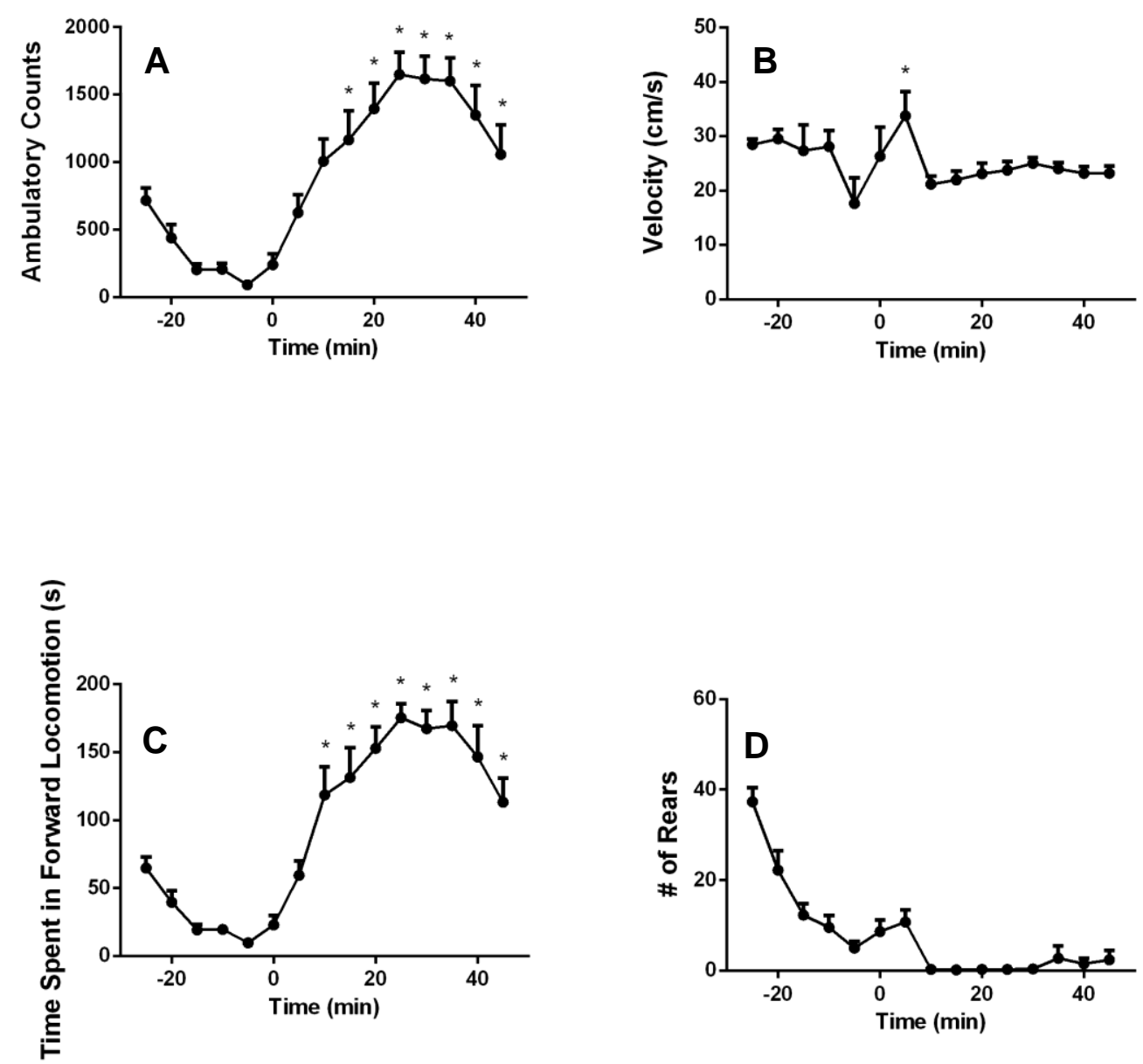

Figure 3.2 displays Ambulatory Counts (A), Velocity of Forward Locomotion (B), Time Spent in Forward Locomotion (C), and Rearing (D) for the Control group following vehicle self-administration. Rats were subjected to 14 days of abstinence prior to behavioural testing. MDMA $(10.0 \mathrm{mg} / \mathrm{kg}$; ip $)$ was administered at Time $=0 . *$ denotes $\mathrm{p}<0.05$ vs behaviour at Time $=-5$ minutes.

The effect of abstinence on behaviours

There were no differences in the various responses during the $30 \mathrm{~min}$ habituation period. Thus, abstinence failed to alter the baseline levels of head- 
weaving, various measures of forward locomotion, or rearing. The effect of abstinence on MDMA-produced responses depended on the behaviour.

Table displays the The magnitude of MDMA-produced head-weaving was dependent on abstinence. A significant interaction was found for head-weaving ( $\mathrm{F}$ $(18,207)=1.90 \mathrm{p}<0.05)$. Head-weaving and was decreased 10 and 15 min following injection for the 5D $(\mathrm{p}<0.01)$, but not the $14 \mathrm{D}$, group.

Effects of abstinence on MDMA-produced hyperactivity depended on the measure. Time spent in forward locomotion was decreased following both abstinence periods, velocity was increased for both abstinence periods, and the number of ambulatory counts was unchanged as a result of abstinence. Rearing was increased for both abstinence groups $(\mathrm{p}<0.01)$.

Table 3.1: Statistical results from ANOVAs conducted on data from each of the behavioural responses to MDMA as a function of time and abstinence group $(*=\mathrm{p}<0.05, * *=\mathrm{p}<0.01, \mathrm{NS}=$ not significant $)$

\begin{tabular}{llllll}
\hline & $\begin{array}{l}\text { Head- } \\
\text { weaving }\end{array}$ & $\begin{array}{l}\text { Time } \\
\text { locomotion }\end{array}$ & Velocity & Counts & Rears \\
& $\mathrm{F}(9,207)=14.67$ & $\mathrm{~F}(14,308)=57.0$ & $\mathrm{~F}(14,308)=2.18$ & $\mathrm{~F}(14,308)=54.2$ & $\mathrm{~F}(14,308)=9.94$ \\
\hline Time & $* *$ & $* * * *$ & $* *$ \\
& $\mathrm{~F}(2,22)=2.4$ & $\mathrm{~F}(2,22)=4.031$ & $\mathrm{~F}(2,22)=7.537$ & $\mathrm{~F}(2,22)=0.502$ & $\mathrm{~F}(2,22)=11.993$ \\
\hline Group & $\mathrm{NS}$ & $*$ & $* *$ & $\mathrm{NS}$ & $* *$ \\
& $\mathrm{~F}(18,207)=1.902$ & $\mathrm{~F}(28,308)=2.20$ & $\mathrm{~F}(28,308)=1.232$ & $\mathrm{~F}(28,308)=1.24$ & $\mathrm{~F}(28,308)=3.09$ \\
& $*$ & $\mathrm{NS}$ & $\mathrm{NS}$ & $\mathrm{NS}$ & $* *$ \\
\hline
\end{tabular}



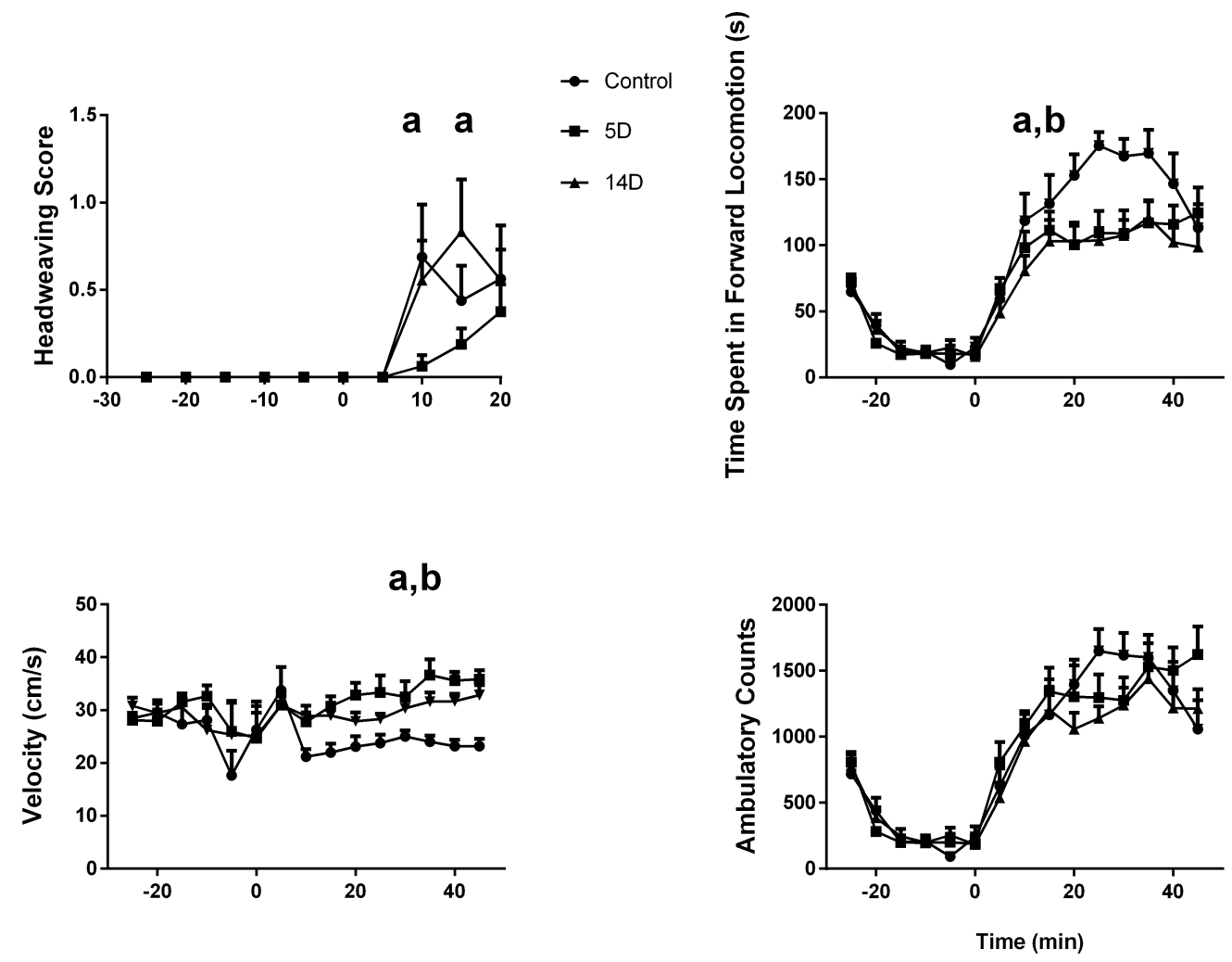

a,b

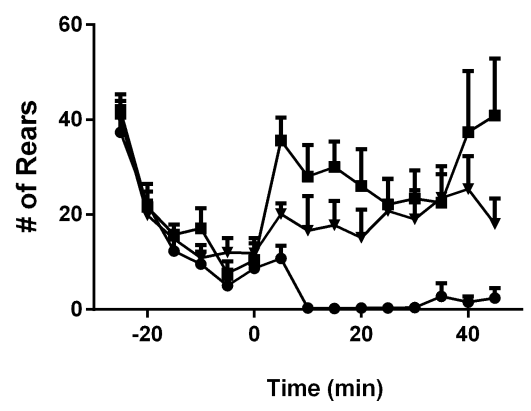

Figure 3.3 shows the behavioural responses to MDMA $(10.0 \mathrm{mg} / \mathrm{kg}$, IP) for control rats that had selfadministered vehicle and for rats that had self-administered MDMA. MDMA was administered at Time $=0$. $\mathbf{a}$ indicates a difference $(\mathrm{p}<0.05)$ between the 5 day abstinence group and control and $\mathbf{b}$ indicates a difference between the 14 day abstinence group and control $(\mathrm{p}<0.05)$. Symbols represent mean + SEM.. 


\section{Discussion}

This experiment was designed to compare behavioural correlates of 5HT (head-weaving) and DA neurotransmission (rearing and hyperlocomotion) for control rats and rats that had self-administered MDMA. In accordance with previous research (Spanos \& Yamamoto, 1989), MDMA produced pronounced head-weaving in the control group. Head-weaving in the 5D abstinence group was significantly lower, suggesting a decrease in the 5HT response after MDMA self-administration, as has been suggested previously (Reveron et al., 2010). The results are consistent with previous research that showed a decrease in MDMA-produced 5HT syndrome following repeated experimenter-administered MDMA (Shankaran \& Gudelsky, 1999). The head-weaving for the 14D group was comparable to that of the control group, supporting the results of neurochemical analyses that also showed recovery of 5HT (Do \& Schenk, 2011).

The length of abstinence required for recovery of $5 \mathrm{HT}$ following selfadministration was shorter than that reported by some other studies following experimenter-administered MDMA. This may be due to the different dosing regimens since the persistence of 5HT deficits were dose-dependent, with higher doses producing greater deficits (for example, Battaglia, Yeh, et al., 1988; Do \& Schenk, 2011; Insel et al., 1989). The dose of MDMA eventually self-administered in the current study was similar to, or greater than, some experimenter-administered doses of MDMA that showed more persistent 5HT deficits (for example, Battaglia, Brooks, et al., 1988; Sabol, Lew, Richards, Vosmer, \& Seiden, 1996; Scanzello, Hatzidimitriou, Martello, Katz, \& Ricaurte, 1993), but the frequency of dosing differed. The studies that used experimenter-administered MDMA injected consistently high daily doses of MDMA $(10-80 \mathrm{mg} / \mathrm{kg})$ for $4-5$ days. In contrast, the daily dose of self-administered MDMA was initially low (about $3 \mathrm{mg} / \mathrm{kg}$ ) and increased across test sessions (to about $15 \mathrm{mg} / \mathrm{kg}$ ). Further, self-administration testing continued for a much longer period of time (about 30 days). These differences in frequency of dosing might account for the differences in time required for recovery of 5HT deficits. The low dose of MDMA self-administered during initial test sessions might have produced a neuroprotective effect to the high doses of MDMA selfadministered during later test sessions. Indeed, previous research reported smaller MDMA-produced 5HT following pre-exposure to an intermittent dosing regimen of MDMA (Piper, Ali, Daniels, \& Meyer, 2010). 
It must be noted that the measurement of behavioural correlates of 5HT transmission was limited. The psychostimulant effects of MDMA produced behaviours that masked all of the behaviours (bar head-weaving) encompassed within 5HT syndrome, rendering them unmeasurable. Thus only one behaviour, headweaving, was used as a measure of 5HT transmission. The measurement of 5HT neurotransmission in this experiment is therefore not ideal.

MDMA did not produce rearing in the control group, as has been previously reported (O'Loinsigh, Boland, Kelly, \& O'Boyle, 2001). Repeated exposure to selfadministered MDMA resulted in pronounced MDMA-produced rearing, as has also been reported previously (Lettfuss et al., 2013). Because rearing is a behavioural correlate of increased synaptic DA (Costall et al., 1982), the data are consistent with the ideas that acute MDMA produced a negligible DA response, and that repeated exposure to MDMA during self-administration enhanced the MDMA-produced DA response. The enhanced response is in accordance with one study that reported augmentation of the DA response produced by the same dose of MDMA (10.0 mg/kg) following self-administration of about $360 \mathrm{mg} / \mathrm{kg}$ MDMA (Colussi-Mas et al., 2010). Another study, however, reported no change in the MDMA-produced DA response following self-administration of about $100 \mathrm{mg} / \mathrm{kg}$ MDMA (Reveron et al., 2010). Thus, the enhanced DA response found following exposure during MDMA selfadministration appears to be dose-dependent.

MDMA-produced rearing was also produced following 14 days of abstinence. This result is particularly interesting because it appears that the enhanced DA response was produced independent of 5HT deficits. Therefore, although there is evidence to suggest that the DA response produced by acute MDMA is modulated by 5HT, repeated exposure to MDMA during self-administration appears to alter this relationship. This might be due to changes in specific receptor mechanisms following self-administration.

It was expected that the enhanced DA response found following MDMA selfadministration would also be reflected in an enhanced hyperlocomotor response, as has been reported previously (Ball et al., 2006; Ball et al., 2011; Ball et al., 2009; Ball et al., 2010; Bradbury et al., 2012; Colussi-Mas \& Schenk, 2008; Kalivas et al., 1998; Lettfuss et al., 2013; Ludwig et al., 2008; McCreary et al., 1999; Modi et al., 2006), but the number of ambulatory counts produced by the self-administration and control groups was comparable. The MDMA self-administration groups exhibited a different 
profile of horizontal locomotion, however: the velocity of forward hyperlocomotion was increased, and the time spent in forward locomotion was decreased. The number of ambulatory counts therefore did not reflect that MDMA self-administration altered MDMA-produced horizontal locomotion. The decreased time spent in forward locomotion combined with the increase in rearing, suggests that horizontal locomotion might have been limited by this competing behaviour.

The complicated nature of the analysis of behavioural responses to psychostimulants has been addressed previously (Flagel \& Robinson, 2007). In particular, high doses of psychostimulants produced stereotypy (Forster, Falcon, Miller, Heruc, \& Blaha, 2002; Kuczenski \& Segal, 1999; Nordquist et al., 2008) that interfered with the forward locomotion response. For example, low doses of AMPH produced hyperlocomotion throughout a test session. High doses of AMPH, however, produced stereotypy and therefore hyperlocomotion was restricted to the end of a test session, when stereotypy decreased (Kuczenski \& Segal, 1999; Robinson \& Becker, 1986). The combination of the three measures of the hyperlocomotor response in the current study indicates that horizontal locomotion was similarly impacted.

Alternatively, the high dose of MDMA used for behavioural testing may have produced a ceiling effect for the hyperlocomotor response. If this is the case, a lower dose of MDMA should allow the observation of group differences in the number of MDMA-produced ambulatory counts.

The results show that exposure to MDMA during the acquisition of selfadministration decreased MDMA-produced head-weaving, a behavioural correlate of the $5 \mathrm{HT}$ response, and increased rearing, a behavioural correlate of the DA response. The results therefore support the idea that MDMA self-administration progresses as MDMA exposure produces deficits of the 5HT response and augmentation of the DA response. Serotonin deficits recovered with extended abstinence, as evidenced by the recovery of MDMA-produced head-weaving. Importantly, the enhanced rearing response was produced even following an abstinence period that produced recovery of the $5 \mathrm{HT}$ response. The two abstinence periods therefore provide a measure to investigate the roles of the 5HT and DA responses in the maintenance of MDMA selfadministration. If the 5HT response is critical to self-administration then responding should be decreased after 14 , but not 5 , days of abstinence. On the other hand, if an enhanced DA response is critical to self-administration, then responding should be comparable after both abstinence periods. 


\section{Chapter 4}

\section{Introduction}

The results from Chapter 3 showed that MDMA-produced head-weaving, a behavioural correlate of the $5 \mathrm{HT}$ response, was decreased 5, but not 14, days after self-administration. Further, a behavioural correlate of the MDMA-produced DA response, rearing, was only observed after rats had been exposed to MDMA selfadministration and this response persisted for at least 14 days following the last selfadministration session. Since neurochemical (Do \& Schenk, 2011) and behavioural measures indicated a recovery of the 5HT response after 14 days, the sensitised DA response observed after 14 days following the last self-administration session cannot be attributed to continued disinhibition of DA resulting from reduced 5HT.

Because, following MDMA self-administration, the MDMA-produced DA response was enhanced irrespective of the 5HT response, the inhibitory effect of 5HT on MDMA self-administration found during the acquisition phase might be reduced during the maintenance phase. Indeed, the progression of self-administration of other drugs of abuse has been attributed to sensitisation of the DA response resulting from repeated exposure (Vezina, 2004). The present study sought to determine whether 5HT deficits impact responding maintained by MDMA. If so, then responding should be reduced following 14 days abstinence when 5HT responses had recovered. Alternatively, if a sensitised DA response maintains self-administration, as has been proposed for other drugs of abuse (Robinson \& Berridge, 1993, 2001), then responding after either 5 or 14 days of abstinence should not differ. 


\section{Method}

Experimental Overview

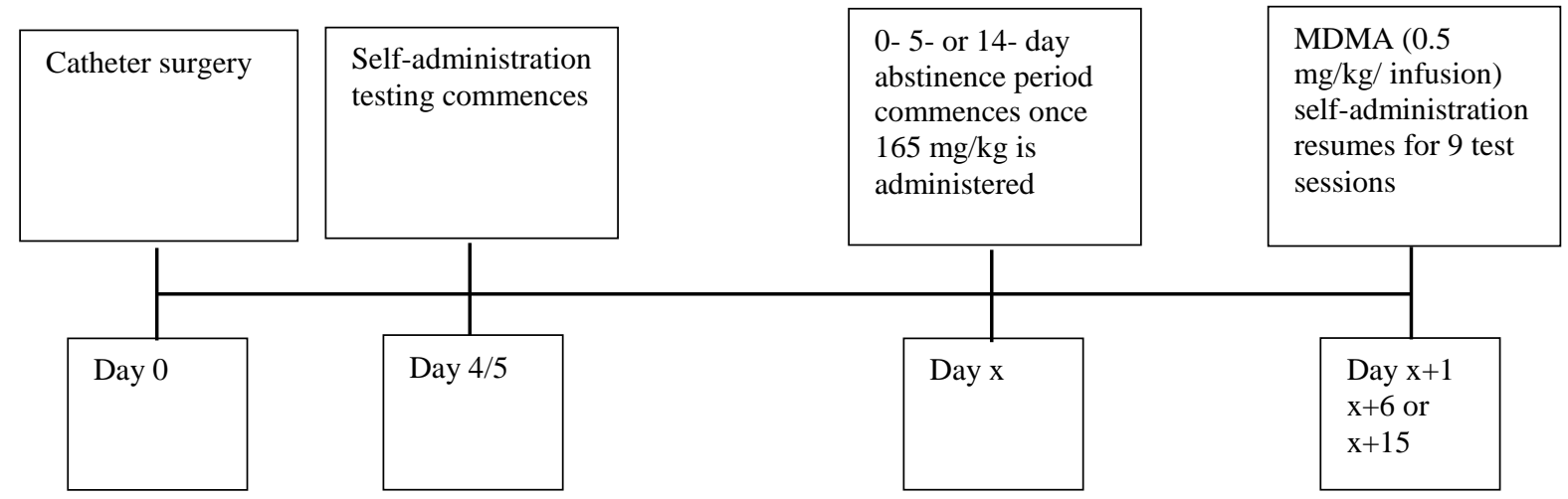

Self-administration Testing

Rats underwent self-administration testing and, following acquisition, the dose of MDMA was decreased to $0.5 \mathrm{mg} / \mathrm{kg} /$ infusion. Testing continued until a further 150 infusions of this dose were self-administered (total self-administered $=165$ $\mathrm{mg} / \mathrm{kg}$ ). An abstinence period was then imposed for some groups before MDMA (0.5 $\mathrm{mg} / \mathrm{kg} /$ infusion) self-administration resumed for 9 daily test sessions. For all tests responding was reinforced according to an FR1 schedule. One group was tested continuously and did not experience an abstinence period (0D; $=7)$; another group was subjected to 5 days of abstinence ( $5 \mathrm{D} ; \mathrm{n}=8)$; and a third group were subjected to 14 days of abstinence (14D; $n=10)$. The 0 -day period represented the selfadministration protocol that is usually employed. The 5-day period was chosen because the results of Chapter 3 suggest that the MDMA-produced DA response was enhanced, and the 5HT response was reduced, after 5 days of abstinence. The 14-day period was chosen because the results of Chapter 3 suggest that the DA response to MDMA was augmented, and the 5HT response recovered, after 14 days of abstinence.

\section{Statistical Analysis}

Self-administration was compared following the various abstinence periods using a repeated-measures ANOVA (Group X Day) on the active lever responses produced during the 9 days of testing. 


\section{Results}

Figure 4.1 shows the average number of responses as a function of group prior to the abstinence period, and during the 9 test sessions after the abstinence session for all groups. Pre-abstinence responding represents the average number of responses on the 3 days prior to the abstinence period. There was no effect of abstinence $(\mathrm{F}(2,23)$ $=1.045, \mathrm{NS})$ or an interaction between days and group $(\mathrm{F}(16,185)=1.318, \mathrm{NS})$ on responding maintained by MDMA infusions.

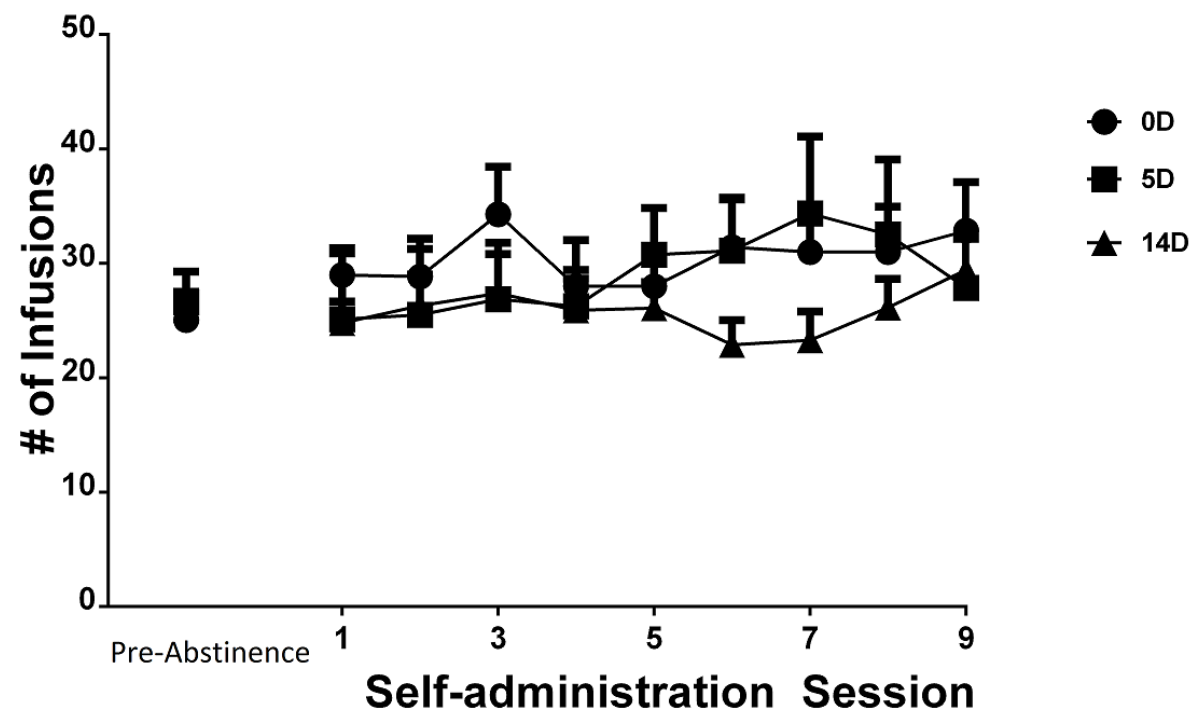

Figure 4.1. Effects of abstinence on MDMA self-administration. The number of infusions selfadministered prior to the abstinence period is an average of the number of infusions self-administered during the 3 sessions prior to the abstinence period. Self-administration was measured for 9 days following either 0 (control) 5 or 14 days abstinence. Symbols represent mean number of responses during each daily $2 \mathrm{hr}$ session + SEM

\section{Discussion}

A previous study showed that tissue levels of 5HT were reduced 5 days, but not 14 days, following MDMA self-administration (Do \& Schenk, 2011). In addition, the results from Chapter 3 showed that MDMA-produced head-weaving, a behavioural correlate of synaptic 5HT, was reduced 5 days, but not 14 days, after selfadministration. MDMA self-administration was therefore measured following 5 or 14 days of abstinence. As expected, the self-administration profile of the 5D and $0 \mathrm{D}$ groups was comparable. However, the profile of self-administration for the 14D group 
was also similar to the 0D group. Thus, although there was recovery of the 5HT response following 14 days of abstinence, responding maintained by MDMA was unaltered. These findings suggest that 5HT does not impact the maintenance of MDMA self-administration.

Recovery of 5HT function might have been expected to decrease responding maintained by MDMA because manipulations that increased synaptic 5HT attenuated responding maintained by a range of drugs of abuse. Reuptake inhibitors, the releasing stimulant, d-fen, and the 5-HT precursor, L-tryptophan, decreased AMPH (Porrino et al., 1989; F. L. Smith et al., 1986), METH (Munzar et al., 1999), COC (Carroll et al., 1990a, 1990b; Czoty et al., 2002; Howell \& Byrd, 1995; A. McGregor et al., 1993; Negus et al., 2007; Porrino et al., 1989), heroin (Higgins et al., 1994; Y. Wang et al., 1995) and morphine (Raz \& Berger, 2010) self-administration. The specific receptor mechanisms that underlie this inhibitory effect are not yet known. However, increased synaptic 5HT attenuated self-administration in a way that resembles the attenuation produced by DA antagonists, suggesting that this effect may be driven by $5 \mathrm{HT}$ Tergic inhibition of the DA response. A growing literature has described 5HTergic modulation of DA neurotransmission by a number of 5HT receptors (see Chapter 3), though the downstream effects of stimulation of these 5HT receptors are potentially very complex and, so far, poorly understood.

The complexity of the 5HT-DA relationship is reflected by findings that stimulation of some 5HT receptors enhanced the MDMA-produced DA response. Agonists of the $5 \mathrm{HT}_{2 \mathrm{~A}}$ receptor enhanced MDMA-produced DA (Gudelsky et al., 1994), and $5 \mathrm{HT}_{2 \mathrm{~A}}$ receptor antagonists decreased MDMA-produced DA (Nash, 1990; Schmidt et al., 1992; Schmidt et al., 1994; B. K. Yamamoto et al., 1995). Based on the idea that DA is critical to MDMA self-administration, antagonism of $5 \mathrm{HT}_{2 \mathrm{~A}}$ receptors would be expected to decrease MDMA self-administration. Indeed, the $5 \mathrm{HT}_{2 \mathrm{~A}}$ antagonists, ketanserin and MDL100907, reduced responding maintained by MDMA in non-human primates (Fantegrossi et al., 2002). Another study reported that the $5 \mathrm{HT}_{1 \mathrm{~A}}$ agonist, 8-OHDPAT, abolished responding for MDMA in a single rat study (De La Garza II et al., 2007). The effects of stimulating $5 \mathrm{HT}_{1 \mathrm{~A}}$ receptors on DA are unknown, but the authors note that the highest dose of 8-OHDPAT inhibited motor behaviour. Therefore, the reduction in responding in this study could be attributed to a non-specific effect. 
In light of the previous research, it might be surprising that the current results showed no effect of abstinence on MDMA self-administration. This discrepancy might be due to the magnitude of MDMA exposure in the current study, which has been associated with reduced extracellular and tissue 5HT (see Chapter 3; Do \& Schenk, 2011; Reveron et al., 2010) that might reflect altered 5HT receptor mechanisms. The downstream effects of an increased 5HT response could therefore differ considerably in these rats. Perhaps more importantly, chronic exposure to selfadministered MDMA also enhanced the DA response (see Chapter 3; Colussi-Mas et al., 2010). It might be the case that the recovered 5HT response had no effect because this sensitised DA response becomes the critical determinant of responding maintained by MDMA. Indeed, the rearing response measured in Chapter 3 was not altered by the recovery of the $5 \mathrm{HT}$ response; probably because the critical determinant of rearing, the DA response, was enhanced. Since the DAergic response and selfadministration profiles following either abstinence period were comparable for both groups, it seems reasonable that the sensitised DA response mediates the maintenance of MDMA self-administration following abstinence.

A substantial amount of literature supports the idea that enhanced DA responses underlie compulsive drug-taking and drug-seeking (see Robinson \& Berridge, 1993, 2001). These ideas are based, in part, on the observation that a sensitised DA response is found in neural pathways that have been associated with drug-produced reinforcement (Wise \& Bozarth, 1987). Repeated intermittent exposure to a wide range of abused drugs enhanced DA neurotransmission, as shown by both behavioural and neurochemical measures (Vezina, 2004). A number of studies have reported behavioural sensitisation of locomotor-stimulating effects of MDMA following repeated experimenter-administered MDMA (Ball et al., 2006; Ball et al., 2011; Ball et al., 2009; Ball et al., 2010; Bradbury et al., 2012; Colussi-Mas \& Schenk, 2008; Kalivas et al., 1998; Lettfuss et al., 2013; Ludwig et al., 2008; McCreary et al., 1999; Modi et al., 2006). Further, repeated exposure to experimenter-administered (Kalivas et al., 1998) or self-administered (Colussi-Mas et al., 2010) MDMA produced neurochemical sensitisation of extracellular DA. Direct support for the idea that an enhanced DA response underlies the maintenance of MDMA self-administration was found when both $\mathrm{D}_{1}$ and $\mathrm{D}_{2}$ receptor antagonists decreased self-administration (Brennan et al., 2009; Daniela et al., 2004; Shin et al., 2008). 
MDMA-seeking has also been attributed to enhanced DAergic mechanisms. The reinstatement paradigm is a model of relapse and craving which measures drugseeking behaviour in subjects with extensive self-administration experience, following a phase of forced abstinence/extinction. MDMA-seeking was reinstated by the DAT inhibitor, GBR 12909, the DA releaser, AMPH, and the $\mathrm{D}_{2}$ receptor agonist, quinpirole. Furthermore, both $\mathrm{D}_{1}$ and $\mathrm{D}_{2}$ receptor antagonists decreased MDMAseeking (Schenk et al., 2011). MDMA-seeking was not, however, reinstated by the SERT inhibitor, clomipramine, the $5 \mathrm{HT}_{2 \mathrm{~A}}$ agonist, DOI, or the $5 \mathrm{HT}_{2 \mathrm{C}}$ agonist, $\mathrm{mCPP}$ (Schenk et al., 2011). The research therefore suggests that DAergic, but not 5HTergic, mechanisms underlie MDMA-seeking and further supports the idea that the DA response is critical to MDMA self-administration.

It is possible that responding maintained by MDMA was not altered by abstinence because of an increased susceptibility to the reoccurrence of 5HT deficits. Responding was measured after 14 days of abstinence because the results from Chapter 3 suggested that the MDMA-produced 5HT response had recovered after this period. That is, MDMA-produced head-weaving, a behavioural correlate of synaptic 5HT, was comparable to that produced by drug-naïve rats. Head-weaving was measured, however, in response to only one administration of MDMA. In the current experiment, the response to MDMA was measured following multiple doses of MDMA across multiple days, and thus it might be the case that repeated exposure to self-administered MDMA reproduced pre-abstinence 5HT deficits. There are two observations that suggest this explanation is unlikely. First, responding maintained by MDMA was not inhibited on the first day of testing after abstinence when the MDMA-produced 5HT response had recovered. Second, previous research described a protective effect of pre-exposure to MDMA when 5HT deficits produced by subsequent MDMA were measured. Deficits of tissue levels of 5HT and SERT produced by a binge dose of MDMA were reduced by previous exposure to repeated intermittent high doses of MDMA (Bhide, Lipton, Cunningham, Yamamoto, \& Gudelsky, 2009; Piper et al., 2010).

It must also be noted that the recovered 5HT response might have altered responding maintained by other doses of MDMA. To test this, a future study should measure responding for a range of MDMA doses following abstinence.

While it appears that the MDMA-produced 5HT response is an important factor during the acquisition of self-administration (see Chapters 1 and 2), findings 
from the current experiment suggest that the 5HT response might not play an important role once self-administration has been acquired. Instead, the data support the idea that sensitisation of the DA response underlies the maintenance of MDMA self-administration. 


\section{General Discussion}

There is a general conception amongst laypeople and researchers that MDMA is a drug with low abuse liability, and that use poses minimal harm. Recent data, however, suggest otherwise. Surveys indicate that some users become dependent and that dependence is associated with increased frequency of use, greater consumption on each occasion and tolerance to some of the behavioural effects (for example, Degenhardt et al., 2004; Degenhardt et al., 2009). There is now a substantial data base indicating that MDMA use compromises 5HT neurotransmission and also leads to persistent behavioural and cognitive deficits.

The pharmacology of MDMA is not, however, consistent with a drug of abuse. Virtually all other drugs of abuse preferentially increase synaptic levels of DA but MDMA preferentially increases 5HT, and increases in DA are relatively small. Resolution of this paradox has focussed on changes in MDMA pharmacology following repeated exposure. It has been shown that repeated exposure decreases MDMA-produced 5HT responses (Reveron et al., 2010) and it has been suggested that this decrease disinhibits the DA response, making MDMA comparable to other drugs of abuse (Schenk, 2011). There have been limited data to address this intriguing hypothesis. The present thesis was, therefore, undertaken to more fully investigate the role of 5HT in the acquisition and maintenance of MDMA self-administration and to assess the idea that 5HTergic responses limit initial acquisition of self-administration but that continued drug taking becomes dependent on DAergic substrates.

Unlike other drugs of abuse, the latency to acquisition of MDMA selfadministration was not dose-dependent (Schenk et al., 2007), acquisition criteria were achieved in a relatively small percentage of rats subjects and when these criteria were met the latency was relatively long (Schenk et al., 2012). Chapter 1 was designed to determine whether some of these differences might be attributed to the substantial 5HT response to initial MDMA exposure.

The MDMA-induced increase in extracellular 5HT was smaller for the group that subsequently acquired MDMA self-administration supporting the idea that 5HT limits the acquisition of MDMA self-administration. Somewhat surprisingly, the MDMA-produced DA response was not related to the initial response to the reinforcing effects of MDMA. This was unexpected because a wealth of data has shown that self-administration of other drugs of abuse is dependent on DAergic mechanisms (Vezina, 2004). Thus the mechanisms underlying this aspect of MDMA 
self-administration appear to differ considerably from other drugs of abuse. The role of 5HT in the acquisition of MDMA self-administration was further investigated in Chapter 2 by examining effects of widespread 5HT depletion produced by a neurotoxic 5, 7-DHT lesion. Following this lesion, 100\% of rats tested met an acquisition criterion for MDMA self-administration. This result is striking because MDMA self-administration is usually acquired by only about $50 \%$ of subjects. The marked increase in the proportion of subjects that acquired MDMA selfadministration complements the correlational study that suggests a role of 5HT in the acquisition of MDMA self-administration and provides experimental data indicating that 5HT is inhibitory to the acquisition of MDMA self-administration.

Rats with a lower propensity to self-administer MDMA might therefore exhibit a distinctive phenotype. Specifically, MDMA-produced 5HT syndrome should be greater in rats with a lower propensity to self-administer MDMA. This idea could be explored by measuring MDMA-produced behaviours such as head-weaving and low body posture prior to the commencement of MDMA self-administration.

With continued exposure to MDMA, 5HT neurotransmission becomes compromised; tissue levels of 5HT (Do \& Schenk, 2011), SERT binding (Schenk et al., 2007) and MDMA-produced increase in 5HT overflow (Reveron et al., 2010) were decreased following self-administration. Because the previous studies showed that 5HT limits MDMA self-administration, it is reasonable to suggest that selfadministration progresses as a result of these decreased 5HT responses. If so, it was hypothesised that this decreased response might "permit" the expression of a more prominent DA response.

In order to assess these possibilities, behavioural responses to MDMA were measured following self-administration in Chapter 3. In particular, behavioural measures of 5HT (head weaving) and DA (forward locomotion and rearing) activation were obtained. Repeated exposure to MDMA during self-administration produced transient deficits in the MDMA-produced 5HT response that were apparent 5, but not 14 , days following the last self-administration session. The time course of recovery is consistent with a previous study that showed deficits and recovery of tissue levels of 5HT following MDMA self-administration (Do \& Schenk, 2011).

A novel and important result was that MDMA self-administration increased the DA response of rearing, consistent with the enhanced DA overflow that had been reported following MDMA self-administration in another study (Colussi-Mas et al., 
2010). In contrast to the transient nature of the decreased 5HT response, the sensitised DA response was persistent. These data suggest that the effects of MDMA on 5HT and DA are dissociable. It is possible, however, that alterations of 5HT receptor mechanisms might persist and that these alterations might modulate DA responses. There are at least 14 different $5 \mathrm{HT}$ receptor subtypes from 7 different families but only some of these receptors have been linked to DA.

The majority of research on 5HT modulation of DA has focussed on the $5 \mathrm{HT}_{1 \mathrm{~A}}, 5 \mathrm{HT}_{1 \mathrm{~B}}, 5 \mathrm{HT}_{2 \mathrm{~A}}$ and $5 \mathrm{HT}_{2 \mathrm{C}}$ receptors, as these receptors have been located on a number of projections that innervate the mesocorticolimbic DA pathway. Investigations of the specific 5HT receptor mechanisms that modulate the acute MDMA-produced DA response have addressed the role of $5 \mathrm{HT}_{2 \mathrm{~A}}$ and $5 \mathrm{HT}_{2} \mathrm{C}$ receptors. The selective $5 \mathrm{HT}_{2 \mathrm{~A}}$ receptor antagonist, MDL 100907, and the $5 \mathrm{HT}_{2 \mathrm{~A} / 2 \mathrm{C}}$ receptor antagonists, ritanserin and ketanserin, blocked the increase in DA produced by MDMA (Nash, 1990; Schmidt et al., 1992; Schmidt et al., 1994; B. K. Yamamoto et al., 1995) and 5 $\mathrm{HT}_{2 \mathrm{~A}}$ receptor agonists enhanced the MDMA-produced DA response (Gudelsky et al., 1994). Following MDMA self-administration, however, the decreased influence of $5 \mathrm{HT}$ on DA suggests that $5 \mathrm{HT}_{2 \mathrm{~A}}$ receptor modulation of the MDMA-produced DA response might be reduced.

All investigations of the effects of repeated MDMA on 5HT receptors have used experimenter-administered MDMA. Further, the majority employed highfrequency regimens of high doses of MDMA. Thus it is difficult to conjecture how the alterations of 5HT receptors in these studies might compare with the effects of self-administered MDMA in the current study.

A small number of studies have investigated the effect of repeated MDMA on the $5 \mathrm{HT}_{2 \mathrm{~A}}$ receptor, and some results suggest that that a down-regulation of the receptor is produced. A regimen of repeated MDMA that resulted in the administration of a total dose similar to that of the current study decreased 5HT levels, but did not produce a change in hippocampal 5HT $2 \mathrm{~A}$ mRNA 14 days later (Yau, Kelly, Sharkey, \& Seckl, 1994) or alter head-twitching or locomotion produced by the $5 \mathrm{HT}_{2 \mathrm{~A}}$ receptor agonist, DOI (Granoff \& Ashby Jr, 1997). A handful of studies reported alterations of the $5 \mathrm{HT}_{2 \mathrm{~A}}$ receptor after a moderate dose of MDMA. Repeated MDMA produced small decreases in 5HT levels and a widespread decrease of 5 $\mathrm{HT}_{2 \mathrm{~A}}$ receptor density (I. McGregor et al., 2003). There are data to suggest that alterations of $5 \mathrm{HT}_{2 \mathrm{~A}}$ receptor density produced by repeated MDMA are related to the magnitude 
of $5 \mathrm{HT}$ depletion. The recovery of $5 \mathrm{HT}_{2 \mathrm{~A}}$ receptor density was correlated with the extent of 5HT depletion (Reneman et al., 2002). Moderate doses of repeated MDMA also decreased function of $5 \mathrm{HT}_{2 \mathrm{~A}}$ receptor mechanisms. Nearly 2 months after MDMA DOI-produced anxiogenic effects and wet-dog shakes were decreased, showing persistent down regulation of $5 \mathrm{HT}_{2 \mathrm{~A}}$ receptor mechanisms (Bull, Hutson, \& Fone, 2004). Interestingly, the same regimen of MDMA resulted in an increase of DOI-induced glucose utilization in the NAc. This result suggests that, following repeated MDMA, stimulation of $5 \mathrm{HT}_{2 \mathrm{~A}}$ receptors produced increased neuronal activity (Bull, Porkess, Rigby, Hutson, \& Fone, 2006).

Two studies measured MDMA-produced alterations of the $5 \mathrm{HT}_{2 \mathrm{~A}}$ receptor following intermittent dosing regimens. The frequency of dosing in these studies also differed markedly from that of the current study, in that MDMA was administered only every $5^{\text {th }}$ or $7^{\text {th }}$ day. A regimen of MDMA that administered a total dose of 60 $\mathrm{mg} / \mathrm{kg}$ produced a decrease in $5 \mathrm{HT}_{2 \mathrm{~A}}$ receptor mRNA (Kindlundh-Högberg, Svenningsson, \& Schiöth, 2006). A higher dose of MDMA (total dose $120 \mathrm{mg} / \mathrm{kg}$ ) produced increased behavioural and endocrine responses to DOI, but did not alter $5 \mathrm{HT}_{2 \mathrm{~A} / 2 \mathrm{C}}$ receptor density (Biezonski, Courtemanche, Hong, Piper, \& Meyer, 2009). Thus the function of $5 \mathrm{HT}_{2 \mathrm{~A}}$ receptors appears to have been enhanced by this regimen.

In monkeys, a moderate dose of repeated MDMA that decreased 5HT levels produced a trend of increased sensitivity to the $5 \mathrm{HT}_{2 \mathrm{~A} / 2 \mathrm{C}}$ receptor antagonist, ketanserin, (Taffe et al., 2002). This finding, therefore, contrasts to those reported in rats. Similarly, increased functional activity of $5 \mathrm{HT}_{2 \mathrm{~A}}$ receptors was found following repeated exposure to MDMA in mice (Varela, Brea, Loza, Maldonado, \& Robledo, 2011). The relevance of this finding to self-administered MDMA in rats must be interpreted cautiously, however, because repeated MDMA does not produce 5HTergic deficits in mice (Stone, Hanson, et al., 1987).

The aforementioned research reported equivocal results. In addition, relating the data to the current study is made more difficult by the markedly different dosing regimens used. Furthermore, the results of studies that used DOI or ketanserin must be interpreted cautiously due to the compounds' affinity for $5 \mathrm{HT}_{2 \mathrm{C}}$ receptors in addition to $5 \mathrm{HT}_{2} \mathrm{~A}$ receptors. Irrespective of these issues, however, there are some data that show decreased function of $5 \mathrm{HT}_{2 \mathrm{~A}}$ receptor mechanisms following repeated MDMA. Because stimulation of $5 \mathrm{HT}_{2 \mathrm{~A}}$ receptors has been associated with increased synaptic DA, and because the DA response is enhanced following MDMA self- 
administration, the data do not support the idea that the decreased influence of 5HT on the MDMA-produced DA response is due to alterations of $5 \mathrm{HT}_{2 \mathrm{~A}}$ receptor mechanisms.

In contrast to the $5 \mathrm{HT}_{2} \mathrm{~A}$ receptor, systemic administration of the $5 \mathrm{HT}_{2 \mathrm{C}}$ receptor agonist, Ro60-0175, dose-dependently decreased the basal firing rate of VTA DA neurons (Gobert et al., 2000) and decreased extracellular levels of DA in the NAc, FC and striatum (De Deurwaerdère, Navailles, Berg, Clarke, \& Spampinato, 2004; Gobert et al., 2000; Ji et al., 2006). Systemic administration of the 5HT $2 \mathrm{C}$ receptor inverse agonist, SB 206553, or the antagonist, SB 242, 084, dosedependently increased the basal firing rate of VTA and substantia nigra DA neurons, increased burst activity in the NAc (Di Giovanni et al., 1999; Gobert et al., 2000), and increased basal levels of extracellular levels of DA in the PFC, NAc and striatum (Di Giovanni et al., 1999; Gobert et al., 2000). The decreased influence of 5HT modulation of the MDMA-produced DA response following MDMA selfadministration might therefore be due to downregulation of this receptor subtype.

Few studies have investigated the effect of repeated MDMA on $5 \mathrm{HT}_{2 \mathrm{C}}$ receptor mechanisms. Following repeated MDMA the inhibitory effect of the dual $\mathrm{D}_{1}$ receptor antagonist/ $5 \mathrm{HT}_{2 \mathrm{C}}$ receptor agonist, $\mathrm{SCH} 23390$, on MDMA-produced hyperlocomotion was enhanced. A subsequent investigation showed this effect to be due to $5 \mathrm{HT}_{2} \mathrm{C}$ receptor mechanisms in the PFC, suggesting that repeated MDMA induced an enhancement of $5 \mathrm{HT}_{2} \mathrm{C}$ receptor function (Ramos, Goñi-Allo, \& Aguirre, 2004, 2005). Lower doses of repeated MDMA that decreased 5HT levels, however, did not alter hyperlocomotor or anxiogenic response to the $5 \mathrm{HT}_{2} \mathrm{C}$ receptor agonist, mCPP (Bull, Hutson, \& Fone, 2003; Jones, Brennan, Colussi-Mas, \& Schenk, 2010). It must be noted that receptor function was tested 2 (Jones et al., 2010) or 3 (Bull et al., 2003) weeks after the final MDMA administration, and therefore any MDMAproduced alteration of $5 \mathrm{HT}_{2 \mathrm{C}}$ receptor function might have recovered during abstinence. In the one study that intermittently administered MDMA (every $7^{\text {th }}$ day), $5 \mathrm{HT}_{2 \mathrm{C}}$ mRNA was dose-dependently increased (Kindlundh-Högberg et al., 2006). In monkeys, repeated high-dose MDMA that decreased 5HT levels produced increased sensitivity to the $5 \mathrm{HT}_{2} \mathrm{C}$ agonist, $\mathrm{mCPP}$, in sustained attention tasks and progressive ratio responding (Taffe et al., 2002). The data suggest that repeated MDMA might induce an enhancement of $5 \mathrm{HT}_{2} \mathrm{C}$ receptor mechanisms. Because stimulation of $5 \mathrm{HT}_{2} \mathrm{C}$ receptor mechanisms has been associated with decreased DA neurotransmission, 
enhancement of the $5 \mathrm{HT}_{2 \mathrm{C}}$ receptor would not support the idea that alterations of this receptor subtype underlie the decrease in influence of 5HT on the MDMA-produced DA response found following MDMA self-administration.

The $5 \mathrm{HT}_{1 \mathrm{~A}}$ receptor is found pre-synaptically on cell bodies of $5 \mathrm{HT}$ neurons where they regulate 5HT synthesis (Hamon et al., 1988; Neckers, Neff, \& Wyatt, 1979). Previous research failed to observe changes in $5 \mathrm{HT}_{1 \mathrm{~A}}$ autoreceptor mechanisms following MDMA exposure (Schenk, Abraham, Aronsen, Colussi-Mas, \& Do, 2013). Post-synaptic $5 \mathrm{HT}_{1 \mathrm{~A}}$ heteroceptors are localised on mesolimbic DA projections (Doherty \& Pickel, 2001) and are therefore well-placed to modulate DA neurotransmission. Systemic administration of a high, post-synaptic receptorstimulating, dose of the $5 \mathrm{HT}_{1 \mathrm{~A}}$ agonist, 8-OH-DPAT, increased extracellular levels of DA in the PFC (Assié, Ravailhe, Faucillon, \& Newman-Tancredi, 2005), but decreased activity of DA neurons in the VTA (Arborelius et al., 1993).

Repeated administration of high doses of MDMA produced region-dependent alterations of $5 \mathrm{HT}_{1 \mathrm{~A}}$ receptor density. Density was increased in the $\mathrm{FC}$, but decreased in the hippocampus, 7 days after the last MDMA exposure. Furthermore, the density of $5 \mathrm{HT}_{1 \mathrm{~A}}$ receptors was positively correlated with $5 \mathrm{HT}_{1 \mathrm{~A}}$ mRNA levels (Aguirre, Frechilla, García-Osta, Lasheras, \& Del Río, 1997; Aguirre, Galbete, Lasheras, \& Del Río, 1995). The same dosing regimen increased 8-OH DPAT-produced hyperthermia, which was correlated with the increase in $5 \mathrm{HT}_{1 \mathrm{~A}}$ receptor density in the $\mathrm{FC}$ (Aguirre, Ballaz, Lasheras, \& Del R1o, 1998). In monkeys, a high-dose regimen of MDMA also increased sensitivity to 8-OH-DPAT in a progressive ratio task (Taffe et al., 2002).

It appears that a moderate dose of repeated MDMA does not alter $5 \mathrm{HT}_{1 \mathrm{~A}}$ receptors. Hippocampal 5HT $1 \mathrm{~A}$ mRNA levels were unchanged (Yau et al., 1994), and 8-OH DPAT-produced hyperthermia (McNamara, Kelly, \& Leonard, 1995), social interaction (M. R. Thompson, Callaghan, Hunt, \& McGregor, 2008) and increases of extracellular acetylcholine in the FC (Nair \& Gudelsky, 2006), were not altered. One study, however, reported decreased 8-OH DPAT-produced fore-paw treading after an abstinence period, suggesting down-regulation of $5 \mathrm{HT}_{1 \mathrm{~A}}$ receptor mechanisms (Granoff \& Ashby Jr, 2001). A regimen of intermittent MDMA did not alter 5HT $1 \mathrm{~A}$ receptor density (I. McGregor et al., 2003; Piper, Vu, Safain, Oliver, \& Meyer, 2006), $5 \mathrm{HT}_{1 \mathrm{~A}}$ receptor mRNA levels (Kindlundh-Högberg et al., 2006) or 8-OH DPATproduced hyperthermia (Piper et al., 2006), but did decrease 8-OH DPAT-produced 5HT syndrome (Piper et al., 2006). The varying effect of the MDMA pre-treatment on 
behavioural responses to 8-OH DPAT might be due to the different behavioural responses reflecting regional differences in MDMA-produced alterations of the $5 \mathrm{HT}_{1 \mathrm{~A}}$ receptor.

The data suggest that repeated MDMA only alters $5 \mathrm{HT}_{1 \mathrm{~A}}$ receptor function following administration of high doses. A total dose of MDMA that was similar to that self-administered in the current study $(160 \mathrm{mg} / \mathrm{kg})$, produced tolerance to the behavioural effects of 8-OH DPAT following abstinence (Granoff \& Ashby Jr, 2001). It is possible, therefore, that the self-administered MDMA in the current study produced a similar effect. Because stimulation of post-synaptic $5 \mathrm{HT}_{1 \mathrm{~A}}$ receptors has been associated with reduced function of VTA DA neurons, such an alteration of $5 \mathrm{HT}_{1 \mathrm{~A}}$ receptor mechanisms would support the idea that the decreased influence of 5HT modulation on the MDMA-produced DA response after MDMA selfadministration was due to changes of specific 5HT receptor mechanisms.

The $5 \mathrm{HT}_{1 \mathrm{~B}}$ receptor is located on pre-synaptic $5 \mathrm{HT}$ neurons, where it acts as an autoreceptor that controls 5HT release, and post-synaptically where it is a heteroceptor that modulates the release of other neurotransmitters (Bruinvels et al., 1994; Sari et al., 1999). Post-synaptic 5НT 1 в heteroceptors are localised on inhibitory gamma- aminobutyric acid (GABA) projections from the NAc to the VTA, and on excitatory glutamatergic projections from the PFC to the NAc. Stimulation of $5 \mathrm{HT}_{1 \mathrm{~B}}$ receptors on GABA neurons inhibits release and thus disinhibits mesolimbic DA. Stimulation of these receptors might therefore be expected to enhance selfadministration. Stimulation of $5 \mathrm{HT}_{1 \mathrm{~B}}$ receptors on glutamatergic terminals decreases release of glutamate and DA, and therefore might be expected to decrease selfadministration since self-administration has been attributed to increases of synaptic DA (for a review, see Sari, 2004). The downstream effects of stimulating $5 \mathrm{HT}_{1 \mathrm{~B}}$ receptors are complicated and depend on the functional balance of stimulating both autoreceptor and post-synaptic heteroceptor populations.

The effect of repeated MDMA on $5 \mathrm{HT}_{1 \mathrm{~B}}$ receptor mechanisms appears to be dependent on the dose and/ or the frequency of administrations. A high-frequency regimen of a moderate dose of MDMA produced tolerance to the locomotoractivating effects of MDMA and the 5 $\mathrm{HT}_{1 \mathrm{~B} / 1 \mathrm{~A}}$ receptor agonist, RU24969 (Callaway \& Geyer, 1992). A lower dose of MDMA, however, induced behavioural sensitisation and enhanced the hyperlocomotor response to RU24969 (McCreary et al., 1999). It is not known how self-administered MDMA might alter the function of post-synaptic 
$5 \mathrm{HT}_{1 \mathrm{~B}}$ receptors. However, because behavioural sensitisation, rather than tolerance, was found following self-administration, it might be expected that enhancement of $5 \mathrm{HT}_{1 \mathrm{~B}}$ receptor mechanisms would occur, akin to the results of McCreary et al. (1999). That behavioural sensitisation, a behavioural correlate of an enhanced DA response, was accompanied by sensitised $5 \mathrm{HT}_{1 \mathrm{~B}}$ receptor mechanisms supports the idea that the decreased modulatory effect of 5HT on the MDMA-produced DA response is due to alterations of 5HT receptors.

The available data support the idea that changes in either $5 \mathrm{HT}_{1 \mathrm{~A}}$ or $5 \mathrm{HT}_{1 \mathrm{~B}}$ hetereceptor mechanisms could account for the sensitised DA response. To investigate this idea further, the function of $5 \mathrm{HT}_{1 \mathrm{~A}}$ and $5 \mathrm{HT}_{1 \mathrm{~B}}$ receptor mechanisms should be measured following MDMA self-administration. One behavioural measure of $5 \mathrm{HT}_{1 \mathrm{~A}}$ receptor activation is reciprocal forepaw treading (Granoff \& Ashby $\mathrm{Jr}$, 2001). Thus this response to the selective $5 \mathrm{HT}_{1 \mathrm{~A}}$ agonist, $8-\mathrm{OH}-\mathrm{DPAT}$, would provide valuable information. A response to $5 \mathrm{HT}_{1 \mathrm{~B}}$ receptor agonists is adipsia (Aronsen, Webster, \& Schenk, in press) as well as hyperlocomotion (McCreary et al., 1999) and so measurement of these behavioural responses would provide an indication of the status of these receptors following MDMA self-administration.

The decreased influence of 5HT on the MDMA-produced DA response might be due to sensitised DA receptor mechanisms in addition to, or instead of, altered 5HT receptor mechanisms, as has been suggested as a mechanism underlying other drugs of abuse (for a review, see Vezina, 2004). Neurochemical and behavioural studies have shown that repeated MDMA induces an enhanced DA response (for example, Kalivas et al., 1998). There are data to suggest that this enhanced response is accompanied by sensitised $\mathrm{D}_{2}$ receptor mechanisms. Repeated exposure to MDMA induced sensitisation of the locomotor-stimulating effects of a subsequent administration of MDMA, that was accompanied by sensitisation of the behavioural effects of the $D_{2}$ receptor agonist, quinpirole (Bradbury et al., 2012).

Further, sensitised $\mathrm{D}_{2}$ receptor mechanisms appear to play a role in MDMAseeking. Compulsive drug-seeking has been attributed to sensitised DA mechanisms (for a review, see Robinson \& Berridge, 1993, 2001). Following extensive MDMA self-administration, administration of the DAT inhibitor, GBR 12909, or the DA releaser, AMPH, induced MDMA-seeking. In addition, the $\mathrm{D}_{2}$ receptor agonist, quinpirole, but not the $\mathrm{D}_{1}$ receptor agonist, $\mathrm{SKF}$ 81297, produced MDMA-seeking (Schenk et al., 2011). Thus the data suggest that exposure to MDMA during self- 
administration produced an enhanced DA response that was accompanied by sensitised $\mathrm{D}_{2}$ receptor mechanisms and therefore support the idea that sensitisation of DA receptor mechanisms occurs independent of 5HT modulation.

It would be of interest to obtain more direct measures of the effect of MDMA self-administration on MDMA-produced 5HT and DA responses using in vivo microdialysis. This was the original plan for the experiment of Chapter 3 and the study was initiated. The experiment could not be completed, however, due to equipment failure. The results of this study would be expected to reflect the data from Chapter 3. Augmented MDMA-induced increases of extracellular DA would be expected in the MDMA self-administration groups after either abstinence period. An attenuated MDMA-induced increase of extracellular 5HT would be expected 5 days, but not 14 days, following MDMA self-administration.

The role of 5HT in the maintenance of MDMA self-administration was investigated in Chapter 4 by measuring responding in rats that had, or did not have, 5HT deficits. Responding maintained by MDMA was comparable for the two groups, suggesting that following acquisition of self-administration 5HT deficits are not a critical determinant. An interesting study that would further determine the role of 5HT in the maintenance of MDMA self-administration could measure the effect of a neurotoxic 5, 7-DHT lesion following acquisition of self-administration. In fact this experiment was also part of the initial plan but in preliminary studies, a large percentage of the rats became ill and so the experiment was abandoned. A more reasonable approach might be to determine the effects of 5HT antagonists on MDMA self-administration.

Taken together, the data support the idea that the DA response becomes critical to the maintenance of MDMA self-administration. This change in the critical determinant of MDMA self-administration from 5HT (acquisition) to DA (maintenance) might underlie the change in the profile of MDMA self-administration. Following extended testing, MDMA self-administration begins to share the characteristics of responding found with other psychostimulants. Responding increases, becomes dose-dependent (Schenk et al., 2012), and is attenuated by DA receptor antagonists (Brennan et al., 2009; Daniela et al., 2004). Further, after extended self-administration DAergic mechanisms induce MDMA-seeking (Schenk et al., 2011). Thus after using a range of experimental procedures to examine the role of 5HT in MDMA self-administration, the data of this thesis suggest that, like other 
drugs of abuse, MDMA self-administration is dependent on stimulation of DA neurotransmission.

A future study could further investigate this by measuring responding maintained by MDMA following depletion of DA. In rats that have acquired MDMA self-administration, the DA neurotoxin, 6-OHDA, or vehicle could be infused centrally into the VTA to lesion mesolimbic DA neurons. Thereafter, responding maintained by MDMA could be measured. Attenuated or abolished responding would support the idea that the DAergic response is the critical determinant of the maintenance of MDMA self-administration.

The findings of this thesis support the wealth of literature that suggests drug-produced reinforcement is mediated by DAergic mechanisms, and adds to the relatively small literature that describes a decrease in drug-produced reinforcement following an increased 5HT response. The findings of this thesis also suggest that the repeated use of ecstasy, of which MDMA is the active ingredient, could result in a sensitised DAergic system and thus lead to an increase in the reinforcing efficacy of ecstasy and other drugs of abuse. In addition, the findings suggest that this enhancement of the DAergic system is persistent, and therefore might lead to the experience of heightened sensitivity remaining for significant periods of time after last ecstasy use.

\section{Conclusions}

The susceptibility to acquire MDMA self-administration is dependent on the 5HT response to initial MDMA, with the propensity to meet an acquisition criterion inversely related to the magnitude of the response. Repeated exposure to MDMA during self-administration produced a reduction of the 5HT response, and sensitisation of the DA response. The enhanced DA response is proposed to underlie the progression of MDMA self-administration. The progression of MDMA selfadministration therefore reflects a shift in the predominant neurochemical effect of MDMA from being 5HTergic to DAergic. 


\section{References}

Advisory on the Misuse of Drugs. (2009). MDMA ('ecstasy') a review of its harms and classification under the misuse of drugs act 1971. London, England. Retrieved from: https://www.erowid.org/chemicals/mdma/mdma_info13.pdf

Aguirre, N., Ballaz, S., Lasheras, B., \& Del R1o, J. (1998). MDMA (Ecstasy') enhances 5-HT1A receptor density and 8-OH-DPAT-induced hypothermia: blockade by drugs preventing 5-hydroxytryptamine depletion. European journal of pharmacology, 346(2), 181-188.

Aguirre, N., Frechilla, D., García-Osta, A., Lasheras, B., \& Del Río, J. (1997).

Differential Regulation by Methylenedioxymethamphetamine of 5-Hydroxytryptamine1A Receptor Density and mRNA Expression in Rat Hippocampus, Frontal Cortex, and Brainstem: The Role of Corticosteroids. Journal of neurochemistry, 68(3), 1099-1105.

Aguirre, N., Galbete, J., Lasheras, B., \& Del Río, J. (1995).

Methylenedioxymethamphetamine induces opposite changes in central preand postsynaptic 5-HT1 A receptors in rats. European journal of pharmacology, 281(1), 101-105.

Allott, K., Canny, B., Broadbear, J., Stepto, N., Murphy, B., \& Redman, J. (2009). Neuroendocrine and subjective responses to pharmacological challenge with citalopram: a controlled study in male and female ecstasy/MDMA users. Journal of psychopharmacology, 23(7), 759-774.

Amit, Z., \& Smith, B. R. (1992). Remoxipride, a specific D2 dopamine antagonist: An examination of its self-administration liability and its effects on damphetamine self-administration. Pharmacology Biochemistry and Behavior, 41(1), 259-261.

Arborelius, L., Chergui, K., Murase, S., Nomikos, G. G., Höök, B. B., Chouvet, G., . . Svensson, T. H. (1993). The 5-HT1A receptor selective ligands,(R)-8-OHDPAT and (S)-UH-301, differentially affect the activity of midbrain dopamine neurons. Naunyn-Schmiedeberg's archives of pharmacology, 347(4), 353-362.

Aronsen, D., Webster, J., \& Schenk, S. (in press). RU24969-produced adipsia and hyperlocomotion: Differential role of 5HT1A and 5HT1B receptor mechanisms. Pharmacology, biochemistry, and behavior.

Assié, M.-B., Ravailhe, V., Faucillon, V., \& Newman-Tancredi, A. (2005). Contrasting contribution of 5-hydroxytryptamine $1 \mathrm{~A}$ receptor activation to neurochemical profile of novel antipsychotics: frontocortical dopamine and hippocampal serotonin release in rat brain. Journal of Pharmacology and Experimental Therapeutics, 315(1), 265-272.

Ball, K. T., Budreau, D., \& Rebec, G. V. (2006). Context-dependent behavioural and neuronal sensitization in striatum to MDMA (ecstasy) administration in rats. European Journal of Neuroscience, 24(1), 217-228.

Ball, K. T., Klein, J. E., Plocinski, J. A., \& Slack, R. (2011). Behavioral sensitization to 3, 4-methylenedioxymethamphetamine (MDMA; ecstasy) is long lasting and modulated by the context of drug administration. Behavioural Pharmacology, 22(8), 847.

Ball, K. T., Wellman, C., Fortenberry, E., \& Rebec, G. (2009). Sensitizing regimens of ( \pm ) 3, 4-methylenedioxymethamphetamine (ecstasy) elicit enduring and differential structural alterations in the brain motive circuit of the rat. Neuroscience, 160(2), 264-274.

Ball, K. T., Wellman, C. L., Miller, B. R., \& Rebec, G. V. (2010). Electrophysiological and structural alterations in striatum associated with 
behavioral sensitization to $( \pm)$ 3, 4-methylenedioxymethamphetamine (ecstasy) in rats: role of drug context. Neuroscience, 171(3), 794-811.

Balster, R. L., Kilbey, M. M., \& Ellinwood Jr, E. H. (1976). Methamphetamine selfadministration in the cat. Psychopharmacologia, 46(3), 229-233.

Bari, A., \& Pierce, R. (2005). D1-like and D2 dopamine receptor antagonists administered into the shell subregion of the rat nucleus accumbens decrease cocaine, but not food, reinforcement. Neuroscience, 135(3), 959-968.

Barrett, A. C., Miller, J. R., Dohrmann, J. M., \& Caine, S. B. (2004). Effects of dopamine indirect agonists and selective D1-like and D2-like agonists and antagonists on cocaine self-administration and food maintained responding in rats. Neuropharmacology, 47, 256-273.

Battaglia, G., Brooks, B. P., Kulsakdinun, C., \& De Souza, E. B. (1988).

Pharmacologic profile of MDMA (3, 4-methylenedioxymethamphetamine) at various brain recognition sites. European journal of pharmacology, 149(1), 159-163.

Battaglia, G., Yeh, S., \& De Souza, E. B. (1988). MDMA-induced neurotoxicity: parameters of degeneration and recovery of brain serotonin neurons. Pharmacology Biochemistry and Behavior, 29(2), 269-274.

Battaglia, G., Yeh, S., O'Hearn, E., Molliver, M. E., Kuhar, M. J., \& De Souza, E. B. (1987). 3, 4-Methylenedioxymethamphetamine and 3, 4-

methylenedioxyamphetamine destroy serotonin terminals in rat brain: quantification of neurodegeneration by measurement of $[3 \mathrm{H}]$ paroxetinelabeled serotonin uptake sites. Journal of Pharmacology and Experimental Therapeutics, 242(3), 911-916.

Baumann, M. H., Clark, R. D., Franken, F. H., Rutter, J. J., \& Rothman, R. B. (2008). Tolerance to 3, 4-methylenedioxymethamphetamine in rats exposed to single high-dose binges. Neuroscience, 152(3), 773-784.

Baumann, M. H., Clark, R. D., \& Rothman, R. B. (2008). Locomotor stimulation produced by 3, 4-methylenedioxymethamphetamine (MDMA) is correlated with dialysate levels of serotonin and dopamine in rat brain. Pharmacology Biochemistry and Behavior, 90(2), 208-217.

Beardsley, P. M., Balster, R. L., \& Harris, L. S. (1986). Self-administration of methylenedioxymethamphetamine (MDMA) by rhesus monkeys. Drug and alcohol dependence, 18(2), 149-157.

Berger, U. V., Gu, X. F., \& Azmitia, E. C. (1992). The substituted amphetamines 3, 4methylenedioxymethamphetamine, methamphetamine, p-chloroamphetamine and fenfluramine induce 5-hydroxytryptamine release via a common mechanism blocked by fluoxetine and cocaine. European journal of pharmacology, 215(2), 153-160.

Bhide, N. S., Lipton, J. W., Cunningham, J. I., Yamamoto, B. K., \& Gudelsky, G. A. (2009). Repeated exposure to MDMA provides neuroprotection against subsequent MDMA-induced serotonin depletion in brain. Brain research, 1286, 32-41.

Biezonski, D. K., Courtemanche, A. B., Hong, S. B., Piper, B. J., \& Meyer, J. S. (2009). Repeated adolescent MDMA ("Ecstasy") exposure in rats increases behavioral and neuroendocrine responses to a $5-\mathrm{HT}<\mathrm{sub}>2 \mathrm{~A} / 2 \mathrm{C}</$ sub $>$ agonist. Brain research, 1252, 87-93.

Biezonski, D. K., \& Meyer, J. S. (2011). The nature of 3, 4methylenedioxymethamphetamine (MDMA)-induced serotonergic 
dysfunction: evidence for and against the neurodegeneration hypothesis. Current neuropharmacology, 9(1), 84.

Biezonski, D. K., Piper, B. J., Shinday, N. M., Kim, P. J., Ali, S. F., \& Meyer, J. S. (2013). Effects of a short-course MDMA binge on dopamine transporter binding and on levels of dopamine and its metabolites in adult male rats. European journal of pharmacology, 701(1), 176-180.

Bogdanski, D. F., Weissbach, H., \& Udenfriend, S. (1958). Pharmacological studies with the serotonin precursor, 5-hydroxytryptophan. Journal of Pharmacology and Experimental Therapeutics, 122(2), 182-194.

Bradbury, S., Bird, J., Colussi-Mas, J., Mueller, M., Ricaurte, G., \& Schenk, S. (2013). Acquisition of MDMA self-administration: pharmacokinetic factors and MDMA-induced serotonin release. Addiction Biology.

Bradbury, S., Gittings, D., \& Schenk, S. (2012). Repeated exposure to MDMA and amphetamine: sensitization, cross-sensitization, and response to dopamine D1and D2-like agonists. Psychopharmacology, 223(4), 389-399.

Brennan, K. A., Carati, C., Lea, R. A., Fitzmaurice, P. S., \& Schenk, S. (2009). Effect of D1-like and D2-like receptor antagonists on methamphetamine and 3, 4methylenedioxymethamphetamine self-administration in rats. Behavioural Pharmacology, 20(8), 688-694.

Britton, D., Curzon, P., Mackenzie, R., Kebabian, J., Williams, J., \& Kerkman, D. (1991). Evidence for involvement of both D1 and D2 receptors in maintaining cocaine self-administration. Pharmacology Biochemistry and Behavior, 39(4), 911-915.

Brodkin, J., Malyala, A., \& Frank Nash, J. (1993). Effect of acute monoamine depletion on 3, 4-methylenedioxymethamphetamine-induced neurotoxicity. Pharmacology Biochemistry and Behavior, 45(3), 647-653.

Bruinvels, A., Landwehrmeyer, B., Gustafson, E., Durkin, M., Mengod, G., Branchek, T., ... Palacios, J. (1994). Localization of 5-HT1B, 5-HT1D $\alpha, 5-H T 1 E$ and 5HT1F receptor messenger RNA in rodent and primate brain. Neuropharmacology, 33(3), 367-386.

Bubar, M. J., Stutz, S. J., \& Cunningham, K. A. (2011). 5-HT2C receptors localize to dopamine and GABA neurons in the rat mesoaccumbens pathway. PloS one, 6(6), e20508.

Buchert, R., Thomasius, R., Wilke, F., Petersen, K., Nebeling, B., Obrocki, J., . . Clausen, M. (2004). A voxel-based PET investigation of the long-term effects of "ecstasy" consumption on brain serotonin transporters. American Journal of Psychiatry, 161(7), 1181-1189.

Bull, E. J., Hutson, P., \& Fone, K. (2003). Reduced social interaction following 3, 4methylenedioxymethamphetamine is not associated with enhanced 5-HT2C receptor responsivity. Neuropharmacology, 44(4), 439-448.

Bull, E. J., Hutson, P. H., \& Fone, K. C. (2004). Decreased social behaviour following 3, 4-methylenedioxymethamphetamine (MDMA) is accompanied by changes in 5-HT2A receptor responsivity. Neuropharmacology, 46(2), 202-210.

Bull, E. J., Porkess, V., Rigby, M., Hutson, P. H., \& Fone, K. C. (2006). Pre-treatment with 3, 4-methylenedioxymethamphetamine (MDMA) causes long-lasting changes in 5-HT2A receptor-mediated glucose utilization in the rat brain. Journal of psychopharmacology, 20(2), 272-280.

Cadoni, C., Solinas, M., Pisanu, A., Zernig, G., Acquas, E., \& Di Chiara, G. (2005). Effect of 3, 4-methylendioxymethamphetamine (MDMA, “ecstasy”) on 
dopamine transmission in the nucleus accumbens shell and core. Brain research, 1055(1), 143-148.

Cadoni, C., Solinas, M., Valentini, V., \& Di Chiara, G. (2003). Selective psychostimulant sensitization by food restriction: differential changes in accumbens shell and core dopamine. European Journal of Neuroscience, 18(8), 2326-2334.

Caine, S. B., Heinrichs, S. C., Coffin, V. L., \& Koob, G. F. (1995). Effects of the dopamine D-1 antagonist SCH 23390 microinjected into the accumbens, amygdala or striatum on cocaine self-administration in the rat. Brain research, 692(1), 47-56.

Caine, S. B., \& Koob, G. F. (1994a). Effects of dopamine D-1 and D-2 antagonists on cocaine self-administration under different schedules of reinforcement in the rat. Journal of Pharmacology and Experimental Therapeutics, 270(1), 209218.

Caine, S. B., \& Koob, G. F. (1994b). Effects of mesolimbic dopamine depletion on responding maintained by cocaine and food. Journal of the experimental analysis of behavior, 61(2), 213-221.

Callaway, C. W., \& Geyer, M. A. (1992). Tolerance and cross-tolerance to the activating effects of 3,4-methylenedioxymethamphetamine and a 5hydroxytryptamine1B agonist. Journal of Pharmacology and Experimental Therapeutics, 263(1), 318-326.

Caron, M. G. (1996). Hyperlocomotion and indifference to cocaine and amphetamine in mice lacking the dopamine transporter. Nature, 379, 15.

Carroll, M. E. (1985). The role of food deprivation in the maintenance and reinstatement of cocaine-seeking behavior in rats. Drug and Alcohol Dependence, 16(2), 95-109.

Carroll, M. E., France, C. P., \& Meisch, R. A. (1979). Food deprivation increases oral and intravenous drug intake in rats. Science.

Carroll, M. E., \& Lac, S. T. (1993). Autoshaping iv cocaine self-administration in rats: effects of nondrug alternative reinforcers on acquisition. Psychopharmacology, 110(1-2), 5-12.

Carroll, M. E., \& Lac, S. T. (1997). Acquisition of iv amphetamine and cocaine selfadministration in rats as a function of dose. Psychopharmacology, 129(3), 206-214.

Carroll, M. E., Lac, S. T., Asencio, M., \& Kragh, R. (1990a). Fluoxetine reduces intravenous cocaine self-administration in rats. Pharmacology Biochemistry and Behavior, 35(1), 237-244.

Carroll, M. E., Lac, S. T., Asencio, M., \& Kragh, R. (1990b). Intravenous cocaine self-administration in rats is reduced by dietaryl-tryptophan. Psychopharmacology, 100(3), 293-300.

Cohen, R. S. (1995). Subjective reports on the effects of the MDMA ('ecstasy') experience in humans. Progress in Neuro-Psychopharmacology and Biological Psychiatry, 19(7), 1137-1145.

Colado, M., \& Green, A. (1994). A study of the mechanism of MDMA ('Ecstasy')-induced neurotoxicity of 5-HT neurones using chlormethiazole, dizocilpine and other protective compounds. British journal of pharmacology, 111(1), 131-136.

Colussi-Mas, J., Wise, R. J., Howard, A., \& Schenk, S. (2010). Drug seeking in response to a priming injection of MDMA in rats: relationship to initial 
sensitivity to self-administered MDMA and dorsal striatal dopamine. The International Journal of Neuropsychopharmacology, 13(10), 1315-1327.

Colussi-Mas, J., \& Schenk, S. (2008). Acute and sensitized response to 3, 4-methylenedioxymethamphetamine in rats: different behavioral profiles reflected in different patterns of Fos expression. European Journal of Neuroscience, 28(9), 1895-1910.

Commins, D., Vosmer, G., Virus, R., Woolverton, W., Schuster, C., \& Seiden, L. (1987). Biochemical and histological evidence that methylenedioxymethylamphetamine (MDMA) is toxic to neurons in the rat brain. Journal of Pharmacology and Experimental Therapeutics, 241(1), 338345.

Cornish, J. L., \& Kalivas, P. W. (2001). Repeated cocaine administration into the rat ventral tegmental area produces behavioral sensitization to a systemic cocaine challenge. Behavioural brain research, 126(1), 205-209.

Corrigall, W. A., \& Coen, K. M. (1991). Cocaine self-administration is increased by both D1 and D2 dopamine antagonists. Pharmacology Biochemistry and Behavior, 39(3), 799-802.

Costall, B., Eniojukan, J. F., \& Naylor, R. J. (1982). Spontaneous climbing behaviour of mice, its measurement and dopaminergic involvement. European journal of pharmacology, 85(2), 125-132.

Cottler, L. B., Womack, S. B., Compton, W. M., \& Ben-Abdallah, A. (2001). Ecstasy abuse and dependence among adolescents and young adults: applicability and reliability of DSM-IV criteria. Human Psychopharmacology: Clinical and Experimental, 16(8), 599-606.

Cowan, R. L., Roberts, D. M., \& Joers, J. M. (2008). Neuroimaging in human MDMA (Ecstasy) users. Annals of the New York Academy of Sciences, 1139(1), 291-298.

Crespi, D., Mennini, T., \& Gobbi, M. (1997). Carrier-dependent and Ca2+-dependent 5-HT and dopamine release induced by (+)-amphetamine, 3 , 4-methylendioxy-methamphetamine, $\mathrm{p}$-chloroamphetamine and (+)-fenfluramine. British journal of pharmacology, 121(8), 1735-1743.

Curran, H. V., \& Verheyden, S. L. (2003). Altered response to tryptophan supplementation after long-term abstention from MDMA (ecstasy) is highly correlated with human memory function. Psychopharmacology, 169(1), 91103.

Curzon, G., Fernando, J., \& Lees, A. (1979). Backward walking and circling: behavioural responses induced by drug treatments which cause simultaneous release of catecholamines and 5-hydroxytryptamine. British journal of pharmacology, 66(4), 573-579.

Czoty, P. W., Ginsburg, B. C., \& Howell, L. L. (2002). Serotonergic attenuation of the reinforcing and neurochemical effects of cocaine in squirrel monkeys. Journal of Pharmacology and Experimental Therapeutics, 300(3), 831-837.

Daniela, E., Brennan, K., Gittings, D., Hely, L., \& Schenk, S. (2004). Effect of SCH 23390 on ( \pm )-3, 4-methylenedioxymethamphetamine hyperactivity and selfadministration in rats. Pharmacology Biochemistry and Behavior, 77(4), 745750 .

De Deurwaerdère, P., Navailles, S., Berg, K. A., Clarke, W. P., \& Spampinato, U. (2004). Constitutive activity of the serotonin $2 \mathrm{C}$ receptor inhibits in vivo dopamine release in the rat striatum and nucleus accumbens. The Journal of neuroscience, 24(13), 3235-3241. 
De La Garza II, R., Fabrizio, K., \& Gupta, A. (2007). Relevance of rodent models of intravenous MDMA self-administration to human MDMA consumption patterns. Psychopharmacology, 189(4), 425-434.

De Vry, J., Donselaar, I., \& Van Ree, J. M. (1989). Food deprivation and acquisition of intravenous cocaine self-administration in rats: effect of naltrexone and haloperidol. Journal of Pharmacology and Experimental Therapeutics, 251(2), 735-740.

Degenhardt, L., Barker, B., \& Topp, L. (2004). Patterns of ecstasy use in Australia: findings from a national household survey. Addiction, 99(2), 187-195.

Degenhardt, L., Roxburgh, A., Dunn, M., Campbell, G., Bruno, R., Kinner, S. A., . . . Topp, L. (2009). The epidemiology of ecstasy use and harms in Australia. Neuropsychobiology, 60(3-4), 176-187.

Dellu, F., Piazza, P., Mayo, W., Le Moal, M., \& Simon, H. (1996). Novelty-seeking in rats-biobehavioral characteristics and possible relationship with the sensation-seeking trait in man. Neuropsychobiology, 34(3), 136-145.

Di Chiara, G. (1999). Drug addiction as dopamine-dependent associative learning disorder. European journal of pharmacology, 375(1), 13-30.

Di Chiara, G., Acquas, E., Tanda, G., \& Cadoni, C. (1992). Drugs of abuse: biochemical surrogates of specific aspects of natural reward? Paper presented at the Biochemical Society Symposium.

Di Chiara, G., \& Imperato, A. (1988). Drugs abused by humans preferentially increase synaptic dopamine concentrations in the mesolimbic system of freely moving rats. Proceedings of the National Academy of Sciences, 85(14), 52745278.

Di Giovanni, G., De Deurwaerdere, P., Di Mascio, M., Di Matteo, V., Esposito, E., \& Spampinato, U. (1999). Selective blockade of serotonin-2C/2B receptors enhances mesolimbic and mesostriatal dopaminergic function: a combined $<\mathrm{i}>$ in vivo $</ \mathrm{i}>$ electrophysiological and microdialysis study. Neuroscience, 91(2), 587-597.

Di Iorio, C. R., Watkins, T. J., Dietrich, M. S., Cao, A., Blackford, J. U., Rogers, B., . .. Kessler, R. M. (2011). Evidence for chronically altered serotonin function in the cerebral cortex of female 3, 4-methylenedioxymethamphetamine polydrug users. Archives of general psychiatry, archgenpsychiatry. 2011.2156 v2011.

Do, J., \& Schenk, S. (2011). Self-administered MDMA produces dose-and time-dependent serotonin deficits in the rat brain. Addiction Biology.

Doherty, M. D., \& Pickel, V. M. (2001). Targeting of serotonin 1A receptors to dopaminergic neurons within the parabrachial subdivision of the ventral tegmental area in rat brain. Journal of Comparative Neurology, 433(3), 390400.

Downing, J. (1986). The psychological and physiological effects of MDMA on normal volunteers. Journal of Psychoactive Drugs, 18(4), 335-340.

Dworkin, S. I., Mirkis, S., \& Smith, J. E. (1995). Response-dependent versus response-independent presentation of cocaine: differences in the lethal effects of the drug. Psychopharmacology, 117(3), 262-266.

Fantegrossi, W. E., Ullrich, T., Rice, K. C., Woods, J. H., \& Winger, G. (2002). 3, 4Methylenedioxymethamphetamine (MDMA," ecstasy") and its stereoisomers as reinforcers in rhesus monkeys: serotonergic involvement.

Psychopharmacology, 161(4), 356-364. 
Fantegrossi, W. E., Woolverton, W. L., Kilbourn, M., Sherman, P., Yuan, J., Hatzidimitriou, G., . . . Winger, G. (2004). Behavioral and neurochemical consequences of long-term intravenous self-administration of MDMA and its enantiomers by rhesus monkeys. Neuropsychopharmacology, 29(7).

Fisk, J. E., Montgomery, C., \& Hadjiefthyvoulou, F. (2011). Visuospatial working memory impairment in current and previous ecstasy/polydrug users. Human Psychopharmacology: Clinical and Experimental, 26(4-5), 313-321.

Fisk, J. E., Montgomery, C., Wareing, M., \& Murphy, P. N. (2005). Reasoning deficits in ecstasy (MDMA) polydrug users. Psychopharmacology, 181(3), 550-559.

Flagel, S. B., \& Robinson, T. E. (2007). Quantifying the psychomotor activating effects of cocaine in the rat. Behavioural Pharmacology, 18(4), 297-302.

Fletcher, P. J. (1998). A Comparison of the Effects of Risperidone, Raclopride, and Ritanserin on Intravenous Self-Administration of $<\mathrm{i}>\mathrm{d}</ \mathrm{i}>$-Amphetamine. Pharmacology Biochemistry and Behavior, 60(1), 55-60.

Fletcher, P. J., Korth, K. M., \& Chambers, J. W. (1999). Selective destruction of brain serotonin neurons by 5, 7-dihydroxytryptamine increases responding for a conditioned reward. Psychopharmacology, 147(3), 291-299.

Fletcher, P. J., Robinson, S. R., \& Slippoy, D. L. (2001). Pre-exposure to ( \pm ) 3, 4methylenedioxy-methamphetamine (MDMA) facilitates acquisition of intravenous cocaine self-administration in rats. Neuropsychopharmacology, 25(2), 195-203.

Forster, G., Falcon, A., Miller, A., Heruc, G., \& Blaha, C. (2002). Effects of laterodorsal tegmentum excitotoxic lesions on behavioral and dopamine responses evoked by morphine and d-amphetamine. Neuroscience, 114(4), 817-823.

Fox, H., Parrott, A., \& Turner, J. (2001). Ecstasy use: cognitive deficits related to dosage rather than self-reported problematic use of the drug. Journal of psychopharmacology, 15(4), 273-281.

Gartside, S., McQuade, R., \& Sharp, T. (1996). Effects of repeated administration of 3, 4-methylenedioxymethamphetamine on 5-hydroxytryptamine neuronal activity and release in the rat brain in vivo. Journal of Pharmacology and Experimental Therapeutics, 279(1), 277-283.

George, J., Kinner, S. A., Bruno, R., Degenhardt, L., \& Dunn, M. (2010). Contextualising psychological distress among regular ecstasy users: the importance of sociodemographic factors and patterns of drug use. Drug and alcohol review, 29(3), 243-249.

Glick, S., Raucci, J., Wang, S., Keller Jr, R., \& Carlson, J. (1994). Neurochemical predisposition to self-administer cocaine in rats: individual differences in dopamine and its metabolites. Brain research, 653(1), 148-154.

Gobert, A., Rivet, J. M., Lejeune, F., Newman-Tancredi, A., Adhumeau-Auclair, A., Nicolas, J. P., . . Millan, M. J. (2000). Serotonin2C receptors tonically suppress the activity of mesocortical dopaminergic and adrenergic, but not serotonergic, pathways: a combined dialysis and electrophysiological analysis in the rat. Synapse, 36(3), 205-221.

Götestam, K. G., \& Andersson, B. E. (1975). Self-administration of amphetamine analogues in rats. Pharmacology Biochemistry and Behavior, 3(2), 229-233.

Gough, B., Ali, S., Slikker Jr, W., \& Holson, R. (1991). Acute effects of 3, 4methylenedioxymethamphetamine (MDMA) on monoamines in rat caudate. Pharmacology Biochemistry and Behavior, 39(3), 619-623. 
Granoff, M. I., \& Ashby Jr, C. R. (1997). The Effect of the Repeated Administration of the Compound 3, 4-Methylenedioxymethamphetamineon the Response of Rats to the5-HT2A, C Receptor Agonist ( \pm )-1-(2, 5-dimethoxy-4-iodophenyl)2-aminopropane (DOI). Neuropsychobiology, 37(1), 36-40.

Granoff, M. I., \& Ashby Jr, C. R. (2001). Effect of the repeated administration of ( \pm )3, 4-methylenedioxymethamphetamine on the behavioral response of rats to the 5-HT1A receptor agonist $( \pm)$-8-hydroxy-(di-n-propylamino) tetralin. Neuropsychobiology, 43(1), 42-48.

Green, A. R., Mechan, A. O., Elliott, J. M., O'Shea, E., \& Colado, M. I. (2003). The pharmacology and clinical pharmacology of 3, 4methylenedioxymethamphetamine (MDMA, “ecstasy"). Pharmacological reviews, 55(3), 463-508.

Greer, E. (1985). Using MDMA in psychotherapy. Advances.

Greer, G., \& Tolbert, R. (1986). Subjective reports of the effects of MDMA in a clinical setting. Journal of Psychoactive Drugs, 18(4), 319-327.

Griffiths, R. (1980). Common factors in human and infrahuman drug selfadministration. Psychopharmacology Bulletin, 16(1), 45-47.

Gu, X. F., \& Azmitia, E. C. (1993). Integrative transporter-mediated release from cytoplasmic and vesicular 5-hydroxytryptamine stores in cultured neurons. European journal of pharmacology, 235(1), 51-57.

Gudelsky, G. A., \& Nash, J. F. (1996). Carrier-Mediated Release of Serotonin by 3, 4-Methylenedioxymethamphetamine: Implications for Serotonin-Dopamine Interactions. Journal of neurochemistry, 66(1), 243-249.

Gudelsky, G. A., Yamamoto, B. K., \& Nash, J. F. (1994). Potentiation of 3, 4methylenedioxymethamphetamine-induced dopamine release and serotonin neurotoxicity by 5-HT2 receptor agonists. European journal of pharmacology, 264(3), 325-330.

Haberzettl, R., Bert, B., Fink, H., \& Fox, M. A. (2013). Animal models of the serotonin syndrome: A systematic review. Behavioural brain research, 256, 328-345.

Hamon, M., Fattaccini, C., Adrien, J., Gallissot, M., Martin, P., \& Gozlan, H. (1988). Alterations of central serotonin and dopamine turnover in rats treated with ipsapirone and other 5-hydroxytryptamine1A agonists with potential anxiolytic properties. Journal of Pharmacology and Experimental Therapeutics, 246(2), 745-752.

Hardman, H. F., Haavik, C. O., \& Seevers, M. H. (1973). Relationship of the structure of mescaline and seven analogs to toxicity and behavior in five species of laboratory animals. Toxicology and applied Pharmacology, 25(2), 299-309.

Hekmatpanah, C. R., \& Peroutka, S. J. (1990). 5-Hydroxytryptamine uptake blockers attenuate the 5-hydroxytryptamine-releasing effect of 3, 4methylenedioxymethamphetamine and related agents. European journal of pharmacology, 177(1), 95-98.

Hemby, S. E., Koves, T. R., Smith, J. E., \& Dworkin, S. I. (1997). Differences in extracellular dopamine concentrations in the nucleus accumbens during response-dependent and response-independent cocaine administration in the rat. Psychopharmacology, 133(1), 7-16.

Higgins, G. A., Wang, Y., Corrigall, W. A., \& Sellers, E. M. (1994). Influence of 5HT3 receptor antagonists and the indirect 5-HT agonist, dexfenfluramine, on heroin self-administration in rats. Psychopharmacology, 114(4), 611-619. 
Hillman, M. G., \& Schneider, C. W. (1975). Voluntary selection of and tolerance to 1, 2 propanediol (propylene glycol) by high and low ethanol-selecting mouse strains. Journal of comparative and physiological psychology, 88(2), 773.

Hooks, M. S., Colvin, A. C., Juncos, J. L., \& Justice Jr, J. B. (1992). Individual differences in basal and cocaine-stimulated extracellular dopamine in the nucleus accumbens using quantitative microdialysis. Brain research, 587(2), 306-312.

Hooks, M. S., Jones, G. H., Smith, A. D., Neill, D. B., \& Justice, J. B. (1991). Response to novelty predicts the locomotor and nucleus accumbens dopamine response to cocaine. Synapse, 9(2), 121-128.

Hooks, M. S., Juncos, J. L., Justice, J. B., Meiergerd, S. M., Povlock, S., Schenk, J., \& Kalivas, P. (1994). Individual locomotor response to novelty predicts selective alterations in D1 and D2 receptors and mRNAs. The Journal of neuroscience, 14(10), 6144-6152.

Hopper, J. W., Su, Z., Looby, A. R., Ryan, E. T., Penetar, D. M., Palmer, C. M., \& Lukas, S. E. (2006). Incidence and patterns of polydrug use and craving for ecstasy in regular ecstasy users: An ecological momentary assessment study. Drug and Alcohol Dependence, 85(3), 221-235.

Horger, B. A., Giles, M. K., \& Schenk, S. (1992). Preexposure to amphetamine and nicotine predisposes rats to self-administer a low dose of cocaine. Psychopharmacology, 107(2-3), 271-276.

Horger, B. A., Shelton, K., \& Schenk, S. (1990). Preexposure sensitizes rats to the rewarding effects of cocaine. Pharmacology Biochemistry and Behavior, 37(4), 707-711.

Howell, L. L., \& Byrd, L. D. (1995). Serotonergic modulation of the behavioral effects of cocaine in the squirrel monkey. Journal of Pharmacology and Experimental Therapeutics, 275(3), 1551-1559.

Hubner, C. B., \& Moreton, J. E. (1991). Effects of selective D1 and D2 dopamine antagonists on cocaine self-administration in the rat. Psychopharmacology, 105(2), 151-156.

Ikemoto, S., Qin, M., \& Liu, Z.-H. (2005). The functional divide for primary reinforcement of D-amphetamine lies between the medial and lateral ventral striatum: is the division of the accumbens core, shell, and olfactory tubercle valid? The Journal of neuroscience, 25(20), 5061-5065.

Insel, T. R., Battaglia, G., Johannessen, J. N., Marra, S., \& De Souza, E. B. (1989). 3, 4-Methylenedioxymethamphetamine (" ecstasy") selectively destroys brain serotonin terminals in rhesus monkeys. Journal of Pharmacology and Experimental Therapeutics, 249(3), 713-720.

Jacobs, B. L. (1974a). Effect of two dopamine receptor blockers on a serotoninmediated behavioral syndrome in rats. European journal of pharmacology, 27(3), 363-366.

Jacobs, B. L. (1974b). Evidence for the functional interaction of two central neurotransmitters. Psychopharmacologia, 39(1), 81-86.

Ji, S.-P., Zhang, Y., Van Cleemput, J., Jiang, W., Liao, M., Li, L., . . Zhang, X. (2006). Disruption of PTEN coupling with 5-HT2C receptors suppresses behavioral responses induced by drugs of abuse. Nature medicine, 12(3), 324329.

Johanson, C. E., \& Balster, R. L. (1978). A summary of the results of a drug selfadministration study using substitution procedures in rhesus monkeys. Bull Narc, 30(3), 43-54. 
Johnson, M. P., Hoffman, A. J., \& Nichols, D. E. (1986). Effects of enantiomers of MDA, MDMA and related analogues on $[3 \mathrm{H}]$ serotonin and $[3 \mathrm{H}]$ dopamine release from superfused rat brain slices. European journal of pharmacology, 132(2), 269-276.

Johnston, L. D., O'Malley, P. M., Miech, R. A., Bachman, J. G., \& Schulenberg, J. E. (2014). Monitoring the Future national survey results on drug use: 1975-2013: Overview, key findings on adolescent drug use. Retrieved from http://www.monitoringthefuture.org/pubs/monographs/mtf-overview2013.pdf

Jones, K., Brennan, K. A., Colussi-Mas, J., \& Schenk, S. (2010). PRECLINICAL STUDY: FULL ARTICLE: Tolerance to 3, 4-methylenedioxymethamphetamine is associated with impaired serotonin release. Addiction Biology, 15(3), 289-298.

Kalivas, P., Duffy, P., \& White, S. R. (1998). MDMA elicits behavioral and neurochemical sensitization in rats. Neuropsychopharmacology, 18(6), 469479.

Kalivas, P., Sorg, B., \& Hooks, M. (1993). The pharmacology and neural circuitry of sensitization to psychostimulants. Behavioural Pharmacology, 4(4), 315-334.

Kalivas, P., \& Stewart, J. (1991). Dopamine transmission in the initiation and expression of drug-and stress-induced sensitization of motor activity. Brain Research Reviews, 16(3), 223-244.

Kelly, P. H., \& Iversen, S. D. (1976). Selective 60HDA-induced destruction of mesolimbic dopamine neurons: abolition of psychostimulant-induced locomotor activity in rats. European journal of pharmacology, 40(1), 45-56.

Kindlundh-Högberg, A., Svenningsson, P., \& Schiöth, H. B. (2006). Quantitative mapping shows that serotonin rather than dopamine receptor mRNA expressions are affected after repeated intermittent administration of MDMA in rat brain. Neuropharmacology, 51(4), 838-847.

Kish, S. J., Lerch, J., Furukawa, Y., Tong, J., McCluskey, T., Wilkins, D., . . Wilson, A. A. (2010). Decreased cerebral cortical serotonin transporter binding in ecstasy users: a positron emission tomography/[11C] DASB and structural brain imaging study. Brain, 133(6), 1779-1797.

Kittler, K., Lau, T., \& Schloss, P. (2010). Antagonists and substrates differentially regulate serotonin transporter cell surface expression in serotonergic neurons. European journal of pharmacology, 629(1), 63-67.

Kivell, B., Day, D., Bosch, P., Schenk, S., \& Miller, J. (2010). MDMA causes a redistribution of serotonin transporter from the cell surface to the intracellular compartment by a mechanism independent of phospho-p38-mitogen activated protein kinase activation. Neuroscience, 168(1), 82-95.

Koch, S., \& Galloway, M. (1997). MDMA induced dopamine release in vivo: role of endogenous serotonin. Journal of neural transmission, 104(2-3), 135-146.

Koob, G. F., Le, H. T., \& Creese, I. (1987). The D1 dopamine receptor antagonist SCH 23390 increases cocaine self-administration in the rat. Neuroscience letters, 79(3), 315-320.

Kuczenski, R., \& Segal, D. S. (1999). Sensitization of amphetamine-induced stereotyped behaviors during the acute response. Journal of Pharmacology and Experimental Therapeutics, 288(2), 699-709.

Kurling, S., Kankaanpää, A., \& Seppälä, T. (2008). Sub-chronic nandrolone treatment modifies neurochemical and behavioral effects of amphetamine and 3, 4methylenedioxymethamphetamine (MDMA) in rats. Behavioural brain research, 189(1), 191-201. 
Lamb, R., \& Griffiths, R. (1987). Self-injection of d, 1-3, 4methylenedioxymethamphetamine (MDMA) in the baboon. Psychopharmacology, 91(3), 268-272.

Leccese, A. P., \& Lyness, W. H. (1984). The effects of putative 5-hydroxytryptamine receptor active agents ond-amphetamine self-administration in controls and rats with 5, 7-dihydroxytryptamine median forebrain bundle lesion. Brain research, 303(1), 153-162.

Leonardi, E. T. K., \& Azmitia, E. C. (1994). MDMA (ecstasy) inhibition of MAO type A and type B: comparisons with fenfluramine and fluoxetine (Prozac). Neuropsychopharmacology, 10(4), 231-238.

Lettfuss, N. Y., Seeger-Armbruster, S., \& von Ameln-Mayerhofer, A. (2013). Is behavioral sensitization to 3, 4-methylenedioxymethamphetamine (MDMA) mediated in part by cholinergic receptors? Behavioural brain research.

Leung, K. S., Ben Abdallah, A., Copeland, J., \& Cottler, L. B. (2010). Modifiable risk factors of ecstasy use: Risk perception, current dependence, perceived control, and depression. Addictive behaviors, 35(3), 201-208.

Lew, R., Sabol, K. E., Chou, C., Vosmer, G. L., Richards, J., \& Seiden, L. S. (1996). Methylenedioxymethamphetamine-induced serotonin deficits are followed by partial recovery over a 52-week period. Part II: Radioligand binding and autoradiography studies. Journal of Pharmacology and Experimental Therapeutics, 276(2), 855-865.

Logan, B. J., Laverty, R., Sanderson, W. D., \& Yee, Y. B. (1988). Differences between rats and mice in MDMA (methylenedioxymethylamphetamine) neurotoxicity. European journal of pharmacology, 152(3), 227-234.

Loh, E. A., \& Roberts, D. C. (1990). Break-points on a progressive ratio schedule reinforced by intravenous cocaine increase following depletion of forebrain serotonin. Psychopharmacology, 101(2), 262-266.

Ludwig, V., Mihov, Y., \& Schwarting, R. (2008). Behavioral and neurochemical consequences of multiple MDMA administrations in the rat: role of individual differences in anxiety-related behavior. Behavioural brain research, 189(1), 52-64.

Lyness, W., Friedle, N., \& Moore, K. (1979). Destruction of dopaminergic nerve terminals in nucleus accumbens: effect on d-amphetamine self-administration. Pharmacology Biochemistry and Behavior, 11(5), 553-556.

Lyness, W., Friedle, N., \& Moore, K. (1980). Increased self-administration of damphetamine after destruction of 5-hydroxytryptaminergic neurons. Pharmacology Biochemistry and Behavior, 12(6), 937-941.

Lyness, W., \& Smith, F. L. (1992). Influence of dopaminergic and serotonergic neurons on intravenous ethanol self-administration in the rat. Pharmacology Biochemistry and Behavior, 42(1), 187-192.

Mandt, B. H., Schenk, S., Zahniser, N. R., \& Allen, R. M. (2008). Individual differences in cocaine-induced locomotor activity in male Sprague-Dawley rats and their acquisition of and motivation to self-administer cocaine. Psychopharmacology, 201(2), 195-202.

Marinelli, M., \& White, F. J. (2000). Enhanced vulnerability to cocaine selfadministration is associated with elevated impulse activity of midbrain dopamine neurons. The Journal of neuroscience, 20(23), 8876-8885.

McCann, U., Eligulashvili, V., Mertl, M., Murphy, D. L., \& Ricaurte, G. A. (1999). Altered neuroendocrine and behavioral responses to $\mathrm{m}$-chlorophenylpiperazine 
in 3, 4-methylenedioxymethamphetamine (MDMA) users.

Psychopharmacology, 147(1), 56-65.

McCann, U., Szabo, Z., Scheffel, U., Dannals, R., \& Ricaurte, G. (1998). Positron emission tomographic evidence of toxic effect of MDMA ("Ecstasy") on brain serotonin neurons in human beings. The Lancet, 352(9138), 1433-1437.

McCann, U., Szabo, Z., Vranesic, M., Palermo, M., Mathews, W. B., Ravert, H. T., . . . Ricaurte, G. A. (2008). Positron emission tomographic studies of brain dopamine and serotonin transporters in abstinent ( \pm ) 3, 4methylenedioxymethamphetamine ("ecstasy") users: relationship to cognitive performance. Psychopharmacology, 200(3), 439-450.

McCreary, A. C., Bankson, M. G., \& Cunningham, K. A. (1999). Pharmacological studies of the acute and chronic effects of $(+)-3,4-$ methylenedioxymethamphetamine on locomotor activity: role of 5hydroxytryptamine1A and 5-hydroxytryptamine1B/1D receptors. Journal of Pharmacology and Experimental Therapeutics, 290(3), 965-973.

McGregor, A., Lacosta, S., \& Roberts, D. (1993). L-tryptophan decreases the breaking point under a progressive ratio schedule of intravenous cocaine reinforcement in the rat. Pharmacology Biochemistry and Behavior, 44(3), 651-655.

McGregor, I., Clemens, K. J., Van der Plasse, G., Li, K. M., Hunt, G. E., Chen, F., \& Lawrence, A. J. (2003). Increased anxiety 3 months after brief exposure to MDMA (" Ecstasy") in rats: association with altered 5-HT transporter and receptor density. Neuropsychopharmacology.

McNamara, M. G., Kelly, J. P., \& Leonard, B. E. (1995). Some behavioural and neurochemical aspects of subacute $( \pm) 3$, 4-methylenedioxymethamphetamine administration in rats. Pharmacology Biochemistry and Behavior, 52(3), 479484.

Miner, L., Backstrom, J., Sanders-Bush, E., \& Sesack, S. (2003). Ultrastructural localization of serotonin2A receptors in the middle layers of the rat prelimbic prefrontal cortex. Neuroscience, 116(1), 107-117.

Modi, G. M., Yang, P. B., Swann, A. C., \& Dafny, N. (2006). Chronic exposure to MDMA (Ecstasy) elicits behavioral sensitization in rats but fails to induce cross-sensitization to other psychostimulants. Behav Brain Funct, 2(1), 1.

Morgan, A. E., Horan, B., Dewey, S. L., \& Ashby Jr, C. R. (1997). Repeated administration of 3, 4-methylenedioxymethamphetamine augments cocaine's action on dopamine in the nucleus accumbens:: A microdialysis study. European journal of pharmacology, 331(1), R1-R3.

Morgan, M., McFie, L., Fleetwood, L., \& Robinson, J. (2002). Ecstasy (MDMA): are the psychological problems associated with its use reversed by prolonged abstinence? Psychopharmacology, 159(3), 294-303.

Munzar, P., Baumann, M. H., Shoaib, M., \& Goldberg, S. R. (1999). Effects of dopamine and serotonin-releasing agents on methamphetamine discrimination and self-administration in rats. Psychopharmacology, 141(3), 287-296.

Nair, S., \& Gudelsky, G. (2006). Effect of a serotonin depleting regimen of 3, 4methylenedioxymethamphetamine (MDMA) on the subsequent stimulation of acetylcholine release in the rat prefrontal cortex. Brain research bulletin, 69(4), 382-387.

Nash, J. F. (1990). Ketanserin pretreatment attenuates MDMA-induced dopamine release in the striatum as measured by in vivo microdialysis. Life sciences, 47(26), 2401-2408. 
Nash, J. F., \& Brodkin, J. (1991). Microdialysis studies on 3, 4methylenedioxymethamphetamine-induced dopamine release: effect of dopamine uptake inhibitors. Journal of Pharmacology and Experimental Therapeutics, 259(2), 820-825.

Navailles, S., \& De Deurwaerdère, P. (2011). Presynaptic control of serotonin on striatal dopamine function. Psychopharmacology, 213(2-3), 213-242.

Nayak, S. V., Rondé, P., Spier, A. D., Lummis, S. C., \& Nichols, R. A. (2000). Nicotinic receptors co-localize with 5-HT3 serotonin receptors on striatal nerve terminals. Neuropharmacology, 39(13), 2681-2690.

Neckers, L., Neff, N., \& Wyatt, R. (1979). Increased serotonin turnover in corpus striatum following an injection of kainic acid: Evidence for neuronal feedback regulation of synthesis. Naunyn-Schmiedeberg's archives of pharmacology, 306(2), 173-177.

Negus, S. S., Mello, N. K., Blough, B. E., Baumann, M. H., \& Rothman, R. B. (2007). Monoamine releasers with varying selectivity for dopamine/norepinephrine versus serotonin release as candidate "agonist" medications for cocaine dependence: studies in assays of cocaine discrimination and cocaine self-administration in rhesus monkeys. Journal of Pharmacology and Experimental Therapeutics, 320(2), 627-636.

Nelson, A. M., Larson, G. A., \& Zahniser, N. R. (2009). Low or high cocaine responding rats differ in striatal extracellular dopamine levels and dopamine transporter number. Journal of Pharmacology and Experimental Therapeutics, 331(3), 985-997.

Nordquist, R., Vanderschuren, L., Jonker, A., Bergsma, M., De Vries, T., Pennartz, C., \& Voorn, P. (2008). Expression of amphetamine sensitization is associated with recruitment of a reactive neuronal population in the nucleus accumbens core. Psychopharmacology, 198(1), 113-126.

O'Hearn, E., Battaglia, G., De Souza, E., Kuhar, M., \& Molliver, M. (1988). Methylenedioxyamphetamine (MDA) and methylenedioxymethamphetamine (MDMA) cause selective ablation of serotonergic axon terminals in forebrain: immunocytochemical evidence for neurotoxicity. The Journal of neuroscience, 8(8), 2788-2803.

O'Loinsigh, E. D., Boland, G., Kelly, J. P., \& O'Boyle, K. M. (2001). Behavioural, hyperthermic and neurotoxic effects of 3, 4-methylenedioxymethamphetamine analogues in the Wistar rat. Progress in Neuro-Psychopharmacology and Biological Psychiatry, 25(3), 621-638.

O'Shea, E., Escobedo, I., Orio, L., Sanchez, V., Navarro, M., Green, A. R., \& Colado, M. I. (2005). Elevation of ambient room temperature has differential effects on MDMA-induced 5-HT and dopamine release in striatum and nucleus accumbens of rats. Neuropsychopharmacology, 30(7), 1312-1323.

O'Shea, E., Granados, R., Esteban, B., Colado, M., \& Green, A. (1998). The relationship between the degree of neurodegeneration of rat brain 5-HT nerve terminals and the dose and frequency of administration of MDMA (ecstasy'). Neuropharmacology, 37(7), 919-926.

Oei, T. P. (1983). Effects of body weight reduction and food deprivation on cocaine self-administration. Pharmacology Biochemistry and Behavior, 19(3), 453455.

Page, I. H. (1958). Serotonin (5-hydroxytryptamine); the last four years. Physiological reviews, 38(2), 277-335. 
Papasava, M., Singer, G., \& Papasava, C. (1986). Food deprivation fails to potentiate intravenous self-administration of fenfluramine in naive rats. Appetite, 7(1), $55-61$.

Paxinos, G., \& Watson, C. (2006). The rat brain in stereotaxic coordinates: hard cover edition: Academic press.

Pelloux, Y., Dilleen, R., Economidou, D., Theobald, D., \& Everitt, B. J. (2012). Reduced forebrain serotonin transmission is causally involved in the development of compulsive cocaine seeking in rats.

Neuropsychopharmacology, 37(11), 2505-2514.

Peroutka, S. J., Newman, H., \& Harris, H. (1988). Subjective effects of 3, 4methylenedioxymethamphetamine in recreational users. Neuropsychopharmacology, 1(4), 273-277.

Pettit, H. O., Ettenberg, A., Bloom, F. E., \& Koob, G. F. (1984). Destruction of dopamine in the nucleus accumbens selectively attenuates cocaine but not heroin self-administration in rats. Psychopharmacology, 84(2), 167-173.

Pettit, H. O., \& Justice Jr, J. B. (1989). Dopamine in the nucleus accumbens during cocaine self-administration as studied by in vivo microdialysis. Pharmacology Biochemistry and Behavior, 34(4), 899-904.

Phillips, G. D., Robbins, T. W., \& Everitt, B. J. (1994). Bilateral intra-accumbens self-administration ofd-amphetamine: antagonism with intra-accumbens SCH23390 and sulpiride. Psychopharmacology, 114(3), 477-485.

Piazza, P. V., Deminèiere, J., Maccari, S., Mormede, P., Le Moal, M., \& Simon, H. (1990). Individual reactivity to novelty predicts probability of amphetamine self-administration. Behavioural Pharmacology, 1(4), 339-346.

Piazza, P. V., Deminière, J.-M., Le Moal, M., \& Simon, H. (1989). Factors that predict individual vulnerability to amphetamine self-administration. Science.

Piazza, P. V., Rougé-Pont, F., Deminière, J. M., Kharoubi, M., Le Moal, M., \& Simon, H. (1991). Dopaminergic activity is reduced in the prefrontal cortex and increased in the nucleus accumbens of rats predisposed to develop amphetamine self-administration. Brain research, 567(1), 169-174.

Pijnenburg, A., Honig, W., Van der Heyden, J., \& Van Rossum, J. (1976). Effects of chemical stimulation of the mesolimbic dopamine system upon locomotor activity. European journal of pharmacology, 35(1), 45-58.

Pijnenburg, A., Honig, W., \& Van Rossum, J. (1975). Inhibition of d-amphetamineinduced locomotor activity by injection of haloperidol into the nucleus accumbens of the rat. Psychopharmacologia, 41(2), 87-95.

Piper, B. J., Ali, S. F., Daniels, L. G., \& Meyer, J. S. (2010). Repeated intermittent methylenedioxymethamphetamine exposure protects against the behavioral and neurotoxic, but not hyperthermic, effects of an MDMA binge in adult rats. Synapse, 64(6), 421-431.

Piper, B. J., Vu, H. L., Safain, M. G., Oliver, A. J., \& Meyer, J. S. (2006). Repeated adolescent 3, 4-methylenedioxymethamphetamine (MDMA) exposure in rats attenuates the effects of a subsequent challenge with MDMA or a 5hydroxytryptamine1A receptor agonist. Journal of Pharmacology and Experimental Therapeutics, 317(2), 838-849.

Porrino, L. J., Ritz, M., Goodman, N., Sharpe, L., Kuhar, M., \& Goldberg, S. (1989). Differential effects of the pharmacological manipulation of serotonin systems on cocaine and amphetamine self-administration in rats. Life sciences, 45(17), $1529-1535$. 
Ramos, M., Goñi-Allo, B., \& Aguirre, N. (2004). Studies on the role of dopamine D1 receptors in the development and expression of MDMA-induced behavioral sensitization in rats. Psychopharmacology, 177(1-2), 100-110.

Ramos, M., Goñi-Allo, B., \& Aguirre, N. (2005). Administration of SCH 23390 into the medial prefrontal cortex blocks the expression of MDMA-induced behavioral sensitization in rats: an effect mediated by 5-HT2C receptor stimulation and not by D1 receptor blockade. Neuropsychopharmacology, 30(12), 2180-2191.

Ranaldi, R., Pocock, D., Zereik, R., \& Wise, R. A. (1999). Dopamine fluctuations in the nucleus accumbens during maintenance, extinction, and reinstatement of intravenous D-amphetamine self-administration. The Journal of neuroscience, 19(10), 4102-4109.

Ranaldi, R., Wang, Z., \& Woolverton, W. L. (2001). Reinforcing effects of D2 dopamine receptor agonists and partial agonists in rhesus monkeys. Drug and Alcohol Dependence, 64(2), 209-217.

Randrup, A., \& Munkvad, I. (1967). Stereotyped activities produced by amphetamine in several animal species and man. Psychopharmacologia, 11(4), 300-310.

Ratzenboeck, E., Saria, A., Kriechbaum, N., \& Zernig, G. (2001). Reinforcing effects of MDMA ('ecstasy') in drug-naive and cocaine-trained rats. Pharmacology, 62(3), 138-144.

Raz, S., \& Berger, B. (2010). Effects of fluoxetine and PCPA on isolation-induced morphine self-administration and startle reactivity. Pharmacology Biochemistry and Behavior, 96(1), 59-66.

Reagan-Shaw, S., Nihal, M., \& Ahmad, N. (2008). Dose translation from animal to human studies revisited. The FASEB Journal, 22(3), 659-661.

Reneman, L., Booij, J., Schmand, B., van den Brink, W., \& Gunning, B. (2000). Memory disturbances in" Ecstasy" users are correlated with an altered brain serotonin neurotransmission. Psychopharmacology, 148(3), 322-324.

Reneman, L., Endert, E., de Bruin, K., Lavalaye, J., Feenstra, M. G., de Wolff, F. A., \& Booij, J. (2002). The acute and chronic effects of MDMA ("ecstasy") on cortical 5-HT2A receptors in rat and human brain.

Reveron, M. E., Maier, E. Y., \& Duvauchelle, C. L. (2010). Behavioral, thermal and neurochemical effects of acute and chronic 3, 4methylenedioxymethamphetamine ("Ecstasy") self-administration. Behavioural brain research, 207(2), 500-507.

Risner, M. E., \& Jones, B. (1975). Self-administration of CNS stimulants by dog. Psychopharmacologia, 43(3), 207-213.

Ritz, M. C., \& Kuhar, M. J. (1989). Relationship between self-administration of amphetamine and monoamine receptors in brain: comparison with cocaine. Journal of Pharmacology and Experimental Therapeutics, 248(3), 1010-1017.

Roberts, D., Corcoran, M. E., \& Fibiger, H. C. (1977). On the role of ascending catecholaminergic systems in intravenous self-administration of cocaine. Pharmacology Biochemistry and Behavior, 6(6), 615-620.

Roberts, D., Koob, G., Klonoff, P., \& Fibiger, H. (1980). Extinction and recovery of cocaine self-administration following 6-hydroxydopamine lesions of the nucleus accumbens. Pharmacology Biochemistry and Behavior, 12(5), 781787.

Roberts, D., \& Koob, G. F. (1982). Disruption of cocaine self-administration following 6-hydroxydopamine lesions of the ventral tegmental area in rats. Pharmacology Biochemistry and Behavior, 17(5), 901-904. 
Roberts, D., Loh, E., Baker, G., \& Vickers, G. (1994). Lesions of central serotonin systems affect responding on a progressive ratio schedule reinforced either by intravenous cocaine or by food. Pharmacology Biochemistry and Behavior, 49(1), 177-182.

Roberts, D., Phelan, R., Hodges, L. M., Hodges, M. M., Bennett, B., Childers, S., \& Davies, H. (1999). Self-administration of cocaine analogs by rats. Psychopharmacology, 144(4), 389-397.

Robinson, T. E., \& Becker, J. B. (1986). Enduring changes in brain and behavior produced by chronic amphetamine administration: a review and evaluation of animal models of amphetamine psychosis. Brain Research Reviews, 11(2), 157-198.

Robinson, T. E., \& Berridge, K. C. (1993). The neural basis of drug craving: an incentive-sensitization theory of addiction. Brain Research Reviews, 18(3), 247-291.

Robinson, T. E., \& Berridge, K. C. (2001). Incentive-sensitization and addiction. Addiction, 96(1), 103-114.

Rodd-Henricks, Z. A., McKinzie, D. L., Li, T.-K., Murphy, J. M., \& McBride, W. J. (2002). Cocaine is self-administered into the shell but not the core of the nucleus accumbens of Wistar rats. Journal of Pharmacology and Experimental Therapeutics, 303(3), 1216-1226.

Rougé-Pont, F., Deroche, V., Moal, M. L., \& Piazza, P. V. (1998). Individual differences in stress-induced dopamine release in the nucleus accumbens are influenced by corticosterone. European Journal of Neuroscience, 10(12), 3903-3907.

Rudnick, G., \& Wall, S. C. (1992). The molecular mechanism of" ecstasy"[3, 4methylenedioxy-methamphetamine (MDMA)]: serotonin transporters are targets for MDMA-induced serotonin release. Proceedings of the National Academy of Sciences, 89(5), 1817-1821.

Sabol, K., Lew, R., Richards, J., Vosmer, G., \& Seiden, L. (1996). Methylenedioxymethamphetamine-induced serotonin deficits are followed by partial recovery over a 52-week period. Part I: Synaptosomal uptake and tissue concentrations. Journal of Pharmacology and Experimental Therapeutics, $276(2), 846-854$.

Sari, Y. (2004). Serotonin1B receptors: from protein to physiological function and behavior. Neuroscience \& Biobehavioral Reviews, 28(6), 565-582.

Sari, Y., Miquel, M.-C., Brisorgueil, M.-J., Ruiz, G., Doucet, E., Hamon, M., \& Verge, D. (1999). Cellular and subcellular localization of 5hydroxytryptamine1B receptors in the rat central nervous system: immunocytochemical, autoradiographic and lesion studies. Neuroscience, 88(3), 899-915.

Scanzello, C. R., Hatzidimitriou, G., Martello, A. L., Katz, J. L., \& Ricaurte, G. (1993). Serotonergic recovery after (+/-) 3, 4-(methylenedioxy) methamphetamine injury: observations in rats. Journal of Pharmacology and Experimental Therapeutics, 264(3), 1484-1491.

Schenk, S. (2011). MDMA ("ecstasy") abuse as an example of dopamine neuroplasticity. Neuroscience \& Biobehavioral Reviews, 35(5), 1203-1218.

Schenk, S., Abraham, B., Aronsen, D., Colussi-Mas, J., \& Do, J. (2013). Effects of repeated exposure to MDMA on 5HT1a autoreceptor function: behavioral and neurochemical responses to 8-OHDPAT. Psychopharmacology, 227(2), 355361. 
Schenk, S., Colussi-Mas, J., Do, J., \& Bird, J. (2012). Profile of MDMA selfadministration from a large cohort of rats: MDMA develops a profile of dependence with extended testing. J Drug Alcohol Res, 1, 235602.

Schenk, S., Gittings, D., \& Colussi-Mas, J. (2011). Dopaminergic mechanisms of reinstatement of MDMA-seeking behaviour in rats. British journal of pharmacology, 162(8), 1770-1780.

Schenk, S., Gittings, D., Johnstone, M., \& Daniela, E. (2003). Development, maintenance and temporal pattern of self-administration maintained by ecstasy (MDMA) in rats. Psychopharmacology, 169(1), 21-27.

Schenk, S., Hely, L., Lake, B., Daniela, E., Gittings, D., \& Mash, D. C. (2007). MDMA self-administration in rats: acquisition, progressive ratio responding and serotonin transporter binding. European Journal of Neuroscience, 26(11), 3229-3236.

Schenk, S., Horger, B. A., Peltier, R., \& Shelton, K. (1991). Supersensitivity to the reinforcing effects of cocaine following 6-hydroxydopamine lesions to the medial prefrontal cortex in rats. Brain research, 543(2), 227-235.

Schenk, S., Valadez, A., McNamara, C., House, D. T., Higley, D., Bankson, M. G., . . . Horger, B. A. (1993). Development and expression of sensitization to cocaine's reinforcing properties: role of NMDA receptors.

Psychopharmacology, 111(3), 332-338.

Schmidt, C. J. (1987). Acute administration of methylenedioxymethamphetamine: comparison with the neurochemical effects of its N-desmethyl and N-ethyl analogs. European journal of pharmacology, 136(1), 81-88.

Schmidt, C. J., Fadayel, G. M., Sullivan, C. K., \& Taylor, V. L. (1992). 5-HT2 receptors exert a state-dependent regulation of dopaminergic function: studies with MDL 100,907 and the amphetamine analogue, 3, 4methylenedioxymethamphetamine. European journal of pharmacology, 223(1), 65-74.

Schmidt, C. J., \& Kehne, J. H. (1990). Neurotoxicity of MDMA: neurochemical effects. Annals of the New York Academy of Sciences, 600(1), 665-680.

Schmidt, C. J., Sullivan, C., \& Fedayal, G. (1994). Blockade of Striatal 5-Hydroxytryptmine2 Receptors Reduces the Increase in Extracellullar Concentrations of Dopamine Produced by the Amphhetamine analogue 3, 4-Methylenedioxymethamphetamine. Journal of neurochemistry, 62(4), 13821389.

Schmidt, C. J., Wu, L., \& Lovenberg, W. (1986). Methylenedioxymethamphetamine: a potentially neurotoxic amphetamine analogue. European journal of pharmacology, 124(1), 175-178.

Scholey, A. B., Parrott, A. C., Buchanan, T., Heffernan, T. M., Ling, J., \& Rodgers, J. (2004). Increased intensity of Ecstasy and polydrug usage in the more experienced recreational Ecstasy/MDMA users: a WWW study. Addictive behaviors, 29(4), 743-752.

Schuster, C., \& Johanson, C. (1974). The use of animal models for the study of drug abuse. Research advances in alcohol and drug problems, 1, 1-31.

Schuster, C., \& Thompson, T. (1969). Self administration of and behavioral dependence on drugs. Annual review of pharmacology, 9(1), 483-502.

Self, D. W., Belluzzi, J. D., Kossuth, S., \& Stein, L. (1996). Self-administration of the D1 agonist SKF 82958 is mediated by D1, not D2, receptors.

Psychopharmacology, 123(4), 303-306. 
Self, D. W., \& Stein, L. (1992). The D1 agonists SKF 82958 and SKF 77434 are selfadministered by rats. Brain research, 582(2), 349-352.

Shankaran, M., \& Gudelsky, G. A. (1999). A neurotoxic regimen of MDMA suppresses behavioral, thermal and neurochemical responses to subsequent MDMA administration. Psychopharmacology, 147(1), 66-72.

Shin, R., Qin, M., Liu, Z.-H., \& Ikemoto, S. (2008). Intracranial self-administration of MDMA into the ventral striatum of the rat: differential roles of the nucleus accumbens shell, core, and olfactory tubercle. Psychopharmacology, 198(2), 261-270.

Shore, P., \& Brodie, B. (1958). Effect of iproniazid on brain levels of norepinephrine and serotonin. Science (New York, NY), 127(3300), 704.

Shulgin, A. T. (1986). The background and chemistry of MDMA. Journal of Psychoactive Drugs, 18(4), 291-304.

Shulgin, A. T., \& Nichols, D. E. (1978). Characterization of three new psychotomimetics. The psychopharmacology of hallucinogens, 74-83.

Singer, G., Wallace, M., \& Hall, R. (1982). Effects of dopaminergic nucleus accumbens lesions on the acquisition of schedule induced self injection of nicotine in the rat. Pharmacology Biochemistry and Behavior, 17(3), 579-581.

Slikker, W. J., Ali, S. F., Scallet, A. C., Frith, C. H., Newport, G. D., \& Bailey, J. (1988). Neurochemical and neurohistological alterations in the rat and monkey produced by orally administered methylenedioxymethamphetamine (MDMA). Toxicology and applied Pharmacology, 94(3), 448-457.

Smith, F. L., Yu, D. S., Smith, D. G., Leccese, A. P., \& Lyness, W. H. (1986). Dietary tryptophan supplements attenuate amphetamine self-administration in the rat. Pharmacology Biochemistry and Behavior, 25(4), 849-855.

Smith, J. E., Guerin, G. F., Co, C., Barr, T. S., \& Lane, J. D. (1985). Effects of 6OHDA lesions of the central medial nucleus accumbens on rat intravenous morphine self-administration. Pharmacology Biochemistry and Behavior, 23(5), 843-849.

Smith, J. E., Shultz, K., Co, C., Goeders, N. E., \& Dworkin, S. I. (1987). Effects of 5, 7-dihydroxytryptamine lesions of the nucleus accumbens on rat inravenous morphine self-administration. Pharmacology Biochemistry and Behavior, 26(3), 607-612.

Soar, K., Turner, J., \& Parrott, A. C. (2006). Problematic versus non-problematic ecstasy/MDMA use: the influence of drug usage patterns and pre-existing psychiatric factors. Journal of psychopharmacology, 20(3), 417-424.

Solowij, N., Hall, W., \& Lee, N. (1992). Recreational MDMA use in Sydney: a profile of 'ecstasy'users and their experiences with the drug. British journal of addiction, 87(8), 1161-1172.

Sorg, B. A., \& Kalivas, P. W. (1991). Effects of cocaine and footshock stress on extracellular dopamine levels in the ventral striatum. Brain research, 559(1), 29-36.

Spanos, L. J., \& Yamamoto, B. K. (1989). Acute and subchronic effects of methylenedioxymethamphetamine [( \pm ) MDMA] on locomotion and serotonin syndrome behavior in the rat. Pharmacology Biochemistry and Behavior, 32(4), 835-840.

Stone, D., Hanson, G., \& Gibb, J. (1987). Differences in the central serotonergic effects of methylenedioxymethamphetamine (MDMA) in mice and rats. Neuropharmacology, 26(11), 1657-1661. 
Stone, D., Merchant, K., Hanson, G., \& Gibb, J. (1987). Immediate and long-term effects of 3, 4-methylenedioxymethamphetamine on serotonin pathways in brain of rat. Neuropharmacology, 26(12), 1677-1683.

Stone, D., Stahl, D. C., Hanson, G. R., \& Gibb, J. W. (1986). The effects of 3, 4methylenedioxymethamphetamine (MDMA) and 3, 4methylenedioxyamphetamine (MDA) on monoaminergic systems in the rat brain. European journal of pharmacology, 128(1), 41-48.

Suto, N., Ecke, L. E., You, Z.-B., \& Wise, R. A. (2010). Extracellular fluctuations of dopamine and glutamate in the nucleus accumbens core and shell associated with lever-pressing during cocaine self-administration, extinction, and yoked cocaine administration. Psychopharmacology, 211(3), 267-275.

Swarts, K. (2006). Club Drugs: Greenhaven Press.

Taffe, M. A., Davis, S. A., Yuan, J., Schroeder, R., Hatzidimitriou, G., Parsons, L. H., ... Gold, L. H. (2002). Cognitive performance of MDMA-treated rhesus monkeys: sensitivity to serotonergic challenge. Neuropsychopharmacology, 27(6), 993-1005.

Taurah, L., Chandler, C., \& Sanders, G. (2013). Depression, impulsiveness, sleep, and memory in past and present polydrug users of 3, 4methylenedioxymethamphetamine (MDMA, ecstasy). Psychopharmacology, $1-15$.

Tessel, R. E., \& Woods, J. H. (1975). Fenfluramine and N-ethyl amphetamine: comparison of the reinforcing and rate-decreasing actions in the rhesus monkey. Psychopharmacologia, 43(3), 239-244.

The United States Department of Justice. (2008). Drug Scheduling, from http://www.justice.gov/dea/druginfo/ds.shtml

Thompson, M. R., Callaghan, P. D., Hunt, G. E., \& McGregor, I. S. (2008). Reduced sensitivity to MDMA-induced facilitation of social behaviour in MDMA preexposed rats. Progress in Neuro-Psychopharmacology and Biological Psychiatry, 32(4), 1013-1021.

Thompson, T., \& Schuster, C. R. (1964). Morphine self-administration, foodreinforced, and avoidance behaviors in rhesus monkeys. Psychopharmacology, 5(2), 87-94.

Tran-Nguyen, L. T., Bellew, J. G., Grote, K. A., \& Neisewander, J. L. (2001).

Serotonin depletion attenuates cocaine seeking but enhances sucrose seeking and the effects of cocaine priming on reinstatement of cocaine seeking in rats. Psychopharmacology, 157(4), 340-348.

Trigo, J. M., Panayi, F., Soria, G., Maldonado, R., \& Robledo, P. (2006). A reliable model of intravenous MDMA self-administration in naive mice.

Psychopharmacology, 184(2), 212-220.

United States Department of Health and Human Services. (2005). Guidance for Industry: Estimating the maximum safe starting dose in initial clinical trials for therapeautics in adult healthy volunteers. Retrieved from http://www.fda.gov/downloads/Drugs/Guidance/UCM078932.pdf

Urban, N. B., Girgis, R. R., Talbot, P. S., Kegeles, L. S., Xu, X., Frankle, W. G., . . . Laruelle, M. (2012). Sustained Recreational Use of Ecstasy Is Associated with Altered Pre and Postsynaptic Markers of Serotonin Transmission in Neocortical Areas: A PET Study with \&lsqb; 11C\&rsqb; DASB and \&lsqb; 11C\&rsqb; MDL 100907. Neuropsychopharmacology, 37(6), 1465-1473. 
Van Ree, J. M., Slangen, J. L., \& de Wied, D. (1978). Intravenous self-administration of drugs in rats. Journal of Pharmacology and Experimental Therapeutics, 204(3), 547-557.

Vanover, K. E., Nader, M. A., \& Woolverton, W. L. (1992). Evaluation of the discriminative stimulus and reinforcing effects of sertraline in rhesus monkeys. Pharmacology Biochemistry and Behavior, 41(4), 789-793.

Varela, M. J., Brea, J., Loza, M. I., Maldonado, R., \& Robledo, P. (2011). Sensitization to MDMA locomotor effects and changes in the functionality of 5-HT2A and D2 receptors in mice. Behavioural Pharmacology, 22(4), 362369.

Vazquez-DeRose, J., Stauber, G., Khroyan, T. V., Xie, X. S., Zaveri, N. T., \& Toll, L. (2013). Retrodialysis of N/OFQ into the nucleus accumbens shell blocks cocaine-induced increases in extracellular dopamine and locomotor activity. European journal of pharmacology, 699(1), 200-206.

Veeneman, M. M., Broekhoven, M. H., Damsteegt, R., \& Vanderschuren, L. J. (2012). Distinct contributions of dopamine in the dorsolateral striatum and nucleus accumbens shell to the reinforcing properties of cocaine. Neuropsychopharmacology, 37(2), 487-498.

Vezina, P. (2004). Sensitization of midbrain dopamine neuron reactivity and the selfadministration of psychomotor stimulant drugs. Neuroscience \& Biobehavioral Reviews, 27(8), 827-839.

von Geusau, N. A., Stalenhoef, P., Huizinga, M., Snel, J., \& Ridderinkhof, K. R. (2004). Impaired executive function in male MDMA ("ecstasy") users. Psychopharmacology, 175(3), 331-341.

von Sydow, K., Lieb, R., Pfister, H., Höfler, M., \& Wittchen, H.-U. (2002). What predicts incident use of cannabis and progression to abuse and dependence?: A 4-year prospective examination of risk factors in a community sample of adolescents and young adults. Drug and Alcohol Dependence, 68(1), 49-64.

Wang, X., Baumann, M. H., Xu, H., Morales, M., \& Rothman, R. B. (2005). ( \pm )-3, 4Methylenedioxymethamphetamine administration to rats does not decrease levels of the serotonin transporter protein or alter its distribution between endosomes and the plasma membrane. Journal of Pharmacology and Experimental Therapeutics, 314(3), 1002-1012.

Wang, Y., Joharchi, N., Fletcher, P., Sellers, E., \& Higgins, G. (1995). Further studies to examine the nature of dexfenfluramine-induced suppression of heroin selfadministration. Psychopharmacology, 120(2), 134-141.

Wee, S., Anderson, K. G., Baumann, M. H., Rothman, R. B., Blough, B. E., \& Woolverton, W. L. (2005). Relationship between the serotonergic activity and reinforcing effects of a series of amphetamine analogs. Journal of Pharmacology and Experimental Therapeutics, 313(2), 848-854.

Weed, M. R., \& Woolverton, W. L. (1995). The reinforcing effects of dopamine D1 receptor agonists in rhesus monkeys. Journal of Pharmacology and Experimental Therapeutics, 275(3), 1367-1374.

Weeks, J. R. (1962). Experimental morphine addiction: Method for automatic intravenous injections in unrestrained rats. Science.

Weeks, J. R., \& Collins, R. J. (1964). Factors affecting voluntary morphine intake in self-maintained addicted rats. Psychopharmacologia, 6(4), 267-279.

Weiss, F., Hurd, Y. L., Ungerstedt, U., Markou, A., Plotsky, P. M., \& Koob, G. F. (1992). Neurochemical Correlates of Cocaine and Ethanol 
Self-Administrationa. Annals of the New York Academy of Sciences, 654(1), 220-241.

Wilkins, C., \& Sweetsur, P. (2008). Trends in population drug use in New Zealand: findings from national household surveying of drug use in 1998, 2001, 2003, and 2006. NZ Med J, 121.

Wilkins, C., Sweetsur, P., Smart, B., Warne, C., \& Jawalkar, S. (2012). Recent trends in illegal drug use in New Zealand: Findings from the 2006, 2007, 2008, 2009, 2010 and 2011 Illicit Drug Monitoring System (IDMS). Auckland: SHORE, Massey University.

Wise, R. A. (1998). Drug-activation of brain reward pathways. Drug and Alcohol Dependence, 51(1), 13-22.

Wise, R. A., \& Bozarth, M. A. (1987). A psychomotor stimulant theory of addiction. Psychological review, 94(4), 469.

Wise, R. A., Leeb, K., Pocock, D., Newton, P., Burnette, B., \& Justice Jr, J. B. (1995). Fluctuations in nucleus accumbens dopamine concentration during intravenous cocaine self-administration in rats. Psychopharmacology, 120(1), 10-20.

Woolverton, W. L., Goldberg, L. I., \& Ginos, J. Z. (1984). Intravenous selfadministration of dopamine receptor agonists by rhesus monkeys. Journal of Pharmacology and Experimental Therapeutics, 230(3), 678-683.

World Drug Report. (2013). United Nations Office on Drugs and Crime. New York.

Yamamoto, B. K., Nash, J. F., \& Gudelsky, G. A. (1995). Modulation of methylenedioxymethamphetamine-induced striatal dopamine release by the interaction between serotonin and gamma-aminobutyric acid in the substantia nigra. Journal of Pharmacology and Experimental Therapeutics, 273(3), 1063-1070.

Yamamoto, B. K., \& Spanos, L. J. (1988). The acute effects of methylenedioxymethamphetamine on dopamine release in the awake-behaving rat. European journal of pharmacology, 148(2), 195-203.

Yamamoto, D., Nelson, A. M., Mandt, B. H., Larson, G. A., Rorabaugh, J. M., Ng, C., .. . Zahniser, N. R. (2013). Rats classified as low or high cocaine locomotor responders: A unique model involving striatal dopamine transporters that predicts cocaine addiction-like behaviors. Neuroscience \& Biobehavioral Reviews, 37(8), 1738-1753.

Yanagita, T., Deneau, G., \& Seevers, M. (1963). Methods for studying psychogenic dependence to opiates in the monkey. Ann Arbor, MI: Committee on Drug Addiction and Narcotics, NRCNAS.

Yau, J., Kelly, P., Sharkey, J., \& Seckl, J. (1994). Chronic 3, 4methylenedioxymethamphetamine administration decreases glucocorticoid and mineralocorticoid receptor, but increases 5-hydroxytryptamine1c receptor gene expression in the rat hippocampus. Neuroscience, 61(1), 31-40.

Yokel, R. A., \& Wise, R. A. (1976). Attenuation of intravenous amphetamine reinforcement by central dopamine blockade in rats. Psychopharmacology, 48(3), 311-318.

Yokel, R. A., \& Wise, R. A. (1978). Amphetamine-type reinforcement by dopaminergic agonists in the rat. Psychopharmacology, 58(3), 289-296. 